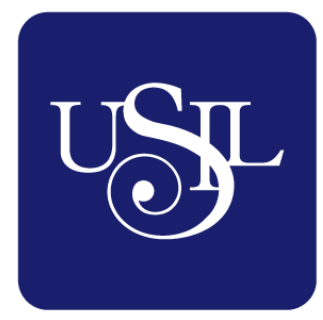

UNIVERSIDAD

SAN IGNACIO

DE LOYOLA

ESCUELA DE POSTGRADO

Maestría en Educación con mención en Docencia en Educación Superior

\title{
ESTRATEGIA METODOLÓGICA PARA CONTRIBUIR AL DESARROLLO DEL PENSAMIENTO CRÍTICO EN LOS ESTUDIANTES DE LA ESPECIALIDAD DE PINTURA DE UNA INSTITUCIÓN EDUCATIVA DE ARTE DE LIMA
}

Tesis para optar el grado de Maestro en Educación con mención en Docencia en Educación Superior

GINO SESSAREGO DÍAZ

Asesor:

Hernán Gerardo Flores Valdiviezo

Lima - Perú

2019 


\section{Dedicatoria}

A mis padres, por su incondicional apoyo, por la formación que me dieron y haberme enseñado la importancia de la educación. 
Agradecimiento

A mi asesor Magister Hernán Flores por sus consejos, su orientación y la ayuda que me proporcionó para la elaboración de esta tesis, la cual me permitió saber mucho más sobre educación.

A mis profesores, maestros universitarios, quienes me apoyaron con sus conocimientos y su ejemplo de vida. 


\section{Índice}

$\begin{array}{ll}\text { Introducción } & 1\end{array}$

Planteamiento del problema de la investigación $\quad 5$

$\begin{array}{ll}\text { Preguntas científicas } & 5\end{array}$

Objetivo general. 6

$\begin{array}{ll}\text { Objetivos específicos o tareas de la investigación. } & 6\end{array}$

$\begin{array}{ll}\text { Categorías y subcategorías apriorísticas } & 6\end{array}$

$\begin{array}{ll}\text { Justificación } & 7\end{array}$

Metodología de la investigación $\quad 8$

$\begin{array}{lr}\text { Tipo y diseño de investigación. } & 8\end{array}$

Métodos Teóricos.

$\begin{array}{lr}\text { Técnicas e instrumentos. } & 10\end{array}$

$\begin{array}{ll}\text { Población, muestra, muestreo: unidad de análisis } & 11\end{array}$

Capítulo I 12

$\begin{array}{ll}\text { Marco teórico } & 12\end{array}$

$\begin{array}{lr}\text { Antecedentes de la investigación } & 12\end{array}$

$\begin{array}{ll}\text { Aproximación al pensamiento crítico } & 16\end{array}$

$\begin{array}{ll}\text { Definición de las subcategorías del pensamiento crítico } & 20\end{array}$

Evolución histórica del pensamiento crítico 26

$\begin{array}{ll}\text { Características del pensamiento crítico } & 30\end{array}$

Elementos y componentes del pensamiento crítico 34

$\begin{array}{ll}\text { Artes visuales y su relación con el pensamiento crítico } & 37\end{array}$

Conceptualización teórica de estrategia metodológica 39

$\begin{array}{lr}\text { Educación. } & 39\end{array}$

Teorías de la educación. $\quad 39$

Definición de estrategia metodológica 42

Conceptualización de las subcategorías de estrategia metodológica $\quad 44$

$\begin{array}{ll}\text { Capítulo II } & 49\end{array}$ 
Análisis, interpretación y discusión de los resultados

Análisis de los resultados de la entrevista semiestructurada a docentes.

Análisis de los resultados de la encuesta aplicada a los estudiantes.

Análisis de los resultados de la guía de observación de clase.

Presentación de los resultados según las categorías emergentes

Conclusiones aproximativas al estudio de campo

Capítulo III

Modelación y validación de la propuesta

Objetivo de la propuesta

Justificación de la propuesta

Fundamentos de la propuesta

Diseño de la propuesta metodológica

Esquema teórico-funcional de la propuesta de la estrategia metodológica

Modelo de pensamiento crítico

Diseño didáctico de la propuesta

Categorías didácticas

Desarrollo e implementación de la estrategia metodológica para contribuir en el desarrollo del pensamiento crítico en los estudiantes de la asignatura de Pintura I en la carrera de artista profesional.

Validación de la estrategia metodológica propuesta

Conclusiones

Recomendaciones 


\section{Índice de figuras}

Figura 1. Categorías emergentes y sumativas $\quad 59$

Figura 2. Categoría emergente bajo desarrollo de pensamiento crítico 60

Figura 3. Categoría emergente falta de apertura mental en los estudiantes 61

Figura 4. Categoría emergente falta de motivación por el aprendizaje en los 62 estudiantes

Figura 5. Categoría emergente carencia de hábito de lectura en los estudiantes 63

Figura 6. Categoría alternativa conceptualización axiológica 64

Figura 7. Categoría alternativa formulación y reformulación de problemas $\quad 65$

Figura 8. Categoría alternativa habilidades de indagación 66

$\begin{array}{ll}\text { Figura 9. Categoría alternativa diálogo reflexivo } & 67\end{array}$

Figura 10. Categoría alternativa base gnoseológica 68

Figura 11. Categoría alternativa entorno socio cultural 69

Figura 12. Diseño analógico de la propuesta de la estrategia metodológica $\quad 76$

$\begin{array}{ll}\text { Figura 13. Modelo de pensamiento crítico de Viterbo Univeristy } & 78\end{array}$

\section{Índice de tablas}

Tabla 1. Dosificación del sistema de clases correspondiente a la unidad 1

Tabla 2. Secuencia de procedimientos en el método propuesto 83

Tabla 3. Actividades de evaluación $\quad 86$

Tabla 4. Especialistas seleccionados para la Validación de la propuesta 91

Tabla 5. Tabla de Valoración $\quad 92$

Tabla 6. Especialistas seleccionados para la validación de la propuesta 92 


\section{Resumen}

Diseñar una estrategia metodológica para contribuir al desarrollo del pensamiento crítico en los estudiantes de la especialidad de pintura de una institución educativa de arte de Lima. La propuesta está fundamentada dentro del paradigma socio crítico e interpretativo, con un enfoque cualitativo, el tipo de investigación es educacional aplicada. La muestra es no probabilística, la que consta de treintaiuno estudiantes y cuatro docentes; se aplicó las técnicas de la entrevista a docentes, la encuesta a estudiantes y la observación de sesión de clase mediante la guía de entrevista, el cuestionario y la guía de observación, que son los instrumentos de recolección de datos.

El trabajo de campo evidenció que los estudiantes tienen un bajo nivel de pensamiento crítico. Bajo nivel de hábito de lectura, falta de apertura mental y falta de motivación por el aprendizaje. El concepto de pensamiento crítico empleado en la investigación precisa que se trata de un juicio o razonamiento deliberado para analizar argumentos, cuyos criterios se sostienen en base a razones sólidas para una correcta disposición al análisis, la evaluación de evidencias, la inferencia, la identificación y valoración con profundidad de los fenómenos de la realidad.

La modelación propone una estrategia metodológica que contribuye al desarrollo del pensamiento crítico, aplicable en estudiantes de arte, esta propuesta se basa en la resolución de problemas, a partir de una lectura que propicie interpretaciones en los distintos aspectos del conocimiento. De estas interpretaciones los estudiantes realizarán sus propuestas artísticas relacionadas a su contexto. Se concluye por validación de expertos, que la propuesta es sólida y puede ser aplicada en los estudiantes de arte. Además, contribuye a la solución del problema que origina esta investigación.

Palabras claves: pensamiento crítico, estrategia metodológica, arte, didáctica desarrolladora. 


\begin{abstract}
This investigation aims to design a methodological strategy to contribute to development of critical thinking in the fine art painting students of a higher technical art institute of Lima. The proposed investigation is framed within the socio-critical and interpretive paradigm and stances in a qualitative approach. The type of investigation is applied educational and the intentional non-probabilistic sampling that consists of thirty one students and four teachers; the following techniques were applied in the fieldwork: teacher interview, student survey and classroom observation through their data collection instruments, interview guide, observation guide and survey questionnaire.

The fieldwork shows low levels of critical thinking among students. Also, students have low levels of reading habits, lack of mental openness and lack of motivation to learn. The concept of critical thinking referred in this investigation points out that it is the intentional reasoning which requires a disposition to identify, analyze, evaluate, infer arguments and judge the phenomena of reality well-supported by strong reasons based on solid premises.

The objective of the investigation modeling is to propose a methodological strategy to contribute to development of critical thinking in the art students. The proposal is designed to aid in solving problems from reading, in order to develop interpretation skills in the various fields of knowledge. These learning experiences allow students to create their own artistic projects related to their context. The validation procedures by experts, guarantees a solid modeling proposal which can be used with art students. Finally, it contributes to solving problems that initiate the investigation.
\end{abstract}

Keywords: critical thinking, methodological strategy, art, didactic developer. 


\section{Introducción}

El siglo XXI ha traído grandes cambios científicos y tecnológicos que representan complejos desafíos para los jóvenes. Asimismo, las formas de aprendizaje de la educación deben afrontar estos cambios mundiales, el desarrollo de competencias y habilidades en la educación son parte de esta transformación en la visión general del aprendizaje de estos tiempos.

A nivel internacional, la Unesco (Organización de las Naciones Unidas para la Educación, la Ciencia y la Cultura), acepta que el dominio de materias esenciales y el aprendizaje vinculado a los ámbitos temáticos, son indispensables para el aprendizaje del siglo XXI. Se trata de buscar un equilibrio en la educación en materias técnicas, de ciencias naturales y materias en cultura y humanidades.

En las últimas dos décadas han surgido varias propuestas sobre marcos y descripción de competencias con enfoques muy variados para preparar a los educandos del siglo XXI. A pesar de que las propuestas difieren en complejidad resultan útiles para cada contexto específico en los cuales fueron elaboradas.

El modelo tradicional de enseñanza impone un aprendizaje a partir de una serie de datos factuales aislados y fuera de contexto. Contrariamente a ese sistema pedagógico rígido, las competencias deben tener una base de conocimientos de contenidos sólidos e integrados, que prepare al educando al compromiso del aprendizaje a lo largo de toda la vida (Delors, 1996). Es decir, la educación del futuro debe permitir generar un balance entre el saber actual y lo que falta por entender, es necesario desarrollar la capacidad de iniciativa, responsabilidad, asunción de riesgos, creatividad, trabajo en equipo, trabajo en red, empatía, gestión, organización, capacidades metacognitivas, etc., para que de esta manera el educando pueda estar preparado para asimilar los retos que se requieran al surgir nuevas competencias.

Es necesario fomentar las capacidades de pensamiento crítico y las capacidades para resolver problemas, competencias para el desenvolvimiento profesional y vida personal, sabiduría, creatividad y el conocimiento en pro del bien común como guía para el aprendizaje del siglo XXI. Según Facione (1990) el pensamiento crítico es el juicio deliberado constituido por habilidades y hábitos mentales para interpretar, analizar, evaluar, inferir, autorregular, razonar y explicar consideraciones de tipo conceptuales, 
metodológicas, de criterio, de evidencia y contextuales, esto permite al buen pensador llegar a un juicio. El pensamiento crítico constituye un reto para la educación superior, ya que de éste dependerá la autonomía del educando para poder llegar al juicio crítico y resolver los problemas que debe enfrentar.

Scott (2015), plantea varios modelos pedagógicos igualmente eficaces basados en la investigación que preparan al estudiante para los mismos propósitos. Es importante destacar que los estudiantes deben desarrollar hábitos mentales para apoyar el pensamiento y la reflexión; por otro lado, plantea la necesidad de desarrollar habilidades de supervivencia como pensamiento crítico y resolución de problemas, colaboración y liderazgo, agilidad y capacidad de adaptación, iniciativa y voluntad empresarial, capacidades comunicativas eficaces oral y escrita, acceso y análisis de la información, curiosidad, creatividad e imaginación. Otros modelos abogan por la enseñanza de competencias relativas al pensamiento, es decir la comprensión profunda de los temas desarrollados para resolver problemas complejos del mundo real en la edad adulta.

En el informe Delors (Unesco, 1996), se propone los principios para establecer las competencias del aprendizaje para el siglo XXI. Se trata de un marco descrito en este informe oficial de la Unesco, que está constituido por cuatro pilares de la educación o perspectivas de aprendizaje: aprender a conocer, aprender a hacer, aprender a ser y aprender a convivir, estos pilares siguen siendo puntos de referencia de actualidad que pueden redefinirse y ampliarse para el siglo XXI. Para que cada individuo pueda cumplir las misiones que le son propias y adaptarse a un mundo en permanente cambio, la educación debe estructurarse en torno a estos cuatro aprendizajes. Estas cuatro vías del saber presentan muchas coincidencias e intercambios y deben recibir una atención equivalente, representan un marco de aprendizaje en el que se determinan competencias y habilidades fundamentales constituidas por la comunicación, colaboración, capacidad de pensamiento crítico y creatividad.

Sin embargo, la enseñanza escolar se orienta de manera exclusiva hacia los dos primeros pilares, esta visión instrumental que apuesta a determinados resultados de tipo experimental, práctico y económico, hace necesario asignar nuevos objetivos a la educación para que cada estudiante incremente sus posibilidades creativas y alcance la plenitud, al lograr su realización como persona y aprenda a ser. Además, con el fin de contribuir en la mejora de la calidad educativa se debe fomentar mayor participación e interés en los docentes al impartir contenidos que ayuden al desarrollo del aprendizaje por medio de estrategias metodológicas. 
Para Velázquez (2014), la estrategia metodológica es un constructo teórico y didáctico que regula la actividad del docente en el proceso de enseñanza- aprendizaje. Este método orientador tiene efecto en la dinámica del proceso de enseñanza, la cual adquiere una dirección hacia el diálogo, la heurística, la reflexión y la problematización transformando al estudiante desde el aprendizaje en el pensar, sentir y hacer.

De acuerdo con el Marco de Acción de Dakar, es necesario establecer estrategias definidas haciendo uso de la creatividad y la imaginación para formar, atraer y retener docentes calificados. Para ello, es necesario capacitar a los docentes, quienes deberán afrontar el desafío de formar estudiantes preparados para afrontar la nueva era económica, basada en el saber, el manejo y el movimiento de la tecnología (Fiske, 2000). Por lo tanto, el desarrollo de estrategias docentes facilitará el entendimiento de la diversidad de estilos de aprendizaje del estudiante, así como su desarrollo físico e intelectual a partir de un entorno que estimule e invite a la participación del proceso de aprendizaje.

A pesar de la notable expansión de las instituciones de educación superior en América Latina, los resultados educativos están por debajo del potencial aceptable debido en parte a la educación de baja calidad en la escuela secundaria o la falta de recursos económicos que hacen improbable la flexibilidad para cambiar de carrera, lo cual genera limitaciones y estancamiento en el plano laboral.

Según la Unesco (2006), el crecimiento en la calidad educativa requerirá la inclusión de la educación artística en entornos educativos formales y no formales, con miras a desarrollar una sociedad creativa y sensible a la cultura. Integrar la educación artística en los sistemas educativos actuales tiene el propósito de generar personas reflexivas y promover al arte, por su valor intrínseco, como medio para potenciar el aprendizaje.

Las declaraciones y convenciones internacionales promueven la inclusión del arte en los programas educativos en los distintos países, ya que un desarrollo pleno del ser humano también incluye una participación en la vida artística y cultural. El arte es una disciplina que trasmite valores y permite el desarrollo de habilidades en niños y adultos. Una educación integral en la cual participe el arte y la cultura es un derecho universal que incluso favorece a las personas que suelen quedar excluidas de la educación.

La educación artística proporciona conocimientos y habilidades que permiten expresar, evaluar críticamente el mundo y desarrollar recursos humanos para explorar el 
capital cultural. Sin embargo, el poco interés por valorar los procesos emocionales en la toma de decisiones y la insistencia en dar prioridad al desarrollo de las capacidades cognitivas, son causa del detrimento del comportamiento ético en la sociedad moderna. La creatividad y el equilibrio entre el desarrollo emocional y cognitivo son exigencias de las sociedades del siglo XXI para una participación más activa de las personas en los distintos aspectos de la realidad en que vivimos.

A nivel nacional el panorama educativo es en realidad desalentador, por las numerosas variables que inciden en el acceso a un sistema educativo de calidad. Al respecto, la Unesco (2017) considera a las diferencias socioeconómicas, la brecha de género, el trabajo infantil, la diversidad lingüística y cultural o la falta de oportunidades en las zonas rurales en contraste con la urbana como las más perjudiciales. A esta realidad crítica, sobre todo en la zona rural, se suman la mala infraestructura y la falta de recursos educativos que, además generan una deficiente gestión y administración en el plano educativo.

El Perú según las pruebas estandarizadas sobre aprendizajes del informe del Programa Internacional para la Evaluación de Estudiantes (Pisa) no alcanza niveles de desempeño de calidad adecuados, principalmente por las brechas mencionadas que generan las desigualdades en el acceso al sistema educativo. La institución educativa a la cual pertenece la unidad de análisis, es la primera escuela de artes plásticas fundada en el país a favor de la cultura e identidad nacional. La institución tiene el deber y el derecho que confiere la ley $N^{\circ} 23733$, Ley Universitaria (2014), para otorgar en nombre de la Nación el grado de bachiller y los títulos de licenciado respectivos con los lineamientos para la planificación y organización de la adecuación al nivel universitario, desde 2011.

De acuerdo con el diseño curricular de la institución educativa, el egresado debe analizar críticamente los procesos creativos, los contenidos de creaciones artísticas, los conceptos de cultura y visualidad. Además, debe conocer las políticas culturales del país para identificar la problemática y encontrar soluciones.

Sin embargo, a pesar de haber logrado el rango universitario, existen aspectos internos y externos que afectan el desarrollo de las actividades de la institución educativa. Cabe mencionar la limitada comunicación y alcance entre rectores, como la Superintendencia Nacional de Educación Superior Universitaria (Sunedu) ley №30220 (2014), el debilitamiento de la imagen institucional ante el Estado y la comunidad en 
general, carencia de un plan que organice los programas complementarios que se vienen dictando, falta de orientación laboral futura, débil acercamiento al público externo, bajo nivel en el clima educativo, bajo nivel en las especialidades de docencia y desvalorización del profesional en restauración, deficiencias en la difusión de normas y procedimientos administrativos en el estudiante, malla curricular desactualizada, poca perspectiva internacional al no existir programas de intercambio, vinculo débil con el Estado, conflictos internos que afectan al público estudiantil, urgencia en la mejora de la propuesta curricular en relación a otras instituciones, falta de capacitación del personal docente.

Por lo tanto, en el marco de una educación artística con rango universitario, la institución educativa requiere la incorporación de metodologías de enseñanza para la generación de proyectos de arte, la educación artística y la gestión cultural, que contribuyan con el desarrollo del país. Además, es imperativo desarrollar habilidades de investigación desde un enfoque interdisciplinar que comprenda la investigación conceptual, técnica y subjetiva en torno al lenguaje visual con un enfoque multidisciplinar y pensamiento crítico. Por lo antes expresado, se plantea el siguiente problema científico de investigación.

\section{Planteamiento del problema de la investigación}

¿Cómo desarrollar el pensamiento crítico en los estudiantes de la especialidad de Pintura de una institución educativa de arte de Lima?

\section{Preguntas científicas}

¿Cuál es el estado actual del pensamiento crítico en los estudiantes de la especialidad de pintura de una institución educativa de arte de Lima?

¿Cuáles son los fundamentos teóricos de una estrategia metodológica para desarrollar el pensamiento crítico en los estudiantes de la especialidad de pintura de una institución educativa de arte de Lima?

¿Qué criterios se tendrá en cuenta en la modelación de la propuesta de una estrategia metodológica para construir el pensamiento crítico en los estudiantes de la especialidad de pintura de una institución educativa de arte de Lima? 
¿Cuáles son las potencialidades curriculares de validez de una estrategia metodológica para contribuir al desarrollo del pensamiento crítico en los estudiantes de la especialidad de pintura de una institución educativa de arte de Lima?

\section{Objetivos}

\section{Objetivo general.}

Diseñar una estrategia metodológica para contribuir al desarrollo del pensamiento crítico en los estudiantes de la especialidad de pintura de una institución educativa de arte de Lima.

\section{Objetivos específicos o tareas de la investigación.}

Diagnosticar el estado actual del pensamiento crítico en los estudiantes de la especialidad de pintura de una institución educativa de arte de Lima.

Sistematizar los fundamentos teóricos de una estrategia metodológica para contribuir al desarrollo de pensamiento crítico en estudiantes de la especialidad de pintura de una institución educativa de arte de Lima.

Determinar los criterios que se tendrán en cuenta en la modelación de la propuesta de una estrategia metodológica para construir el pensamiento crítico en estudiantes de la especialidad de pintura de una institución educativa de arte de Lima. Identificar las potencialidades curriculares de validez de una estrategia metodológica en estudiantes de la especialidad de pintura de una institución educativa de arte de Lima.

\section{Categorías y subcategorías apriorísticas}

La investigación tiene dos categorías, la de pensamiento crítico y la de estrategia metodológica, la primera categoría está dividida en 4 subcategorías y la segunda en tres categorías, a continuación, se definirán las categorías.

\section{Pensamiento crítico.}

El pensamiento crítico es un juicio o razonamiento deliberado que establece métodos de análisis de argumentos, cuyos criterios, en su intención de ser sostenidos, deben basarse 
en razones bien asentadas, con disposición a analizar, evaluar evidencias, inferir, identificar y valorar con profundidad las cuestiones (Herrero, 2008). En esta categoría tenemos 4 subcategorías, que son: juicio crítico, conceptualización axiológica, base gnoseológica, rol del estudiante.

\section{Estrategia metodológica.}

Para Velázquez (2014) la estrategia metodológica es un constructo teórico y didáctico que regula la actividad del docente en el proceso de enseñanza- aprendizaje. Este método orientador tiene efecto en la dinámica del proceso de enseñanza, la cual adquiere una dirección hacia el diálogo, la heurística, la reflexión y la problematización transformando desde el aprendizaje al estudiante en el pensar, sentir y hacer. En esta categoría tenemos 4 subcategorías, que son: constructo teórico-didáctico, proceso de diálogo y comunicación, proceso de enseñanza y aprendizaje, rol del docente.

\section{Justificación}

Teórica.

La investigación responde a uno de los procesos reflexivos dirigidos a moldear el pensamiento y tomar decisiones razonadas, la importancia teórica del pensamiento crítico en la formación del artista profesional se basa en el propósito investigativo de explorar la situación, fenómeno o problema que lleve a una reflexión para integrar la información y justificarla.

\section{Metodológica.}

Al finalizar la investigación, se obtendrá una metodología cuyo objetivo será mejorar el proceso de enseñanza-aprendizaje. Mediante esta metodología se brindará las herramientas necesarias para que el docente pueda conducir el aprendizaje a través del diálogo, la reflexión, la creatividad y genere pensamiento crítico. Esta metodología de la enseñanza debe transformar el pensar, sentir y el hacer del estudiante de arte.

\section{Práctica.}

Vivimos en una época que se nos presenta marcada por grandes cambios, y tener la capacidad de adaptarnos a ellos es un desafío que debe trabajarse desde la educación. Desde una perspectiva práctica, tomar conciencia de los cambios sociales, políticos 
culturales y económicos de estos tiempos hace que el conocimiento se convierta en fuente de riqueza y fortalezca las capacidades de los estudiantes para que logren ser miembros activos de la sociedad y contribuyan, desde la investigación y el pensamiento crítico, a estos cambios.

\section{Metodología de la investigación}

El desarrollo de la investigación está enmarcado en una metodología cualitativa, para lo cual se define en seguida el tipo y diseño de investigación, métodos teóricos, las técnicas e instrumentos a emplearse.

\section{Tipo y diseño de investigación.}

La investigación está delineada por el paradigma socio-crítico, el cual estudia el proceso educativo como una relación entre sujeto y objeto, en el que interviene el sistema de ideas vigente y está determinada por los valores e intereses de los sujetos. Este paradigma pretende mejorar las prácticas de la enseñanza aprendizaje, dicho de otro modo, se quiere transformar y mejorar la realidad en base de estrategias diseñadas para tal fin. (Lanuez, Martínez y Pérez, 2008).

El carácter de la investigación es cualitativo porque nos permite organizar la investigación educativa de forma libre e interpretativa, esto quiere decir que se parte de un análisis de un tema o problema de nuestro entorno para buscar una solución en base de la interpretación de los factores que concurren a esa problemática. Este tipo de investigación consiste en la observación y recolección de datos que nos muestran la realidad en estudio, permitiendo además un contacto directo con los sujetos de estudio y la acción misma que se quiere solucionar (Sánchez, 2006).

Con respecto al diseño, la investigación es aplicada a la educación, estando enfocada al estudio de una problemática de enseñanza y aprendizaje, es específica y delimitada, que busca resultados concretos para poder ser aplicada en la realidad.

\section{Métodos Teóricos.}

En esta investigación se empleará los siguientes métodos teóricos. La investigación tiene un método histórico-lógico, porque el objeto de estudio se desarrolla en el tiempo, el cual está en continuo movimiento y transformación. Los cambios de trayectoria del objeto de 
estudio y revelar su naturaleza cualitativa es una cuestión que concierne a lo histórico; es decir, lo establecido por la sociedad. En cambio, lo lógico surge como respuesta de lo esencial del contenido histórico del objeto, aunque no en todas sus etapas, se trata de revelar lo universal y primordial del objeto (Lanuez, Martínez y Pérez, 2008).

Inductivo-deductivo, siendo importante precisar que la inducción es un razonamiento que va de lo específico a lo general concentrándose en asuntos singulares. Por otro lado, el marco teórico de la deducción va de proposiciones generales a otras más específicas. Ambos métodos se complementan, sirviendo al desarrollo de la investigación y como apoyo en los estudios que se aplican a la educación (Lanuez, Martínez y Pérez, 2008).

El estudio incluye el método análisis y síntesis, del problema se hará un análisis para llegar a conocerlo y proponer soluciones, el análisis consiste en la descomposición del todo en sus partes, en sus diferentes relaciones y componentes, luego se realiza una síntesis para una fácil comprensión del problema, es decir se establece la unión entre las partes, se determina sus leyes o relaciones interiores y se propone soluciones, a través de la abstracción y la generalización. (Lanuez, Martínez y Pérez, 2008).

El método de lo abstracto a lo concreto permite que la abstracción posibilite el funcionamiento esquemático de los fenómenos sociales, omitiendo una gran cantidad de factores causales, pero no determinantes, lo cual posibilita que se pueda revelar las leyes que rigen de forma efectiva el fenómeno y sus aspectos esenciales. Este método permite hallar las particularidades, regularidades y cualidades generales y permanentes. Una vez que se ha podido identificar el funcionamiento del fenómeno de forma abstracta, se pasa a comprobar si las relaciones halladas funcionan en el campo real (Díaz, 2009).

El dialéctico, es un método que tiene como principio la realidad objetiva existente, enfatizar los cambios y el desarrollo permanente. Luego, la realidad cambia por contradicciones internas de los elementos o aspectos principales que se dan en todos los fenómenos, la realidad se presenta en distintos niveles. El método dialéctico busca encontrar la esencia de los procesos, descubrir sus verdaderas causas y las formas de sus variaciones. Este método es usado para conocer objetivamente la realidad, así como el desenvolvimiento de ella (Rojas, 2002).

La modelación, es el método empleado en la investigación que estudia los fenómenos para luego explicarlos y comprenderlos. El modelo es una referencia que deberá ser imitada o reproducida. En tal sentido, la modelación vista como ideal, recoge, 
representa e imita la estructura y comportamiento de un fenómeno (Martínez y Calva, 2005). El instrumento empleado para la modelación es teórico, su aplicación permite diseñar y modelar una propuesta didáctica para contribuir al desarrollo del pensamiento crítico de los estudiantes de la especialidad de pintura. La modelación es el resultado del diagnóstico realizado por un estudio de campo.

\section{Técnicas e instrumentos.}

Entre los métodos empíricos que forman parte del proceso de investigación, se usará la técnica de la observación, la entrevista y la participación.

La observación a clase es un método empírico para obtener información primaria de los objetos investigados o para comprobar la aplicación de determinados procedimientos o métodos, la observación permite conocer el estado de las cosas, su organización, las conductas de las personas o grupos sociales, es un método directo, el investigador se aproxima al fenómeno para conocer los elementos que le permitan una certeza en sus conclusiones, es una forma básica de obtener información y tiene la ventaja de que los datos recogidos son objetivos (Lanuez, Martínez y Pérez, 2008). En tal sentido, este método consiste en la percepción directa del objeto de estudio. Permite aproximarse a la realidad a través de las percepciones por cercanía con los objetos y fenómenos de estudio. Al inicio se emplea en el diagnóstico del problema de la investigación, luego adquiere características propias como método. Este método se aplicó en la investigación para la observación de la sesión de clase del tercer ciclo del taller de Pintura I de una institución educativa de arte de Lima.

La entrevista es un método empírico que consiste en un intercambio verbal entre dos o más personas; por un lado, el entrevistador, quien recaba información pertinente que servirá a la investigación, su función consiste en realizar una serie de preguntas con el fin de lograr explicar el problema planteado en la investigación. Por otro lado, el entrevistado o entrevistados proporcionan los datos requeridos que forman parte del problema y que pueden servir para la solución. Se requiere que el entrevistador tenga claros sus objetivos y posea un entrenamiento para aplicar con precisión y rigurosidad este método, a su vez debe ser flexible dinámico, lo cual ayuda al entrevistado a sentirse seguro y colabore con la información necesaria (Lanuez, Martínez y Pérez, 2008). Por lo expuesto, este método sirve para obtener datos que de otro modo serían muy difíciles de obtener, para ello se hace uso del diálogo, el entrevistado debe tener conocimiento del tema de investigación y formar parte de la muestra. El instrumento empleado en la 
investigación fue el cuestionario, aplicado a los docentes de la asignatura Pintura I. Para el éxito de la entrevista fue necesario desarrollar un cuestionario adecuado, con preguntas desenvueltas y con el fin de esclarecer el nivel de pensamiento crítico de los estudiantes de la especialidad de pintura.

Finalmente, se empleará el método empírico de la encuesta, el cual permite obtener información de grupos amplios, cuyos resultados son procesados de forma cuantitativa. Es un método por el cual podemos recabar cantidades significativas de información en un corto plazo. La encuesta es de utilidad para conseguir información sobre algún fenómeno, a partir de las respuestas de las personas involucradas en dichos fenómenos, los resultados obtenidos se procesan para arribar a conclusiones reales, las cuales se enmarcan directamente a los problemas estudiados (Lanuez, Martínez y Pérez, 2008). En este sentido, fue necesario aplicar la encuesta para determinar si los docentes promueven el pensamiento crítico en la sesión de clase y establecer cuál es el nivel de esta capacidad reflexiva en los estudiantes del taller de Pintura I.

\section{Población, muestra, muestreo: unidad de análisis}

Según Gomes, Deslauriers y Alzate (2010), la población es un conjunto de individuos que comparten diversas características y que pertenecen al campo en el que se realiza el estudio, la información obtenida de los individuos debe ser relevante para llegar a conclusiones que estén relacionadas al objeto de estudio.

La población para estudiar está constituida por dos grupos que suman un total de ochenta y cuatro alumnos del tercer ciclo de artes visuales de la institución educativa. Gomes, Deslauriers y Alzate (2010) afirman que la muestra es un grupo representativo de elementos de una población a estudiar. La muestra a la cual se le aplicará los instrumentos empíricos será de treinta y uno estudiantes y cuatro profesores.

La unidad de análisis para el presente estudio está conformada por los estudiantes del tercer ciclo de la institución educativa, a quienes se les aplicó una encuesta para conocer su capacidad de pensamiento crítico. De igual manera, la unidad de análisis comprende a los docentes a cargo del grupo, los cuales son entrevistados y observados en su aula durante el dictado de clases. 


\section{Capítulo I}

\section{Marco teórico}

\section{Antecedentes de la investigación}

En el trabajo se procedió a investigar diversas publicaciones, logrando encontrar antecedentes del desarrollo del pensamiento crítico en estudiantes de educación superior. El concepto de pensamiento crítico se ha ido desarrollando a través del tiempo, y existen varios trabajos al respecto que expondremos a continuación:

\section{Antecedentes internacionales.}

Rodríguez (2018), efectuó una investigación de tipo no experimental, ex post facto, con el propósito de evaluar el nivel de pensamiento crítico en estudiantes de nivel medio superior en México. Se realizó un muestreo no probabilístico de conveniencia, con 278 estudiantes de bachillerato, hombres y mujeres de 15 y 18 años. Los participantes respondieron a un cuestionario socio demográfico y académico como instrumento de aplicación, y un instrumento de autonomía en el aprendizaje. Además, los estudiantes elaboraron un texto argumentativo a partir del cual se pudo evaluar el avance del pensamiento crítico, para ello se elaboró una rúbrica. Los resultados de la investigación mostraron un incremento en el nivel del pensamiento crítico conforme los alumnos avanzaban en sus estudios de educación media superior, no habiéndose encontrado diferencias entre ambos sexos. Se concluye que, es posible evaluar de forma práctica las habilidades de pensamiento crítico en los estudiantes que son expuestos a los problemas cotidianos, pero significativos para ellos.

Por su parte, Águila (2014) propuso el desarrollo de habilidades y estrategias para propiciar el pensamiento crítico y creativo en el alumnado de la Universidad de Sonora, México. Conocer el valor de las herramientas y el lenguaje del pensamiento crítico dentro del aprendizaje por medio de métodos, técnicas y estrategias, fue el objetivo de la investigación que se abordó desde un enfoque cualitativo y cuantitativo (estudio mixto) con un diseño exploratorio-descriptivo. Además, la investigación consideró la necesidad del fomentar el pensamiento crítico desde los niveles preuniversitarios que le permita al estudiante abordar los estudios superiores teniendo la habilidad de analizar, evaluar, generar razonamiento entre otras. Para el propósito de la investigación se trabajó con una población participante de los programas de estudio de 500 estudiantes, de los cuales se extrajo la muestra que estuvo constituida por entre 20 y 40 estudiantes de distintos 
programas de estudio, todos pertenecientes al turno matutino. El instrumento aplicado fue el cuestionario de preguntas cerradas y abiertas para diagnosticar la percepción de los estudiantes con respecto a las variables del estudio. Otro instrumento consistió en el análisis de un artículo periodístico para que los estudiantes puedan expresar elementos del pensamiento. Se concluye que la investigación documental efectuada determinó que el pensamiento crítico es un lenguaje imprescindible, tanto en la educación como en la vida diaria.

Mora (2015) realizó un estudio de tipo investigación acción, cuyo objetivo fue ofrecer una estrategia de aprendizaje que contribuya al desarrollo del pensamiento crítico en los estudiantes principiantes de la Corporación Universitaria Uniciencia del Programa de Ingeniería Ambiental en Bogotá-Colombia. La muestra con la cual se llevó a cabo la propuesta de enseñanza aprendizaje estuvo conformada por 22 estudiantes. Esta investigación tuvo un enfoque mixto, es decir, involucró el enfoque cuantitativo y el cualitativo y con un alcance exploratorio y descriptivo.

Para el desarrollo de la propuesta se aplicaron los siguientes instrumentos: la prueba pedagógica de entrada, las tablas de sistematización de datos, las unidades didácticas, las rúbricas de evaluación, la prueba pedagógica de salida. La investigadora resalta que la propuesta puede aplicarse a cualquier área del conocimiento adecuando las unidades didácticas al tema específico de la cátedra en cuestión. La correcta aplicación de la estrategia de aprendizaje de la investigación puede servir para realizar trabajos interdisciplinares.

A su vez, Colmenares (2018), efectuó una investigación que combina teoría y praxis, de tipo no experimental y de carácter interpretativo, con el propósito de comprender la importancia del dibujo artístico como técnica de estudio y su posterior impacto en el desarrollo del pensamiento crítico; partiendo de las experiencias suscitadas en el Taller de Dibujo Artístico del Departamento de Artes Visuales de la Dirección Central de Cultura de la Universidad de Carabobo en Venezuela. Se realizó un muestreo no probabilístico en el cual los informante claves fueron los participantes del taller de dibujo artístico. Por ser una investigación cualitativa, la técnica utilizada fue la observación participante no estructurada, además los integrantes del taller fueron sometidos a un registro que requirió el empleo de un diario de campo. Se concluye que, el dibujo artístico es de gran utilidad dentro del ambiente educativo y laboral como herramienta para generar sensibilidad y el desarrollo del pensamiento crítico. 
Alejo (2017) realizó una investigación para obtener el grado de doctor con el objetivo de conocer y valorar la capacidad de Pensamiento Crítico que posee el estudiantado del grado de Maestro/a de Educación Primaria.

La investigación es mixta, tanto cuantitativa y cualitativa, para ello utilizó los siguientes instrumentos: guía de entrevista, prueba pedagógica y observación de clase. Se comprobó que es posible educar para formar un pensamiento crítico que genere en el individuo la capacidad de razonar como lo empleaba Sócrates desde su retórica y a través de su dialéctica para constituir personas cuya capacidad no se vea limitada y sigan preguntándose y generando sus propias preguntas y respuestas para llegar a culminar en un razonamiento crítico con la sociedad. Se concluye que a través de la educación se puede crear un proceso de enseñanza-aprendizaje de la capacidad del pensamiento crítico que implique una ética personal y social fundamentada en una educación cívica, en convivencia, en libertad y en igualdad, es decir, plenamente democrática, para generar ese pensamiento crítico que transforme a la sociedad y podamos optar a la toma de decisiones de forma libre y sin prejuicio alguno.

\section{Antecedentes nacionales.}

Bolo (2017) publicó una investigación explicativa causal sobre la importancia de abordar el pensamiento crítico desde la filosofía para tomar una actitud reflexiva ante la sociedad. El objetivo principal de la investigación pretendía determinar como a través de la lectura de textos filosóficos se puede influir en el desarrollo del pensamiento crítico en alumnos del primer ciclo de la Facultad de Ciencias Empresariales de la Universidad de Lima, estas lecturas forman parte del curso Pensamiento Crítico y Prospectivo en dicha universidad y aplican el método socrático y de interrogación crítica, de gran ayuda en la aplicación de estrategias metodológicas. De tres grupos que conformarían la población se optó por trabajar con el grupo de la tarde, el cual presentaba mayores dificultades en su proceso de lectura. De una población de 160 estudiantes fueron 60 quienes integrarían la muestra, para lo cual se aplicó durante un semestre el test Cloze, a manera de Pre y Post Test y lecturas que miden el grado de comprensión lectora de los estudiantes, con el fin de mejorar los índices de reflexión, pensamiento crítico y la capacidad evaluativa de los estudiantes.

La tesis de maestría de Melchor (2018), de la Universidad Cayetano Heredia, propuso por su parte, el desarrollo del pensamiento crítico en relación con una asignatura artística en la Escuela Nacional Superior Autónoma de Bellas Artes del Perú. Esta 
investigación, aplicada e investigativa, hizo uso del portafolio como una forma de evaluación que permite al alumno desarrollar el análisis reflexivo de sus labores durante el curso y ayuda al profesional a elaborar un registro de su trabajo. La investigación de diseño experimental y de tipo cuasi experimental, determinó que el portafolio digital mejoró la capacidad de análisis de la información en el pensamiento crítico en los estudiantes. Además, se demostró que el portafolio mejoró la capacidad de argumentar posición, inferir implicancias y resolución de problemas en el pensamiento crítico. Para ello, se trabajó con una muestra compuesta por 20 estudiantes de una población total de 40. Como técnicas de trabajo se emplearon cuestionarios, observación y evaluación, mientras que los instrumentos empleados fueron la encuesta, la ficha de observación y el registro de evaluación.

Motta (2012), en su investigación tuvo como objetivo general explicar, determinar y analizar la relación existente entre resiliencia, actitud creativa hacia actividades académicas y habilidad de pensamiento crítico de los estudiantes de primer ciclo de la Escuela Académico Profesional de Educación de la Facultad de Educación de la Universidad Nacional Mayor de San Marcos. Esta investigación es de tipo cuantitativa, transversal y aplica un diseño correlacional. La población y muestra a la vez está conformada por 121 estudiantes del primer ciclo, la muestra es intencional en muestreo no probabilístico. Finalmente, para la obtención de los datos se aplicaron tres instrumentos de medición: escala de Likert de resiliencia, escala de Likert de actitud creativa hacia actividades académicas y la escala de Likert de habilidad de pensamiento crítico.

Por su parte, Díaz (2012), publicó una investigación descriptiva-correlacional, de corte transversal sobre la importancia de formar una actitud crítica en los estudiantes de nivel superior y la influencia de las estrategias metodológicas que emplean los docentes para ese fin. Por lo tanto, el objetivo principal de la investigación pretendía determinar la relación entre las estrategias metodológicas empleadas por los docentes y la actitud crítica de los estudiantes ingresantes de la Facultad de Educación de la Universidad Nacional Mayor de San Marcos. La población estuvo constituida por 170 alumnos y 20 docentes de la Facultad de Educación. El tipo de muestreo utilizado fue probabilístico, con un tamaño muestral fijado con un margen de error de 0.05 y nivel de confianza de $0.95 \%$. Para el estudio se elaboró dos encuestas, la primera para medir el nivel de las estrategias metodológicas y la segunda para medir el nivel de pensamiento crítico en los estudiantes. De acuerdo con los resultados obtenidos, se concluyó que es necesario realizar un replanteamiento de las estrategias metodológicas empleadas por los 
docentes, ya que es necesario involucrar más al estudiante con la práctica investigativa generando aspectos que hagan posible la retroalimentación por parte del docente y de los integrantes del aula.

De igual forma Guevara (2016), realizó una investigación para obtener el grado de Maestro, cuyo objetivo era determinar la relación del pensamiento crítico con el desempeño docente en los estudiantes del décimo ciclo del pregrado de la especialidad de primaria de la Facultad de Educación de la Universidad Mayor de San Marcos. La investigación fue de carácter cuantitativa con una muestra de 60 estudiantes, a quienes se aplicaron los instrumentos: la ficha de observación y cédula de cuestionario. Se concluyó que existe relación significativa entre el pensamiento crítico y el desempeño en los docentes y los estudiantes de la especialidad mencionada, Se recomienda que se mejore el desarrollo del pensamiento crítico durante la ejecución de las actividades de aprendizaje para obtener mejores resultados en el desempeño docente, así como mejore la meta cognición y los criterios de evaluación en los estudiantes del décimo ciclo de pregrado de la especialidad de primaria de la Facultad de Educación de la Universidad Mayor de San Marcos.

\section{Aproximación al pensamiento crítico}

\section{Definición de pensamiento crítico.}

La Real Academia de la Lengua Española (RAE, 2014) señala que la palabra pensamiento posee los siguientes significados: 1. Facultad o capacidad de pensar. 2. Conjunto de ideas propias de una persona, de una colectividad o de una época.

Zatongy (2002) cita a Piaget, para quien pensamiento es una acción interiorizada, primeramente, como asimilación representativa de lo real o la percepción del mundo que nos rodea, a los esquemas iniciales del pensamiento que genera una representación interior.

La autora afirma que, según Piaget, el pensamiento es una actividad mental simbólica que implica una actividad global del sistema cognitivo, y que opera con todo tipo de representaciones mentales: palabras, imágenes, etc. El pensamiento es un producto del pensar, es decir, un proceso psicológico racional, subjetivo, de conocer, comprender y juzgar los objetivos y hechos. El desarrollo intelectual es una evolución que depende de estadios de pensamientos cualitativamente distintos, siendo un desarrollo 
diferente en cada edad. Campos refiere "El término crítico proviene del griego Kritike, que significa el "arte del juicio". Es decir, la aplicación de nuestro juicio en la toma de acción, de aceptación o rechazo de una información" (2007, p. 19).

Por otro lado, Rozitchner (2012) afirma que la crítica es un instrumento que nos permite ver más allá de aquello que nos dicen o aquello que nos quieren vender. Es decir, nos libra del peligro de caer en lo que la sociedad quiere que pensemos, y es precisamente a través del pensamiento que debemos desnudar la realidad, ya que el mundo en el que vivimos está lleno de trampas y apariencias.

A su vez, Eliot define la crítica como una actividad instintiva, posible en una mente privilegiada (Alfonso, 2001). Acerca del pensamiento crítico, numerosas perspectivas han sido expresadas para tratar el tema. Entre ellos Herrero, manifiesta que se trata de un razonamiento deliberativo que le permite al individuo saber sobre lo que debe creer y debe hacer. "El pensamiento crítico se centra en la construcción de argumentos y en su uso en el razonamiento" (2018, p. 18).

El pensamiento crítico establece métodos de análisis de argumentos, cuyos criterios, en su intención de ser sostenidos, deben basarse en razones bien asentadas. Al respecto el autor refiere.

Juzgar si hay razones suficientes, relevantes y aceptables para hacer o creer algo, o para no hacerlo o no creerlo: en eso consiste el pensamiento crítico, se trata de un razonamiento reflexivo, juicioso, que cuestiona lo que lee o lo que escucha (2018, p. 18).

Al analizar esta posición podemos afirmar que el pensamiento crítico es una habilidad organizada e intencional que se lleva a cabo con el conocimiento y se desarrolla para que el individuo tome determinaciones. En otras palabras, el pensamiento crítico es el juicio deliberado constituido por habilidades y hábitos mentales para interpretar, analizar, evaluar, inferir, autorregular, razonar y explicar consideraciones de tipo conceptuales, metodológicas, de criterio, de evidencia y contextuales, esto permite al buen pensador explicar lo que piensa y como puede llegar a un juicio (Facione, 1990 y Campos, 2007). 
Ser crítico implica abandonar el escepticismo cuando la fuerza de la razón se impone, las razones son las pruebas, evidencias o premisas y deben ser contundentes. Al respecto Herrero sostiene que:

Implica saber diferenciar entre los hechos que son relevantes y los que no lo son; advertir las semejanzas y las diferencias significativas; evaluar las evidencias, las suposiciones, las inferencias; identificar las contradicciones; utilizar el lenguaje con propiedad críticamente; determinar la credibilidad de los recursos; leer y escuchar críticamente; evaluar los argumentos, las creencias, los valores, las interpretaciones (2018, p. 19).

En tal sentido, para sostener una afirmación se necesitan razones, evidencias y tener un sustento que lo respalde. La información de la que se dispone debe ser examinada de forma crítica, es decir relacionar los hechos, contrastarlos, verificarlos con la razón y conocimientos previos. En resumen, el pensador crítico debe identificar diversos puntos de vista y tomar una postura en base a argumentos sólidos. (Blanco, 2016; Herrero, 2018)

El autor sostiene que una afirmación necesita razones, evidencias, debidamente respaldadas y la información de la que se dispone debe ser examinada de forma crítica, relacionar los hechos que verificamos y conocemos previamente. El pensador crítico a través del argumento busca aproximarse a la verdad, y la verdad es la relación entre una idea y una creencia. Al enjuiciar una cuestión hay que ser muy claro y preciso en cada término empleado para reducir las posibilidades de malinterpretación o confusión. Al respecto Herrero afirma:

Una proposición, un juicio, aquello que se sostiene, puede ser un hecho o una opinión. La diferencia es sencilla: es un hecho si es algo que puede ser verificado y contrastado de forma objetiva y empírica. Se refiere al mundo tal cual es. ...Es una opinión si se refiere a cómo uno cree que es algo o cómo debería o podría ser. En este caso, pueden ser más o menos aceptables (2018, p. 28). 
Por lo expuesto, se puede asegurar que nuestros actos son producto de la reflexión, por lo tanto, debemos manejar las emociones, ser reflexivos, desarrollar la inteligencia y vivir en base a los valores éticos. Además, es necesaria la autocrítica y respetar a los demás para justificar nuestros pensamientos, que deberán ser positivos. En resumen, pensar críticamente mejora la calidad del pensamiento (Paul y Elder, 2003; Espíndola, 2005).

Así, es necesario ser claro en los hechos que se exponen para argumentarlos correctamente y no se desvíe el argumento hacia otros temas por encontrar significados derivados de los términos expuestos. Además, solo deben someterse a consideración cuestiones concretas para evitar un análisis erróneo por partir de diferentes concepciones de los términos empleados. Puede ser necesario consensuar las definiciones de los términos empleados (Herrero, 2018).

Con respecto a esta idea, el autor refiere que no se debe tomar toda la información como cierta, sin haberla pasado por un análisis previo o contrastado con sus conocimientos u otros conocimientos que puede ser capaz de buscar e investigar.

De esta apreciación, consideramos que el individuo puede integrar varias habilidades mentales para llegar a un buen juicio. Se trata de lograr un proceso reflexivo que ayudará a tomar decisiones acertadas y respaldadas por la razón, para saber cómo debemos actuar y en que debemos creer. Entonces, es importante explorar la situación para poder acceder a una conclusión integradora, con el propósito de justificar lo que se pretende evaluar (Ennis, 1996; Kurfiss, 1988).

Según el autor existe otras tendencias que dificultan el pensar críticamente, entre ellas tenemos el efecto del falso consenso, el efecto arrastre, los prejuicios, los estereotipos y etnocentrismo. Ante esas tendencias, es mejor suspender cualquier emisión de juicios y reconocer que no se sabe sobre algo cuando no se cuenta con la información que pueda ser evaluada y justificada. En tal sentido, el buen juicio debe apoyarse en criterios y debe ser sensible al contexto.

Hacer uso del razonamiento permite al pensador identificar la falsedad de los argumentos infundados o que no se sustentan en evidencias. Estas características hacen la diferencia entre un pensador ordinario y un pensador crítico. El pensador ordinario adivina, refiere, agrupa, cree, infiere, asocia conceptos, nota relaciones, supone, ofrece opiniones sin razones y hace juicios sin criterios. En cambio, el pensador crítico estima, evalúa, clasifica, asume, infiere lógicamente, obtiene principios, nota relaciones en otras 
relaciones, hipotetiza, ofrece opiniones con razones y hace juicios con criterios (Campos, 2007).

Por otro lado, el pensamiento crítico es muy importante en la educación, es necesario para crear habilidades como: investigar, informarse, contrastar, verificar debidamente todo conocimiento o verdades que se tienen como absolutas; en otras palabras, desarrolla la reflexión antes de tomar decisiones u opiniones.

Por último, el pensamiento crítico es un fenómeno humano que se extiende a todos los intereses del saber del ser humano, científico, filosófico y artístico. Pensar críticamente permite enfocar la vida, ser un profesional de calidad, tener sensibilidad social y preservar el planeta, prácticamente tiene sus raíces desde el inicio de la civilización, desde las cavernas hasta la modernidad; a través del pensamiento crítico el ser humano se ha desarrollado y a su vez, la carencia de este lo está llevando a un indiscriminado uso de los recursos naturales, contaminación ambiental y recalentamiento global.

\section{Definición de las subcategorías del pensamiento crítico}

\section{Juicio crítico.}

El juicio es el resultado del proceso dinámico de la inteligencia y la razón, que permite conseguir un saber experto. La actividad de juzgar hace que se cuestione la verdad de las cosas sin importar lo brillante, deliciosa o plausible que sea una explicación, siempre es necesario cuestionar si las cosas son de tal manera o de otra (Gromi, 2017). Esta actividad de cuestionar es posible porque el hombre es un animal racional capaz de emitir juicios y conoce del proceso de cómo ha llegado a formularlos.

En tal sentido, el juicio es una forma consciente del pensamiento para analizar conceptos o dividirlos en sus partes, con el fin de diferenciar lo verdadero de lo falso; por lo tanto, es una capacidad para expresar una idea de forma lógica, conectando conceptos que permitan afirmar algo con convencimiento y así poder obtener una opinión razonada. En resumen, se puede definir al juicio como la capacidad de la razón humana para diferenciar lo verdadero, lo falso, lo verificable, lo irrelevante, lo bueno y lo malo.

Rozitchner (2012), afirma que la crítica es un instrumento que permite al hombre ver más allá de aquello que es considerado una verdad absoluta, es decir, aquello que es 
socialmente correcto para el pensamiento, alejando el peligro de permanecer únicamente en lo dictado por las creencias sociales. Se puede afirmar que la crítica es un ejercicio por el cual el pensamiento descubre la realidad, lo contrapone con la realidad, y genera conciencia sobre este mundo lleno de apariencias y falsas verdades, de imposiciones culturales o de poder. El efecto que produce los resultados de la crítica es el de llegar a la verdad por medio de cuestionamientos, de poner en duda, de investigar verdades que se imponen como absolutas, con lo cual se va descubriendo sus fisuras o están bajo supuestos erróneos, que muchas veces no son percibidos, pero que podemos descubrir en un ambiente crítico.

En este sentido, se considera que la crítica es la visión juiciosa que tenemos sobre algo para destacar lo verdadero de lo falso. La crítica es un ejercicio que implica analizar los elementos más significativos, descomponerlos para un mejor conocimiento de los hechos y sintetizarlos, creando una opinión personal, que comprende la naturaleza, las causas y los efectos de las cosas, para tener conciencia sobre ellas y no dejarnos persuadir, imponer ideas o crear opinión no sustentable con la verdad. Una mente crítica cuestiona todo, incluyendo lo aparente como verdad absoluta, tales como los valores y las normas que rigen su entorno, con el fin de tener un punto de vista propio para ser independiente y autónomo. Solo en tal escenario, el pensador crítico puede tomar decisiones propias y resolver los problemas que se presenten.

Por lo expuesto, el juicio crítico es una capacidad intelectual que le permite al estudiante interpretar la realidad cotidiana, es un instrumento que sirve como elemento central en la didáctica para aprender a entender, juzgar y evaluar. Además, el juicio crítico es una herramienta que le será de utilidad al docente, en su función orientativa, para lograr que el educando construya el significado de las cosas en relación con su entorno (Gromi, 2017).

Así, en el proceso de educación, es necesario desarrollar la capacidad de juicio crítico como una herramienta importante para el desenvolvimiento del estudiante y su incorporación a la vida profesional y social. Para adaptarse a las nuevas exigencias de los tiempos modernos tenemos que desarrollar habilidades que nos permitan adaptarnos, innovar y liderar los cambios, interpretar la realidad y comprenderla para poder comunicarnos. No debemos aceptar como verdadero todo aquello que forma parte de nuestro contexto sin antes analizar y evaluar, solo así podemos estructurar y construir nuestros propios esquemas mentales. 
Para ello, el rol del docente es fundamental en la comprensión de su función educativa y deberá estar capacitado para pensar de forma reflexiva y crítica sobre sus conocimientos. Asimismo, deberá entender la complejidad y multifuncionalidad de su labor, la cual debe renovarse constantemente y adaptarse a los cambios del futuro (Nuñez et al., 2018).

Del mismo modo, el artista debe tener una función crítica de la realidad y no ser sólo un productor de imágenes, técnicamente bien logradas. El artista con juicio crítico articula conceptos técnicos, compositivos, culturales, sociales y políticos, para poder crear su propio imaginario. Ello servirá, además, al descubrimiento de su originalidad expresiva (Lentini et al., 1986). El artista debe contrastar las ideas que va adquiriendo para poder desenvolverse con independencia en su entorno. En su accionar crítico debe dominar las cuestiones que está tratando para evitar propuestas artísticas sin propósito.

Por otro lado, Angvik (1999) cita a Mariátegui para quien la crítica no debe ser parcial ni subjetiva y debe preocuparse por la moral, los temas filosóficos y políticos. Pues el artista comprometido no es conformista y busca a través del arte las respuestas a los problemas y circunstancias que le toca vivir.

Se comprende entonces, que el sentido autocrítico también debe ser desarrollado por el artista para determinar aspectos relevantes o irrelevantes en su propia obra, de lo contrario lo superfluo podría apropiarse de ésta. La obra artística debe tener un contenido, los medios empleados, el estilo, las formas, la impresión que producen los colores y texturas debe reflejar la expresión del artista. En resumen, el artista debe estar familiarizado con la realidad social para poder ser su expresión y así poder optar por romper lo convencional en lugar de seguir reglas para escapar de lo tradicional y vano. Además, todos los medios empleados en la producción de la obra artística, determina el discurso.

\section{Conceptualización axiológica.}

La conceptualización es el proceso que permite identificar la realidad de forma parcial o concreta por medio de la elaboración de conceptos creados por la mente. Es decir, los conceptos son imágenes mentales o abstracciones de la realidad relacionada con el pensamiento y el proceso de aprendizaje. Es la representación mental de un fenómeno por medio de la observación directa o indirecta de situaciones o aspectos de la realidad. Para generar el concepto de un objeto o fenómeno es necesario abstraer sus características fundamentales, la conceptualización es un proceso ejecutado de forma 
sistemática en las tareas intelectuales, este proceso consiste en abstraer impresiones de los sentidos (Ramírez, 2007).

Por lo expuesto, podemos decir que la conceptualización es un enfoque abstracto y simplificado del conocimiento global, por medio de esta representamos lo que sabemos sobre el mundo. En otras palabras, a través de la conceptualización se genera un proceso mental que permite el surgimiento de ideas y conceptos para reconocer y representar nuestro entorno, desde lo específico hasta lo general.

Por otro lado, la RAE (2014), precisa que la axiología es la teoría de los valores, Del fr. axiologie, y este del gr. ä́ıos áxios 'digno', 'que tiene valor' y el fr. -logie '-logía'. Es también una rama de la filosofía que se encarga del estudio de los juicios valorativos, valores y cualidades de las personas y objetos. Desde esta perspectiva, el eje axiológico representa un conjunto de actitudes y valores que busca consolidar la formación integral del estudiante, orientándolo hacia la adquisición de valores humanistas y sociales con una formación profunda en conocimientos y compromiso social, a través del respeto por el medio ambiente, la identidad y diversidad cultural, incluyendo todas sus manifestaciones, la adquisición de valores éticos con proyecciones positivas del individuo que le permita estar en armonía con el entorno y uno mismo (Casillas y Santini, 2006).

En tal sentido, los juicios de valor surgen en la conciencia como estimaciones que dependen de la cultura. Los valores pueden ser positivos o negativos y ser jerarquizados. Una persona sin principios opta por obtener lo que quiere sin importar los medios, es aquí donde interviene la axiología, que cumple su función reflexiva sobre los valores humanos. Esa actitud axiológica debe estar presente también al pensar críticamente, que no tiene nada que ver con usar el sentido común, porque este puede no condecirse con lo verdadero, y a su vez es cambiante.

No se trata de tener una opinión, una opinión debe primero ser aceptada y probada. La moderación o tener una postura entre dos que se encuentran enfrentadas no siempre es lo correcto. Algunas veces lo correcto está en medio del camino entre dos posturas enfrentadas, pero otras veces tener una postura radical o tolerancia cero es lo correcto (Ñaupas, Mejía, Novoa y Villagómez, 2014).

Según Garzón y Garcés (1989), la conceptualización axiológica es una expresión mental producida para representar las cualidades principales de los individuos y las clases de valor. Se trata de un proceso en el cual el individuo genera conceptos a partir de la valoración de las cosas, conceptos que deben tener su origen en las vivencias 
personales, sobre el valor en cuestión, para que sean significativos. De acuerdo con lo expuesto, se considera que los valores son producidos en las relaciones sociales, con lo cual, se determina la esencia humana. Entonces, la práctica social es el origen de las dimensiones valorativas, y son precisamente los valores parte constitutiva de la realidad social.

El mundo del arte se ve envuelto por la estética y la ética, la primera dirige su interés hacia las formas, el goce visual, la segunda en los criterios, principios, valores y normas. Ambas señalan los caminos por el cual debe transitar el arte, lo que debe o no debe hacer el artista, ya que la ética no nos permite aceptarlo todo, aunque sea posible. La estética por la estética tiene un límite ético, que el artista debe respetar, pues cada manifestación estética debe tener un sustento ético.

\section{Base gnoseológica.}

Según la RAE (2014), el término base se refiere al fundamento o componente principal que sirve para apoyar algo. La gnoseología (del griego gnosis, conocimiento o facultad de conocer, logos) o teoría del conocimiento trata de establecer el alcance, la naturaleza y el origen del conocimiento general, el ordinario, el filosófico, el científico, etc. La gnoseología es una teoría general del conocimiento, por lo que, como psicología también se interesa por cualquier forma del conocimiento, científico o no.

Según Báez (2007), es posible caer en confusión al emplear las palabras epistemología y gnoseología, dado que autores de origen anglosajón y francés otorgan a la palabra epistemología significado similar al que tiene gnoseología. De hecho, la palabra inglesa epistemology se suele traducir a nuestro idioma como gnoseología. En castellano hay una distinción con respecto a la definición de estas palabras, la epistemología se circunscribe al conocimiento científico mientras que gnoseología aborda el conocimiento en general.

De acuerdo a lo mencionado, se considera que la gnoseología estudia el conocimiento en general y comprende sus aspectos racionales y no racionales, es decir, para esta rama de la filosofía no todo conocimiento proviene de una vertiente científica. El conocimiento del mundo no solo es científico, también se conoce por medio del pensamiento, es decir por la filosofía y, además, por medio de las emociones o a través del arte. 
A partir de las definiciones mencionadas podemos concluir que la base gnoseológica es la fundamentación teórica que adquiere el campo del saber al estudiar el conocimiento en su totalidad. En este aspecto, el hombre establece relación con su entorno desde lo cotidiano, lo individual y personal. Por lo tanto, todo conocimiento en general que es estudiado desde su origen y naturaleza proviene de un enfoque gnoseológico.

De acuerdo a lo expuesto, podemos relacionar la gnoseología con el arte, al respecto Fallas y Cárdenas (2006) refieren que, a partir de un enfoque gnoseológico, se entiende que el arte es una técnica de la observación con una lectura de la realidad. Entonces, se establece con los resultados artísticos formas de mirar, con actitud estética, contemplación y goce de la belleza. En tal sentido, se puede afirmar que desde el enfoque gnoseológico todo artista en sus creaciones simbólicas produce conocimiento a partir de lo emocional, y si este conocimiento lo incorpora a su contexto crea formas de mirar y evidencian problemas sociales, culturales y filosóficos, para que su obra esté al servicio no solo de la creación de un imaginario nacional sino una propuesta ética.

\section{Rol del estudiante.}

La RAE (2014), precisa que la palabra rol significa papel o función desempeñado por alguien. En relación con el nivel educativo, el rol es un desempeño que demanda multiplicidad, responsabilidad y complejidad en las funciones del docente y del educando. Por otro lado, el estudiante es agente en todo proceso general de educación de los cambios educativos, determinándose así mismo una meta o haciendo lo que le proponen. Si bien la acción del docente puede generar conductas en el educando existen límites en su capacidad pedagógica, pues debe respetar la condición de agente del educando, esto se aplica en cualquier logro cultural, incluidas las artes (Touriñán, 2010).

En este aspecto, el estudiante es la parte central del proceso de enseñanzaaprendizaje. A través de la mediación del docente, construirá conocimientos, habilidades, destrezas, desarrollará su ser y su convivencia armoniosa con los demás. Para un aprendizaje significativo ellos tendrán que mostrar interés, estar motivados y construir conocimientos de acuerdo con su medio social.

Desde otra perspectiva, en el campo artístico el estudiante puede mostrar interés y aprender temas que sería solo posible a través de lecturas especializadas. Estimular la sensibilidad del educando por medio de la exploración dinámica de las obras de arte, es un apoyo didáctico que el docente debe saber explotar al máximo. Por ejemplo, sería 
muy significativo desarrollar el aprendizaje por medio del recorrido visual de una pintura, escultura o monumento arquitectónico, en presencia de estos y no desde un libro. Algo similar ocurre al escuchar una melodía o leer una poesía (Flórez, 2007).

Se comprende entonces que el arte, a través de las emociones, nos permite descubrir el mundo y le brinda la oportunidad al estudiante de conocer diversos temas y problemáticas sociales, analizarlas, desarrollar su obra a partir de estas, hacer evidente estos problemas y encontrar posibles soluciones.

\section{Evolución histórica del pensamiento crítico}

El pensamiento crítico aparece desde la edad antigua con la creación del método de raciocinio y análisis de Sócrates, para desarrollar la capacidad crítica de las personas y poder así llegar a respuestas racionales. Entonces, Sócrates daba mucha importancia al cuestionamiento para poder indagar con el fin de llegar al fondo de las cosas. Como pionero del pensamiento crítico, Sócrates hizo esto posible a través de la mayéutica, que es el diálogo mediante el cual se descubre conocimientos que aparentemente no se tenían. Para él, era necesario pensar claro, con lógica y conciencia, así como buscar las evidencias y examinar minuciosamente, analizar conceptos de lo que se dice y hace. A través de sus preguntas el filósofo cuestionaba a la sociedad y los asuntos de su tiempo.

Más adelante Platón difundiría las ideas socráticas y luego Aristóteles haría lo mismo con las ideas de los dos anteriores. Las ideas Aristotélicas sobre pensamiento crítico se pueden apreciar en su obra "Lógica". Según los tres filósofos clásicos, la mente debe ser entrenada para ver más allá de las apariencias de la vida (Campos, 2007).

La edad Media trajo consigo pensadores franciscanos influyentes como John DunsScotus (1270-1308), quien desde su enfoque espiritual desarrolló un pensar inquieto que busca la razón y verdad de las cosas. En su filosofía, de reflexión filosófica y teológica, Escoto parte de cuestiones concretas que trascienden hasta la interminable cuestión humana. Su reflexión tiene un propósito práctico, el de orientar al ser humano a través de la fe cristiana (Utrilla, 2008).

Otro pensador franciscano fue Willian de Ockham (1280 - 1349) a quien se atribuye una célebre expresión sobre el pensamiento crítico, la cual establece que en condiciones similares, la solución más simple siempre será la correcta (Campos, 2007). 
El teólogo y filósofo Santo Tomás de Aquino (1225-1274), aportó enfoques sobre el pensamiento crítico en su obra "La Suma Teológica". Su pensamiento se valía de los instrumentos de la ciencia de aquel entonces para describir hechos que hicieran posible acceder de una forma racional al conocimiento de Dios. Sus ideas reflejan una teología que está bien articulada con la filosofía, lo cual era una mezcla peligrosa para la época e inquietaba al lector (Maurial, 2015).

La necesidad de pensar críticamente se mantuvo con el paso de los siglos XV y XVI gracias a los aportes críticos de los ingleses Thomas More (1478 - 1535) y Francis Bacon (1551 - 1626), el primero propone una visión crítica que sirve de modelo para superar las imperfecciones de la sociedad. A través de su obra Utopía, busca descubrir un mundo mejor que se construye en base a la capacidad de organización del ser humano. More, es un observador clarividente, que se adelanta a las consecuencias que el sistema tiene preparado para el individuo, su obra crítica se anticipa a las sociedades disciplinarias de los tiempos modernos y su visión particular se aplica sin duda al pensamiento crítico (Bidegain, 2010).

Por su parte, Bacon construye sus ideales en base a un enfoque empírico de las ciencias, que coloca al hombre en una nueva posición moral frente a la naturaleza, el sentido epistemológico de su obra tiene origen en el trasfondo moral, su obra se interpreta desde los referentes éticos, políticos, epistemológicos y ontológicos. Bacon encuentra en la filosofía el recurso para establecer la función del hombre que domina la naturaleza y no a otros hombres, pues en su visión transformadora propone un afán de servicio al hombre, caridad, virtud y humildad (Prada, 2011).

Descartes (1596 - 1650), también realizó aportes a través de sus textos en relación al pensamiento crítico, en su obra Reglas para la dirección de la mente, desarrolla métodos de descubrimiento para pensar, cuestionar y poner en duda cada pensamiento y luego verificarlo, con el objetivo de descubrir verdades a partir de reglas fijas. El análisis propuesto por Descartes se basa en el fraccionamiento de una dificultad; es decir, un problema considerado en bloque y dividido en numerosas partes hasta hallar elementos que puedan ser considerados como verdades. Para el filósofo, matemático y físico francés lo verdadero es lo evidente y claro, o aquello que se separa del conjunto de ideas que conforman el problema.

Descartes considera que el criterio de verdad de las ideas debe ser intrínseco, ya que todo el conocimiento adquirido se basa en ideas, escapando del yo para verificarlas. 
Por otro lado, conocer las ideas claras y distintas forma parte del proceso de intuición o conocimiento inmediato, que es un paso fundamental en la adquisición del conocimiento. Luego, las intuiciones deben enlazarse y formar una sucesión de intuiciones, lo cual se conoce como deducción. Descartes propone este proceso para ir de una verdad evidente a otra, con el fin de llegar a aquello que queremos demostrar (Descartes, 2010).

Al llegar a la Edad Contemporánea ubicamos a John Dewey (1858-1952), educador, psicólogo y filósofo quien sostiene que el pensamiento reflexivo se desarrolla al trabajar una idea de forma persistente y cuidadosa, considerándola activamente desde las bases en las cuales se apoya y el posterior resultado de sus conclusiones.

En este sentido, desarrollar pensamiento crítico implica pensar, formular preguntas y encontrar información relevante por sí mismo, esto representa un proceso necesario por el cual podemos llegar a conclusiones propias. Dicho proceso puede tomar tiempo, ya que requiere de evaluaciones y del cuidado de la repercusión que pueda tener nuestras creencias sobre algo para la toma de decisiones (León, 2014).

Es destacable que el término pensamiento crítico fue introducido por Dewey, para quien esta actividad mental representa una forma para hallar solución a los problemas, indagar y reflexionar (Campos, 2007).

Por su parte, Benjamín Bloom (1913-1999) desarrolló una taxonomía de habilidades cognitivas que divide en tres dominios el proceso de aprendizaje y realza la importancia de los desempeños intelectuales del individuo, este énfasis se produce en el primer nivel, conocido como nivel Cognitivo. El uso de las palabras claves y preguntas pueden ser de gran valor para el establecimiento, estímulo y desarrollo del pensamiento crítico, sobre todo en niveles superiores (Fowler, 2002).

Otro importante difusor del pensamiento crítico es Robert Ennis, quien define esta capacidad como un pensamiento reflexivo razonado que permite evaluar los hechos para poder decidir qué hacer o decir. Ennis tuvo gran interés por las ventajas del pensamiento crítico; es decir, las capacidades de reflexionar, razonar y evaluar. Para el filósofo estadounidense el pensamiento crítico puede desarrollarse al adquirir habilidades que permiten conocer el proceso del pensamiento propio, que son consecuencia de la deducción del conocimiento personal sobre el aprendizaje en comunidad.

Según Ennis, esto es posible al habilitar espacios de pensamiento en los cuales se desarrolle la participación activa, crítica y deductiva sobre los temas de mayor interés 
formativo, hechos sociales, etc. Esta forma de ver el proceso educativo permite al estudiante ser constructor de su propio proceso de aprendizaje (De-Juanas, 2013).

En coincidencia con Ennis, Richard Paul sostiene que el pensamiento crítico es un proceso reflexivo, en el cual el individuo puede prescindir de aspectos irrelevantes de entre varias perspectivas, propias o ajenas, para aproximarse a la verdad que considere más apropiada y posibilite resolver problemas (Patiño, 2014).

Por último, Matthew Liptman propone una filosofía dirigida a los niños con el desarrollo de programas educativos que promueven esta actividad reflexiva, el uso de la lógica y práctica filosófica. Él sostiene que los niños son filósofos naturales, curiosos por saber el porqué de las cosas, actitud que los mantiene en continuo cuestionamiento sobre los fenómenos de la realidad, este es el punto de partida esencial para desarrollar el pensar filosófico. Entonces, es a temprana edad que el ser humano desarrolla su capacidad de razonamiento, dirigido de forma inductiva y deductiva incluso antes de desarrollar el lenguaje. Sin embargo, esta conducta filosófica tiende a disminuir con el paso del tiempo (Campos, 2007).

Liptman, también asegura que la capacidad de hacer afirmaciones verdaderas de forma consciente debe implicar hábitos de auto observación y autocorrección, que esclarezca los criterios que sirven de base a los juicios propios, considerando los contextos en los cuales se expresan y sus implicaciones (Patiño, 2014).

Ha habido otros difusores en distintas partes del mundo y desde tiempos antiguos, cabe mencionar a Lao-Tzu, Confucio y Ashoka por sus aportes del pensamiento. Sin embargo, el gran interés por desarrollar pensamiento crítico a nivel académico y práctico surge en las décadas de los ochenta y los noventa a través de numerosas publicaciones realizadas en Estados Unidos. En un comienzo, las publicaciones tenían como base a filósofos, más adelante fueron psicólogos y educadores quienes a partir de sus contribuciones posibilitaron el desarrollo de propuestas más innovadoras y audaces que permitieran el cultivo del pensamiento crítico. Estos aportes son de gran valor en la sociedad de la información en la cual vivimos actualmente. El desarrollo de habilidades del pensamiento crítico a nivel educativo es vital para discernir acertadamente entre el vasto océano de información disponible y los complejos procesos sociales que debemos afrontar (Campos, 2007).

Según lo expuesto, este interés por conceptualizar el pensamiento crítico lo podemos evidenciar a través distintas definiciones de otros autores significativos hasta 
ahora no mencionados, entre ellos tenemos la concepción de Facione (1990), para quien el pensamiento crítico es un juicio autorregulado y deliberado útil para analizar, interpretar, evaluar y finalmente inferir. Además, nos permite explicar las formas conceptuales, de criterio, metodológicas, de contexto y evidencias que sirven de base al juicio final.

Por otro lado tenemos la definición de Scriven, quien sostiene que se trata de un proceso hábil, disciplinado y creativo que favorece al proceso de conceptualización, síntesis, evaluación de toda la información obtenida o generada a través de la experiencia, razonamiento, reflexión o comunicación, que facilita el entendimiento y la toma de decisiones. En tal sentido, el individuo puede por medio de la razón y la evaluación tomar decisiones acertadas sobre un asunto específico (Campos, 2007).

\section{Características del pensamiento crítico}

Para hacer uso adecuado del pensamiento crítico es necesario emplear el razonamiento para reconocer el engaño y otras argumentaciones falsas carentes de evidencias. Campos (2007) afirma que el pensador crítico debe cuestionar el tema de interés, analizar las ideas que conformen la base del razonamiento para llegar de una forma clara a conclusiones y solucionses. El autor menciona a Wade, quien determina que para pensar críticamente es necesario cuestionar las cosas, resolver un problema, examinar las evidencias, analizar los argumentos, librarse de toda forma de pensamiento emocional, evitar simplificar las cosas exageradamente, acoger otras consideraciones y ser tolerante a opciones ambiguas.

Campos, también se refiere a Jones y Ratchiff, quienes consideran que ser conciente de nuestros propios pensamientos, otra característica del pensamiento crítico, nos ayuda a tener dominio de las actividades que realizamos.

Por otro lado, el autor cita Bayer, quien define algunos aspectos fundamentales del pensador crítico: disposiciones, para representan la capacidad de ver las cosas con mente abierta, buscando la presición de las evidencias; criterios, para determina la veracidad de las cosas, en base a evidencias confiables, precisas y verídicas; el agumento, es la proposición basada en hechos relevantes que le sirven de soporte, con el análisis y la evaluación de los hechos se puede argumentar; el razonamiento, que construye a través de la examinación de los datos conclusiones de las premisas; el punto 
de vista, representa la apreciación que cada uno tiene de los fenómenos, modelando su construcción en base a significados y los procedimientos para aplicar criterios, el pensador crítico debe disponer de varios procedimientos, tales como realizar preguntas y hacer juicios.

Además, el pensamiento crítico debe caracterizarse por ser un proceso activo en el cual el individuo controla su pensamiento, intencional por ser un razonamiento deliberado basado en principios que lo definen como proceso ordenado y evaluativo que permite distinguir y valorar lo correcto e incorrecto (Campos, 2007).

El autor cita a Schafersman, para quien el pensador crítico debe caracterizarse por: formular preguntas pertinentes, priorizar la información de mayor importancia empleando la abstracción en la evaluación de argumentos, ser imparcial en el manejo de las evidencias, ser sistemático en la articulación y síntesis de los pensamientos, reconocer las inferencias correctas de las no correctas, no emitir un juicio ante la falta de pruebas, actuar con prudencia para evitar actos alternativos, apreciar las analogías que no son visibles, tener un gran interés por el aprendizaje.

Además, se debe buscar soluciones desde el punto de vista de otras especialidades, buscar lo esencial en la argumentación, admitir puntos de vistas contrarios a su posición, cuestionar sus propias creencias, ser sensible con respecto a la autenticidad de una idea y la forma como se respalda, saber los límites de la capacidad de entendimiento del ser humano, poner en duda toda verdad y q no existen verdades absolutas, utilizar ante todo la razón para alcanzar sus conclusiones comparándolas con modelos relevantes, estar dispuesto a cambiar su juicio ante el surgimiento de nuevas evidencias.

Asimismo, el autor cita a Silverman, quien considera que el pensador crítico es capaz de: estudiar asuntos complicados y tener base en su sustento, tener gran capacidad de síntesis para alcanzar juicios razonados, tener en cuenta la lógica, si los datos son importantes y si son válidos, solucionar problemas complejos, contar con un bagaje intelectual y comprensión para el análisis y resolución de nuevos problemas, debe poner en duda todas las verdades que creamos ciertas por venir de la sabiduría oficial, distinguir entre observación y deducción, reconocer las proposiciones y principios de los argumentos y cuestionarlos, descubrir la naturaleza del razonamiento que se emplea y saber cuándo hacer un análisis inductivo o deductivo. 
Según un artículo de la University of New México, una persona con pensamiento crítico posee las siguientes características básicas: tiene una mente abierta, busca siempre la verdad, es analítico, tiene seguridad en sí mismo, es maduro, flexible, creativo e intuitivo. (College of Nursing, 2005).

De igual manera, el autor cita a Ennis, quien considera las siguientes cualidades del pensador crítico: posee una mente abierta dispuesta a aceptar opciones distintas a sus propias creencias, busca información con base en las evidencias, cuestiona la veracidad de las fuentes, reconoce conclusiones, razones y premisas, cuestiona la condición de los argumentos, desarrolla y defiende una postura lógica y convincente, busca explicar los argumentos mediante la formulación de preguntas acertadas, planifica y formula hipótesis de forma ejemplar, precisa los términos adecuadamente según el contexto, es precavido al derivar conclusiones, integra todas las características mencionadas anteriormente cuando decide como actuar.

Por otro lado, el pensador crítico está dispuesto a tomar decisiones de forma responsable, ser justo en sus apreciaciones en base a la información disponible, presentar una postura clara, honesta y precisa, tomar consciencia que sus propias creencias pueden cambiar, considerar todo punto de vista y valorar la opinión y sentimientos de los otros respetando su forma de pensar, preocuparse por el bienestar de las personas.

El autor cita a Facione, para quien el pensamiento crítico ayuda al individuo a enfrentar ciertas situaciones, en principio el pensador crítico debe ser claro en sus exposiciones y cuestionamientos, ha de trabajar con esmero, rapidez, interés, eficacia y de forma organizada en circunstancias complejas buscando siempre información relevante.

Además, un pensador crítico debe seleccionar y poner en práctica criterios acorde a la razón siendo cuidadoso al focalizarse en un tema en cuestión, es persistente no obstante la complejidad de las circunstancias. Para el autor, el buen pensador crítico debe respaldarse en criterios, es sensible a su entorno y resuelve problemas y errores por sí mismo, estas características determinan su buen juicio y lo alejan del pensamiento ordinario. Según esta apreciación, adivinar, agrupar, inferir sin lógica, notar relaciones, ofrecer opiniones sin razones, referir, creer, asociar conceptos, suponer y hacer juicios sin criterios son formas de actuar de un pensador ordinario. En cambio, estimar, clasificar, inferir lógicamente, notar relaciones dentro de otras relaciones, ofrecer 
opiniones con razones, evaluar, asumir, obtener principios, hipotetizar y hacer juicios con criterios caracterizan al buen pensador crítico.

El autor también cita a Paul, quien considera que el pensador crítico debe caracterizarse por tener: independencia intelectual, coraje intelectual, empatía intelectual, integridad intelectual, perseverancia intelectual, fe en la razón y acciones justas. El autor sostiene que el pensamiento crítico trasciende a las disciplinas o contenidos basándose en habilidades intelectuales, las cuales serán de gran utilidad en el desarrollo y procesamiento de la información. Estas habilidades del pensador crítico se potenciarán con su práctica.

Por otro lado, Ennis, citado por el autor, afirma que el pensamiento crítico se fundamenta en la razón, siendo un proceso reflexivo basado en el análisis del pensamiento y dirigido hacia un hecho determinado y al mismo tiempo es evacuativo porque infiere a través de evidencias para comprobar la veracidad de estas. Entonces, se trata de un proceso auto dirigido, en el cual el individuo se corrige a sí mismo, controla el desarrollo de sus acciones y regula su propio comportamiento, haciendo uso racional de modelos ejemplares para poder analizar y obtener conclusiones.

El autor cita a Paul y Elder, para mostrarnos las cualidades intelectuales que diferencian a un buen pensador crítico de uno que no lo es. La persona con pensamiento crítico posee independencia intelectual, humildad intelectual, perseverancia intelectual, curiosidad intelectual, empatía intelectual, coraje intelectual, integridad intelectual, confianza en la razón y mente justa. En cambio, la persona que carece de pensamiento crítico tiene conformidad intelectual, arrogancia intelectual, pereza intelectual, indiferencia intelectual, mente intelectualmente cerrada, cobardía intelectual, hipocresía intelectual, desconfianza en la razón e injusticia intelectual.

El autor afirma que el pensamiento crítico sirve en la educación como un poder liberador, mejora las condiciones de las personas, es un acto humano en que la razón es su principal característica y la investigación forma parte de sus actitudes. El pensador crítico sabe de sus limitaciones, de sus sesgos personales por lo que es honesto, flexible y cuidadoso en sus opiniones, las cuales puede evaluar nuevamente reconsiderando sus juicios de valor. Por tanto, un buen ciudadano debe ser educado con esas características. 


\section{Elementos y componentes del pensamiento crítico}

Para abordar los elementos y componentes del pensamiento crítico, se analiza los aportes de algunos autores, quienes han investigado acerca del tema:

Para Herrero (2018), el pensamiento crítico es una capacidad que va más allá de la simple obtención de contenidos, ya que pensamiento y conocimiento tienen significados distintos. El siglo XXI nos ofrece cambios científicos y tecnológicos que favorecen el acceso a la información, sin embargo, el reto de nuestros tiempos consiste en evaluar y analizar críticamente los datos por medio de la razón, acciones indispensables para construir argumentos lógicos y conclusiones respaldadas por evidencias sólidas. Por tanto, para el autor se definen los siguientes elementos del pensamiento crítico:

\section{El argumento.}

Es la suma de la premisa o premisas y la conclusión. Ambas, premisa y conclusión son proposiciones. Para entender el concepto claramente, se definen los términos premisa, proposición, conclusión y cuestión: la premisa es una afirmación o idea que se da como cierta y que sirve de base a un razonamiento o una discusión, la premisa, razones, pruebas o evidencias sostiene la proposición. Las premisas respaldan a la conclusión y la vuelven solvente. En cambio, la proposición es la propuesta, es decir, una oración enunciativa para declarar si algo es cierto o falso. Por otro lado, la conclusión es la consecuencia lógica de lo que se expresa, establece un hecho o hace una recomendación, se determina sabiendo que se quiere demostrar o de qué se quiere convencer. La verdad de la conclusión depende de la verdad de las premisas.

Por último, el asunto es aquello que se somete a argumentación, su análisis puede tener un punto de vista práctico o moral, desde el ser o el deber ser, cuando se determina la cuestión, recién se puede argumentar. Por lo tanto, debe existir una conclusión que se pretenda defender. Además, es necesario distinguir entre un argumento y una simple afirmación, exclamación o pregunta. No todo lo expuesto constituye un argumento.

\section{Las evidencias.}

Son las pruebas objetivas o razones que respaldan a la conclusión. En caso sean fiables, representan un recurso que aporta razones solventes que apoyan a la proposición, de lo contrario no justifican la conclusión y generan un argumento 
inconsistente. Estas deben ser suficientes, ya que depende de una o más razones contundentes que al ser expuestas deben sostener la conclusión, estableciendo una relación directa con esta.

Las evidencias deben proceder de fuentes confiables y su aceptabilidad dependerá de la calidad del testimonio, declaración, estudio o encuesta. Las premisas pueden ser independientes si aun suprimiendo otras siguen respaldando a la conclusión, o dependientes si al suprimir alguna premisa o más pierden sentido. En resumen, es necesario que las evidencias sean relevantes.

\section{Las falacias.}

Se entiende el término falacia cuando los argumentos carecen de fuerza por falta de consistencia o relevancia, en tal circunstancia no pueden sostener una conclusión. En cambio, ante argumentos sólidos y consistentes es difícil rechazar la validez de una afirmación. Las falacias adoptan apariencias de argumentos convincentes, sin embargo, quebrantan las leyes del pensamiento crítico porque carecen de suficiencia, aceptabilidad y relevancia. No necesariamente una falacia representa una mentira o engaño en el argumento, éstas simplemente pueden adolecer de veracidad por ser inexactas e irrelevantes, lo cual significa que ante esta debilidad del argumento nos veremos distanciados de aquello que pretendemos demostrar, pues con su presencia es imposible que las evidencias respalden a la conclusión.

Las investigaciones realizadas por algunos autores sugieren que se establecen más de cien tipos de falacias, aunque, las más recurrentes no superan las cuarenta. Las categorías se pueden diferenciar por la falta de relevancia, aceptabilidad y suficiencia. Por otro lado, también se pueden identificar por la presencia de elementos cuestionables en su estructura argumental, por falta de evidencia, inferencia no válida e imprecisiones en la formulación del argumento. Sin embargo, las falacias más habituales son aquellas que se caracterizan por la falta de relevancia, evidencias o razones que se necesitan para sostener una conclusión. Por ejemplo, al carecer de lo ya mencionado el objetivo que promueve la falacia dirige su atención contra la persona en lugar de cuestionar el argumento, a esta falacia se le denomina argumento at hominem.

\section{El lenguaje.}

El lenguaje no puede ser manipulado ni aceptar prejuicios, además, debe ser neutral y parcial, ya que es indispensable comprender en su totalidad el argumento para su 
análisis y cuestionamiento. El lenguaje es probablemente lo más importante, ya que emprender todas las consideraciones expuestas anteriores depende del manejo apropiado de la lengua. Muchas veces, surgen argumentaciones frustrantes por el uso inadecuado del lenguaje o por su manipulación deliberada, lo cual conlleva a condicionar las interpretaciones y por desidia, que es consecuencia del bajo dominio del conocimiento.

Para el análisis, evaluación y cuestionamiento de cualquier argumento es fundamental entender lo que se expone. Debe quedar de lado todo tipo de manipulación, sesgo, parcialidad y prejuicio al momento de argumentar, el lenguaje debe ser preciso y exacto, lo mismo en la selección de conceptos y construcciones gramaticales. Por otro lado, si bien el uso de terminología especializada es recomendable en determinados ámbitos profesionales, su empleo cuando no es requerido puede oscurecer el asunto en cuestión, lo cual puede dificultar su comprensión. Por último, el lenguaje empleado debe evitar la presencia de ambigüedades y vaguedad que propicie falsas conclusiones.

Otros aportes relevantes fueron realizados por Paul, Binker, Jensen y Kreklau, citados por Campos (2007), quienes realizaron una lista de 35 dimensiones del pensamiento crítico, las cuales se dividen en estrategias afectivas y estrategias cognitivas, estas últimas se agrupan en micro y macro habilidades. Del mismo modo, Campos (2007) cita a Piette, quien agrupa las habilidades del pensamiento crítico en tres categorías: capacidad de esclarecer cualquier duda sobre la información, capacidad de desarrollar un juicio sobre la validez de la información y la capacidad de evaluar la información. Además, es necesario desarrollar habilidades metacognitivas para controlar, conducir y evaluar el pensamiento propio.

Por otro lado, el autor cita a Facione, quien considera las siguientes habilidades intelectuales que conforman el pensamiento crítico: interpretación, que permite entender el significado de datos y una variedad de experiencias, juicios de valor, creencias, etc.; análisis, que implica identificar las relaciones explicitas o implícitas en el discurso, es un proceso en el cual se examinan las ideas, además, se detectan y analizan los argumentos, el análisis tiene como sub habilidades: examinar las ideas, descubrir y analizar argumentos; evaluación, es un proceso en el que valoramos la fiabilidad de una premisa u otros tipos de representación o descripción de las interpretaciones mentales, juicios, situación, experiencia, opinión o creencia de una persona, de igual forma, valorar las relaciones entre las deducciones actuales o previstas entre preguntas, descripciones, enunciados, u otras formas de pensamientos, la evaluación requiere además de otras 
habilidades menores como reconocer y juzgar; inferencia, que implica identificar elementos esenciales como afirmaciones, juicios, pruebas, datos para obtener conclusiones razonables, de todas aquellas formas de representación fluye la información relevante y las deducciones de las consecuencias.

Existen otras habilidades del pensador crítico expuestas por Facione: la explicación, son enunciados que resultan del razonamiento personal, tienen que justificarse tomando en cuenta los conceptos, el contexto, las evidencias, las metodologías, los criterios de razonamiento, es necesario presentar el razonamiento personal en forma de argumentos fiables y convincentes; por último, la autorregulación, proceso por el cual de forma consciente se monitorea las actividades cognitivas propias, los recursos empleados en tales actividades y los resultados a los que hemos llegado después de la aplicación de sus destrezas en el análisis y evaluación de los juicios inferenciales en vista de poner en duda, confirmar, validad o corregir los razonamientos y los resultados obtenidos.

El autor también cita a Ennis, quien considera varias habilidades que componen el pensamiento crítico: centrarse en una pregunta, analizar argumentos, juzgar o cuestionar la credibilidad de una fuente, observar y juzgar informes de observaciones, deducir y juzgar deducción, inducir y juzgar inducción, realizar y juzgar juicios de valor, considerar definir términos y juzgar definiciones, atribuir premisas no enunciadas; considerar y razonar a partir de premisas, razones, posiciones y otras proposiciones con las cuales se está en desacuerdo; integrar otras habilidades y disposiciones para tomar y defender una decisión, proceder de una manera ordenada y apropiada para la situación; por último, ser sensible a los sentimientos, nivel de conocimiento y grado de satisfacción de otros, emplear estrategias retóricas apropiadas en la discusión y presentación oral y escrita.

\section{Artes visuales y su relación con el pensamiento crítico}

Bernal (2008) cita a Heidegger para quien el arte es un poema, en el sentido que nos permite descubrir la verdad de las cosas y traer hacia lo exterior lo interior del ser, develándolo. Para lograrlo, Heidegger afirma que el arte se materializa, y en esta materialización muestra la verdad que no es visible a nuestros ojos.

Según la autora, Heidegger cree que el arte viene del interior del ser, del espíritu. La autora también cita a Kandinsky, quien propone que el arte es un acontecimiento, una 
apropiación. Ambos, afirman que el arte es una relación entre una presencia mística, poética y la técnica que hace que se materialice, por lo cual, la crítica de arte solo es válida si se hace desde el sentido poético y espiritual. Se puede concluir que el arte es el triunfo del espíritu sobre la materia, del bien sobre el mal, de la libertad y purificación sobre las disonancias.

Por su parte, Amo (1993), sostiene que el arte representa una serie de normas para realizar algo de forma correcta, ese concepto proviene de la antigua Grecia y lo encontramos en el vocablo téchne, que se refiere a aquellas actividades de adiestramiento técnico que hoy conocemos como artesanía, es decir del quehacer hecho a mano.

En contraste, los criterios axiológicos y conciencia estética de la actualidad difieren de los criterios de valor que el hombre en el pasado apreciaba del arte. En este sentido, el proyecto educativo interdisciplinario llevado a cabo por Fernández y Sañudo (2014), tuvo como objetivo el desarrollo del pensamiento crítico por medio del arte, la ética y la filosofía, a través del análisis de textos, la autorreflexión individual y grupal.

La propuesta además incluía la interpretación y manifestación de lo comprendido por medio de expresiones diversas, con el propósito de favorecer el progreso del pensamiento crítico y el aprendizaje que se construye de forma experiencial. Desde la perspectiva artística, el proyecto abordó las corrientes relacionadas al expresionismo, desde el siglo XX hasta la actualidad. Por medio de la investigación, el análisis de obras artísticas, la discusión grupal y la reflexión, los alumnos pudieron compartir sus experiencias en temas pictóricos, realización de videos, representaciones e instalaciones (Fernández y Sañudo, 2014).

Las autoras consideran que la educación formal propicia que el educando únicamente se limite a memorizar datos y conceptos, lo cual lo frustra y le genera una sensación de indiferencia frente al aprendizaje. En cambio, se busca a partir del proceso cognitivo derivado de la investigación, la autorreflexión y la experiencia, fomentar actividades interdisciplinarias y artísticas para desarrollar el pensamiento crítico, elemento fundamental en la educación.

A partir de la lectura de obras literarias que contienen fundamentos del existencialismo y del expresionismo se analizan los personajes y se entiende su visión. Luego, cada estudiante elabora un dibujo o pintura con estilo expresionista para plasmar el análisis propio de la obra literaria. Por último, en grupos reducidos se busca 
complementar la experiencia interdisciplinaria por medio de la realización de un video, abordando temas relacionados al arte, la ética y sociedad actual. En conclusión, por medio de la plástica se busca expresar una visión personal, logrando obtener toma de conciencia y reflexión.

Las autoras decidieron llevar a cabo esta actividad con el fin de fomentar el pensamiento crítico por medio de la actividad artística y multidisciplinaria. Revisando la bibliografía existente sobre pensamiento crítico llegaron a determinar que esta actividad era esencial para el desarrollo de la asignatura, influyendo profundamente en los contenidos de los cursos.

\section{Conceptualización teórica de estrategia metodológica}

\section{Educación.}

Vygotsky, citado por Turner (2015), refiere que la educación se consigue a través de un proceso de aprendizaje por el cual las personas pueden conducirse a sí mismas. De acuerdo con esta perspectiva, el individuo es capaz de entender los signos y valores que serán significativos, en su desempeño como estudiante, para controlar su atención, su memoria, sus respuestas, su visión propia como persona y de los procesos de aprendizaje cuyos beneficios deberán transcender las aulas.

\section{Teorías de la educación.}

Para entender el proceso enseñanza aprendizaje, distintos autores han desarrollado diversas teorías sobre la educación.

\section{Teoría constructivista.}

Entre las teorías más actuales se encuentra la constructivista, que considera al individuo constructor de sí mismo, tanto en los aspectos cognitivos y sociales. El individuo que se construye a sí mismo es producto de la interacción de su entorno y sus disposiciones internas, factores que además comprenden las características afectivas y del comportamiento. En otras palabras, el enfoque constructivista es una creación humana que no copia la realidad, en lugar de ello, se basa en la relación con su entorno para generar esquemas propios (Carretero, 2005). 


\section{Teoría comprensiva.}

La comprensión es un fenómeno por el cual se interpreta e indaga los fenómenos desde sus causas interiores, siendo valorados en su integridad. La comprensión es una forma de conocer y transformar los hechos reales que son valorados y adquieren significados a partir de las intenciones de los sujetos, procurando entender los complejos comportamientos de los seres humanos en los escenarios más diversos, apelando a la cambiante actitud y a veces percepciones de las personas en los diferentes procesos interactivos. La comprensión ocurre con una aproximación en apertura y búsqueda permanente, en continua disposición positiva para observar y valorar las múltiples perspectivas y enfoques de la conciencia, el desenvolvimiento de las personas y sociedades, y el descubrimiento de las situaciones emergentes para una buena toma de decisiones razonables.

La enseñanza entendida y desarrollada desde esta perspectiva y adaptando la forma del conocimiento e interpretación de los fenómenos humanos, representa un modo nuevo de entender los mensajes del proceso formativo, así como la amplitud y flexibilidad con la que hemos de enfocar la tarea docente y la autonomía discente. La enseñanza se vuelve comprensiva cuando su práctica es flexible y vislumbra el impacto de la duda que es característica de la sociedad actual, junto al impostergable avance en la valoración e interpretación de las concepciones y actitudes del profesorado en torno a las acciones formativas, que son la finalidad básica de la docencia (Medina, Domínguez y De La Herrán, 2014).

Lorenzo y Pla (2001), afirman que los valores en los que se sustenta la teoría comprensiva son: capacidad, para desarrollar los conocimientos de manera comprensiva; aprendizaje de temas básicos de las materias o el conjunto de cursos a estudiar; motivación, para una plena dedicación y auto compromiso; uso activo y transferencia del conocimiento y aprendizaje; enfoques organizados y sistemáticos para una enseñanza en que el alumno sea partícipe; diferentes estilos pedagógicos, incluyendo la enseñanza tradicional; por último, el trabajo en equipo para compartir conocimientos entre los estudiantes y apoyarse mutuamente.

\section{Teoría socio-comunicativa.}

Es el fenómeno de construcción del saber y la práctica comunicativa, como un hecho que adquiere múltiples direcciones en las relaciones de los seres humanos y de un mundo en constante cambio por la tecnología y los sistemas de información. La comunicación nos 
ayuda a entender, comprender y mejorar la práctica y la conceptualización de la enseñanza, dado que esta es básicamente un proceso interactivo-comunicativo, que bien dirigido por las intenciones formativas tienen la finalidad de la formación intelectual y humana de los participantes, a la vez que genera un conjunto creativo-transformador de soluciones para responder a los profundos desafíos sociales y personales a los que han de crear respuestas a estudiantes y docentes.

La comunicación se establece en la reflexión y acción en común tanto lingüística como existencial entre los individuos, quienes comparten concepciones, imágenes y puntos de vista del mundo y de ellos mismos, aportando los estilos de aceptación mutua y progreso en el saber, personal y colaborativo. La enseñanza es entendida como una actividad que propicia las interacciones humanas, promueve la inteligencia socio-afectiva, actitudes singulares, permite la obtención de valores de comunidad y colaboración, la tolerancia y el esfuerzo compartido para crear conocimiento, comprender y transformar los discursos. Este enfoque de la educación es empática, socializadora y promovedora de interacciones abiertas, responsables de las formas genuinas de vida, valoración y crecimiento de la comunidad, desarrollando los estilos docentes a un gran compromiso generador de saber, conscientes de la diversidad de cada ser humano y de la pluralidad cultural que caracteriza el mundo (Medina, Domínguez y De La Herrán, 2014).

\section{Teoría artística.}

La enseñanza como arte tiene dos dimensiones que se relacionan. Primero, como se puede expresar de modo singular la realidad conforme a reglas de expresión artísticas; así el dominio, lo segundo se concentra en lo innovador, en el valor de lo creativo que construye o reconstruye la realidad en la que de modo específico se interviene. El proceso de enseñanza-aprendizaje, es un fenómeno formativo, emergente, cambiante y de imposible generalización y de soluciones universales, lo que explica el modo único de aprender de cada estudiante y que la tarea educativa es irrepetible y que ha de atenderse por los docentes de manera creativa.

La enseñanza vista como arte tiene que tener en cuenta las formas especiales de expresarse del docente en sus múltiples y cambiantes situaciones, pero se basará en la constante búsqueda, en la voluntad y el esfuerzo que requiere la incertidumbre de lo formativo, ahondando en los estilos personales y de búsqueda, originales e irrepetibles en la acción del profesor, pensado desde las peculiaridades del arte, como modo de entender las tareas del aprendizaje, procurando formarlo para aceptar el reto de lo nuevo 
y la necesidad de aprender a aprender los cambios de la sociedad y de sí mismo (Medina, Domínguez y De La Herrán, 2014).

\section{Definición de estrategia metodológica}

Estrategia, del latín strategra y procede a su vez de las voces griegas stratos (ejército) y agein (conductor o guía). Podemos decir entonces, que la estrategia es el arte de dirigir las operaciones militares. La Real Academia de la Lengua Española RAE (2014), coincide en tal definición y además, incluye la acepción: Arte, traza para dirigir un asunto. Por lo tanto, una estrategia representa una serie de acciones meditadas que llevan a un fin determinado.

Por otro lado, la metodología es una disciplina empírica y descriptiva que forma parte del área de la filosofía que estudia los procedimientos, criterios y reglas específicas de la investigación científica para crear, evaluar y aceptar hipótesis, leyes y teorías.

Rodríguez (1985), citado por Meneses (2007), plantea que la enseñanza es un proceso cuyos contenidos, traducidos en signos, son compartidos por el emisor y receptor. En otras palabras, el acto educativo o acto didáctico en sí es una forma concreta de comunicación.

Macías (2014), propone que el proceso de aprendizaje consiste en la obtención o modificación de conocimientos, valores, habilidades y actitudes como resultado de la experiencia y la educación. Quiroz (2003), define que las estrategias metodológicas son procedimientos que permiten alcanzar los objetivos, que el investigador se propone, en un modo eficaz. Además, amplían la perspectiva sobre la verdad que el investigador desea conocer, valorar, analizar etc.

Pimienta (2012), propone que las estrategias metodológicas son instrumentos que sirven al docente como apoyo en el desarrollo de competencias durante el proceso de formación del educando. El autor afirma que estas estrategias ayudan a mejorar los logros del estudiante y a adquirir habilidades necesarias para su desempeño en la vida diaria y la posteridad.

Díaz y Hernández (2010), afirman que las estrategias metodológicas son procedimientos que el educando va adquiriendo para lograr el aprendizaje, apoyándose en la motivación y el trabajo cooperativo. 
Además, se puede definir a la estrategia metodológica como un sistema de acciones organizadas que se planifican de forma consciente. Está enfocada en la dirección del proceso de enseñanza aprendizaje. En el ámbito educativo, la estrategia busca la transformación de un objeto desde su estado real a un estado deseado, con lo cual lo optimiza. Entonces, la situación actual del objeto al ser transformada implica todo un proceso de organización a través de una estructura o plan general cuyos objetivos son lograr un estado superior de desarrollo, incorporando nuevos elementos teóricos y reformulando los actuales (Rodríguez, Cañarte, Pibaque, De Acuña, Pionce y Caicedo, 2017).

Para Velázquez (2014), la estrategia metodológica es un constructo teórico y didáctico que regula la actividad del docente en el proceso de enseñanza- aprendizaje. Este método orientador tiene efecto en la dinámica del proceso de enseñanza, la cual adquiere una dirección hacia el diálogo, la heurística, la reflexión y la problematización transformando desde el aprendizaje al estudiante en el pensar, sentir y hacer.

La aplicación de un eje metodológico tienes proyecciones hacia el entorno laboral, social y cultural. Es necesario en la generación de conocimientos, recursos, técnicas y acciones creativas.

Según el Ministerio de Educación del Perú (Minedu), las estrategias metodológicas son acciones flexibles con sentido y coordinación, orientadas al desenvolvimiento del desarrollo formativo de enseñanza-aprendizaje integral, creativo y crítico, con una perspectiva social intra e intercultural, a través de la selección, organización y empleo de métodos y técnicas para lograr un objetivo holístico.

La estrategia metodológica se entiende como procedimientos que el agente de enseñanza emplea en forma reflexiva y flexible para promover el logro de aprendizajes significativos en los alumnos (Díaz \& Hernández, 2010).

"Se refieren a las utilizadas por el profesor para mediar, facilitar, promover, organizar aprendizajes, esto es, en el proceso de enseñanza" (Campos, 2018). La formación metodológica permite el desarrollo de competencias en los estudiantes, basándose en prácticas sociales que se experimentan en el aula, sirve como estrategia transversal que incorpora una perspectiva integrada del conocimiento y posibilita la mejora de los programas educativos, desde sus contenidos en la estructura curricular, a través de las habilidades básicas de comunicación, investigación y toma de decisiones con sentido ético. Al respecto Rué sostiene: 
Las estrategias metodológicas en cualquier proceso de enseñanza, contrariamente a lo que sostiene una concepción muy extendida, no son nunca esencialmente técnicas, por lo menos en la justificación última que da sentido a su elección. Ninguna opción que dé sentido de racionalidad a la acción humana se halla libre de valores. Por ello, una vez argumentados algunos aspectos de fondo que justifican la propuesta de reforzar el grado de autonomía en los alumnos, es necesario razonar sobre la funcionalidad, formativa de este enfoque del aprendizaje. En definitiva, se trata de dar respuestas plausibles a las razones que justificarían esta estrategia por encima de otras, en la voluntad de brindarles a los alumnos oportunidades para un mejor aprendizaje (2009, p.81).

\section{Conceptualización de las subcategorías de estrategia metodológica}

\section{Constructo teórico y didáctico.}

Un constructo es un modo de construir o interpretar el mundo, el constructo influye en la dirección de una conducta para categorizar eventos y representa un conjunto de sistemas organizados de forma estructural que surgen de la interpretación de los acontecimientos. Del contraste de ideas o semejanzas entre hechos surgen construcciones conceptuales que llevan a la formación de un constructo. Debido a que no todos los hechos son similares, el individuo debe generar abstracciones para establecer las diferencias y semejanzas entre los hechos, de esta manera elabora constructos, cuya función es la de organizar y regular el mundo. (Ontoria, Ballesteros, Cuevas, Giraldo, Martín, Molina, Rodríguez y Vélez, 2017).

En tal sentido, el constructo es una capacidad para construir la realidad interpretándola. Dicho de otra manera, se trata de un concepto o idea generada con el fin de organizar las experiencias que se obtienen del mundo real. Las ideas que conforman el constructo se elaboran mediante un pensamiento abstracto que tiene como propósito interpretar las diferencias entre los hechos o aspectos del mundo que nos rodea. Entonces, se puede afirmar que un constructo o construcción mental se genera mediante códigos elaborados y organizados por la mente que explican aspectos de la realidad. 
La teoría es un sistema de respuestas orientada hacia el conocimiento que aclara las interrogantes sobre aspectos de la realidad que no resultan evidentes, es decir cuestiones que no pueden ser explicadas desde el sentido común (Piñon, 2006).

Conforme a lo expuesto, la teoría es un conjunto de estructuras que constituyen un sistema lógico de las cuestiones que nos brinda un apoyo para tener diferentes perspectivas de la realidad. En este sentido, podemos decir que la teoría es una estructura de la realidad, conformada por conceptos, definiciones y proposiciones relacionados entre sí que nos ayuda a explicar las cuestiones, es decir, asuntos 0 interrogantes que requieren ser resueltas.

La didáctica es la disciplina que se concentra en la reflexión y el análisis de los procesos de enseñanza-aprendizaje y se aplica a la solución de los problemas de estos procesos, de su naturaleza y mejora permanente (Medina, 2009).

De acuerdo a lo mencionado, la didáctica se encarga del estudio de los procesos y elementos en la enseñanza y el aprendizaje. Como herramienta pedagógica es de gran utilidad para el docente quien la aplica con otros métodos de enseñanza fortaleciendo su función. Por otro lado, la didáctica interactúa con los educandos, permitiendo al docente generar un vínculo con ellos, en el cual fluyen los conocimientos y el aprendizaje. En su función mediadora, el docente aplica la didáctica para romper el esquema tradicional de enseñanza y desarrollar actividades interactivas y de cooperación que generen un aprendizaje significativo en los estudiantes (Capacho, 2011).

\section{Proceso de diálogo y comunicación.}

El diálogo es un instrumento fundamental para componer los modos de convivencia, la organización de las relaciones y la vida en el aula. Es decir, es el eje de la actividad colectiva que emplea el docente para favorecer el debate y el contraste de ideas, con lo cual, es posible llegar a un mensaje transparente, abordando temas significativos para el educando con un propósito moral (García y Puig, 2007). En la antigua Grecia, Sócrates dirigía a sus discípulos por medio del diálogo, pues gracias a éste lograba educarlos y conducirlos a la verdad, su método era conocido como un modelo del saber dialogar (Valero, 2003).

Por otro lado, la comunicación es una acción que permite establecer y crear relaciones sociales, vincular cosas, personas y lugares. Esta acción hace posible intercambiar y transmitir los principios y valores humanos (Julien, 2007). En tal sentido, la 
relación directa entre docente y discente depende del diálogo; por un lado, esta actividad enriquece los vínculos que existen entre los seres humanos, pues a través de la palabra el estudiante puede expresar sus propias ideas y emociones. Por lo tanto, la comunicación favorece al proceso educativo, puesto que, sin diálogo tanto docente como discente se convierten en objetos y dejan de ser personas, con lo cual es muy difícil educar (Valero, 2003).

\section{Proceso de enseñanza aprendizaje.}

El proceso en la educación se refiere al desarrollo o transformación del individuo, nada permanece inalterable, todo recae en lo temporal, sujeto a un antes y un después. El proceso para el hombre es el transcurrir de su recorrido por el mundo, lo que fue, lo que es y lo que proyecta ser, con todas sus posibilidades (García, Ruíz, García, 2016).

Con relación a lo referido, se considera que el proceso educativo es una sucesión de acciones, operaciones y experiencias que se organizan en el tiempo para que el individuo aprenda a vivir y a ser, con lo cual puede desarrollar valores y saberes. En este recorrido se enseña y se aprende, aunque en algunos casos quienes aprenden también pueden enseñar. Por lo tanto, se trata de un proceso interactivo que le permite al estudiante adquirir los saberes necesarios para desenvolverse en la sociedad, desarrollando valores y formas de conducta.

Según Jeter (2013), la enseñanza es la impartición de conocimientos que despiertan la mente del estudiante y estimula su interés por el aprendizaje, con la finalidad de recibir y retener una verdad que pueda ser significativa en su proceso educativo. Por lo expuesto, se puede entender que existe una relación estrecha entre enseñanza y aprendizaje, lo cual hace indispensable el vincular ambos procesos al definirlos.

El aprendizaje es un proceso surgido del intercambio e interacción de docente y estudiante dentro de un contexto determinado. En dicho contexto, se aplican estrategias dirigidas a los estudiantes a través de las cuales pueden llegar a incorporar nuevos conocimientos (Zabalza, 2004). En tal sentido, el aprendizaje es la adquisición de conocimientos y conductas por parte del educando a través de la impartición de estrategias específicas que el docente aplica en un determinado contexto. En otras palabras, el aprendizaje es una función mental que desarrolla habilidades, destrezas y valores en el individuo para transformarlo y sea el motor de su crecimiento personal y desarrollo de su entorno y preservación del planeta. 
Contreras (1990), afirma que los procesos de enseñanza-aprendizaje representan un fenómeno intencional de interacción e intercambio que se origina desde el interior y que hace posible el aprendizaje. Por otro lado, el proceso enseñanza-aprendizaje también se determina desde el exterior al ser partícipe de la estructura de instituciones sociales, desempeñando funciones relacionadas con la estructura social. Entonces, al hablar de enseñanza-aprendizaje nos referimos a un sistema de comunicación deliberado, productor de estrategias dirigidas hacia el aprendizaje dentro de un marco constitucional.

\section{Rol del docente.}

El docente es un servidor de la sociedad que actúa como mediador, en contacto permanente con sus estudiantes, en las interacciones de enseñanza-aprendizaje. En su labor hace frente a la problemática del contexto actual. La crisis de la enseñanza repercute en el docente y lo reta a trabajar en lo sociológico, psicológico y pedagógico para mejorar el desarrollo humano (Salanova, Grau, Cifre, Llorens y García-Renedo, 2004).

El docente es un objeto de representación institucional que interactúa con los estudiantes, padres de familia, colegas, directivos y miembros de la comunidad en general. El vínculo establecido con los estudiantes hace que el docente sea percibido como figura de afecto y de autoridad gracias a la función pedagógica. Representa un pilar o figura ejemplar en la formación de los individuos en su formación académica, que motiva y estimula el interés sobre diversos contenidos para el aprendizaje. Además, es un guía que ayuda a mejorar el rendimiento de los educandos que en el futuro formarán las bases para mejorar sus vidas (Jeter, 2013; Hernández y Guárate, 2017).

Lavín y Del Solar (2000), afirman que el rol docente consiste en una serie de demandas múltiples y divergentes percibidas en las perspectivas del quehacer y del deber ser, que generan una multiplicidad de expectativas asignadas por la sociedad y que son internalizadas por el docente. Se identifican cuatro tipos de roles presentes en el deber ser del docente: El primero es el rol social, en el cual el docente asume un papel de redentor o agente de cambio social, seguido por el rol cultural o de integración social.

Después tenemos el rol pedagógico, que desarrolla habilidades, transmite conocimientos, valores y que conecta al educando con el docente a través de la construcción del conocimiento. Finalmente, el rol de investigador o productor de conocimientos, que propicia la transformación de la propia práctica docente. 
En tal sentido, el rol del docente es un trabajo educativo social en el cual el educador debe estar preparado para enfrentar los retos educativos y así poder moldear a los individuos inmersos en el proceso de enseñanza-aprendizaje con el fin de capacitarlos en la solución de problemáticas sociales, económicas, políticas y culturales que afecten su entorno. Para lograrlo, el docente debe conocer entre otras cosas, las destrezas, habilidades, conocimientos, valores, intereses, personalidad que conforman las características de sus educandos. El rol del docente implica la actualización constante de la información que le permita crear nuevos esquemas de conocimiento. Además, el docente debe tomar decisiones correctas para resolver imprevistos y transmitir valores a los estudiantes a través del diálogo, así se puede lograr un equilibrio en la comunicación. Para ello, es importante que el docente transmita humildad, evitando acciones o posturas que denoten superioridad o intolerancia (Bautista, Borges, Forés, 2006; Blanco, 2016).

Por lo expuesto, se considera que el docente en su función de motivador presenta el objeto de estudio al estudiante promoviendo su interés y motivación por éste. Para que exista un nexo entre el estudiante y lo estudiado, el objeto de estudio debe servir como instrumento de enseñanza. Entonces, la necesidad de aproximarse al objeto de estudio hará que el educando se apropie de su esencia, creando nexos afectivos entre lo cultural, que está presente en el objeto, y los conocimientos que el estudiante ya tiene, es lo esencial para generar un aprendizaje significativo. 


\section{Capítulo II}

\section{Diagnóstico o trabajo de campo}

\section{Análisis, interpretación y discusión de los resultados}

Este capítulo se centra en presentar la información hallada al emplear las distintas técnicas e instrumentos de recolección de datos, para lo cual se aplicó una entrevista semi estructurada a cuatro docentes y la observación de sesión de clase a dos docentes del tercer ciclo de una institución educativa de arte de Lima. Asimismo, se realizó una encuesta cerrada a treinta y uno de los estudiantes del ciclo antes mencionado, seleccionados por criterio de muestreo no probabilístico. A continuación, se presenta los resultados por técnicas e instrumentos de la investigación.

\section{Análisis de los resultados de la entrevista semiestructurada a docentes.}

Para conocer el estado actual del pensamiento crítico, su enseñanza y aprendizaje de los estudiantes del tercer ciclo de la especialidad de pintura de una institución educativa de arte de Lima se entrevistó a cuatro docentes que tienen a su cargo los cursos de pintura y dibujo. La entrevista semi estructurada cuenta con veintiséis preguntas; las que fueron validadas a través de juicio de expertos y surgió como consecuencia de las categorías de pensamiento crítico y estrategia metodológica, y sus respectivas subcategorías e instrumentos desarrollados en el capítulo anterior.

Respecto al primer entrevistado (D1), otorga importancia al desarrollo del pensamiento crítico; Ennis (1996), define esta capacidad como un pensamiento reflexivo razonado que permite evaluar los hechos para poder decidir qué hacer o decir. En tal sentido, el docente aplica las siguientes estrategias: el juego de roles para que cada estudiante asuma posturas distintas, relacionar al estudiante con todo tipo de manifestaciones artísticas para ampliar su base gnoseológica, la dramatización de casos reales para obligar a los estudiantes a tomar postura, para que los alumnos expongan sus problemas y los problemas de su entorno sociocultural para propiciar soluciones factibles y reales, propiciar talleres de actualidad nacional e internacional, promover la investigación y generar conocimiento. 
El docente (D1) también señaló las características del pensamiento crítico: saber formulación y reformulación de problemas, habilidades de indagación, apertura mental, hábitos de lectura, una relación estrecha con su entorno sociocultural, poseer valores éticos y haber desarrollado su autoestima para poder opinar y sustentar sus ideas.

El segundo docente (D2), opinó de igual manera que el pensamiento crítico es importante durante el proceso de formación artística, para lo cual desarrolla diferentes estrategias: trabajo en equipo, uso de TIC, el diálogo reflexivo para poder comprender los diferentes puntos de vista, enseñar a tomar decisiones acertadas, realizar diagnósticos y análisis de los problemas que se le presenten a los estudiantes.

Además, el docente (D2) mencionó como características del pensamiento crítico: formulación y reformulación de problemas para que personas puedan ver los problemas en su medio y encuentren soluciones a ellos, habilidad de indagación para que puedan contrastar la información que se les imparte en la sesión de clase, conceptualización axiológica para que valoren la información adquirida y discernir entre lo verdadero y lo falso, tomar referentes para la construcción de su propuesta artística y construir valores éticos que le permitan formular opiniones de acuerdo a su espacio tiempo.

El tercer docente (D3) coincide con los anteriores profesores entrevistados, en cuanto el pensamiento crítico es importante en la formación de los estudiantes de arte, para que puedan desarrollar una propuesta con contenido que desarrolle el arte nacional y sea instrumento de cambio en la sociedad. Entre las estrategias que el docente emplea para desarrollar el pensamiento crítico en sus estudiantes figuran: el trabajo en equipo, el seguimiento personalizado al proceso, el uso de referentes, el contacto con su contexto y la experimentación con materiales alternativos a los tradicionales en las propuestas artísticas.

Para desarrollar el pensamiento crítico en estudiantes, el docente (D3) considera necesario lo siguiente: apertura mental, generar nuevos conceptos e ideas, habilidades de indagación, base gnoseológica, formular y reformular proyectos, conceptualización axiológica y valores éticos.

El cuarto docente (D4) entrevistado manifiesta, al igual que sus colegas, que el pensamiento crítico es necesario en el desarrollo del artista profesional, y debe ser transversal durante todo el proceso de formación. Asimismo, el docente afirma que 
según la malla curricular de la institución educativa es necesario ejercitar esta capacidad en los estudiantes. Sin embargo, esta capacidad reflexiva solo se limita a un curso, el cual no es transversal.

Entre las estrategias empleadas por el docente (D4) tenemos: la motivación al estudiantes, es la forma de interrelacionar estudiante y docente para facilitar o limitar el proceso de enseñanza aprendizaje (Ospina, 2006). De lo cual, se puede deducir que la motivación es necesaria para desarrollar propuestas con contenido conceptual. Además, el autor menciona el uso de las TIC para ayudarnos a investigar y crear, el uso de portafolios para ver la evolución del proceso del estudiante y desarrollar sus capacidades autocríticas y auto evaluativas.

Por su parte, el estudiante debe incorporar su historia personal, cultura y tradiciones en la formulación de sus propuestas profesionales. Según el docente, todo pensador crítico debe tener las siguientes características: apertura mental, autoestima elevada, capacidad para formular y reformular problemas, identificación con su entorno sociocultural, hábitos de lectura y motivación por el aprendizaje.

\section{Análisis de los resultados de la encuesta aplicada a los estudiantes.}

Se aplicó un cuestionario a 31 estudiantes del curso Pintura I del tercer ciclo de la carrera de artes plásticas. El objetivo del cuestionario fue recoger el punto de vista de los estudiantes en referencia al desarrollo del pensamiento crítico y si los docentes tienen estrategias para conseguir esta habilidad, los datos obtenidos fueron procesados obteniéndose las tablas de frecuencia y los respectivos gráficos por cada pregunta del cuestionario. A continuación, se detallan los resultados obtenidos en el proceso investigativo.

En referencia al pensamiento crítico como una habilidad necesaria para el artista, 25 estudiantes es decir el $81 \%$ contestaron que si es una habilidad necesaria para poder desarrollar propuestas artísticas con contenido, creativas y con transcendencia.

En cuanto a la pregunta si el docente desarrolla el pensamiento crítico en sus clases de taller; es decir, hace hincapié en la valoración de conceptos, juicio crítico, conocimiento, investigación y referentes, dieciséis alumnos contestaron que el profesor no desarrolla el pensamiento crítico, esto representa el $52 \%$ del total de los encuestados, lo cual evidencia que no existe una sistematización del pensamiento crítico a través de los cursos impartidos. 
En referencia a la pregunta si el profesor impulsa interpretaciones de la realidad usando una conceptualización axiológica, el 74\% de los encuestados refirieron que a veces o casi nunca realiza esta actividad el profesor en la sesión de clase, el $26 \%$ de los alumnos contestaron que el profesor a veces o siempre impulsa estas interpretaciones.

Según Casillas y Santini (2006), la conceptualización axiológica es una capacidad mental producida para representar las cualidades principales de los individuos y las clases de valor. Se trata de un proceso en el cual el individuo genera conceptos a partir de la valoración de las cosas, conceptos que deben tener su origen en las vivencias personales, sobre el valor en cuestión, para que sean significativos. Por lo tanto, podemos interpretar que en la mayoría de clases el docente no conecta su clase con la realidad, ni la interpreta, ni pide a los estudiantes juicios de valor.

Con respecto a la pregunta sobre si los estudiantes entienden, investigan y evalúan los conocimientos impartidos por el profesor, el 58\% contestó que a veces o casi nunca realizan estas actividades en relación a estos nuevos conocimientos, el $42 \%$ refirieron que siempre o casi siempre realizan estas actividades con respecto a los nuevos conocimientos. De lo cual podemos inferir que los estudiantes en su gran mayoría se quedan conformes con los conocimientos impartidos por el docente.

A la pregunta, si las propuestas artísticas están relacionadas con los conocimientos impartidos en el aula y la realidad sociocultural del estudiante, el $65 \%$ manifestó que no existe relación entre su obra y su medio sociocultural, el $35 \%$ de los estudiantes refirieron que siempre o casi siempre relacionan sus obras con su contexto. Podemos deducir que en su gran mayoría, los estudiantes al realizar sus propuestas artísticas, no articulan los conocimientos adquiridos en las sesiones de clase y los conocimientos adquiridos en su contexto sociocultural.

En cuanto a la pregunta si los estudiantes realizan propuestas artísticas con conocimientos sólidos en base a su entorno sociocultural, el $71 \%$ afirma que a veces y casi nunca construyen soluciones a partir del conocimiento de su entorno, el $29 \%$ afirma lo contrario. En tal sentido, se puede sostener que la gran mayoría de los estudiantes, al realizar sus propuestas artísticas, no tienen unas bases sólidas de conocimientos, ni relacionan su propuesta con su entorno.

Con respecto a la pregunta si el profesor motiva a incorporar en la propuesta artística un análisis y valoración del entorno sociocultural, el 58\% de estudiantes contestó que a veces o casi nunca incluyen en sus propuestas los problemas de su entorno, el 
$42 \%$ manifiesta que siempre o casi siempre consideran su entorno en sus propuestas. Podemos inferir que gran parte de los estudiantes no realizan un análisis de su entorno, ni lo valoran; por tal motivo, los estudiantes no consideran el entorno sociocultural en sus propuestas artísticas.

En referencia a la pregunta si el estudiante cuestiona su obra según sus conocimientos de estética, crítica y semiótica, el $52 \%$ contestó que a veces o casi nunca cuestiona su obra, por otro lado, el $48 \%$ contestó que sí. De estos datos, podemos interpretar que aproximadamente la mitad de los estudiantes no cuestionan su obra, mientras la otra mitad sí lo hace.

En cuanto a la pregunta si los estudiantes participan en la sesión de clase con ideas que aporten a la construcción del conocimiento, el 68\% de estudiantes contestó que a veces o casi nunca participan de forma significativa en la sesión de clase, el 32\% contestó que sí participa con ideas y opiniones. De lo cual, podemos inferir que la mayoría de los estudiantes no participa activamente en la clase, ni construye nuevos conocimientos.

A la pregunta, si los estudiantes creen que a partir de la reflexión pueden aplicar los aprendido a la resolución de los problemas de su entorno, el 55\% considera que a veces o casi nunca realizan esta reflexión, en cambio, el $45 \%$ de los estudiantes afirma que sí lo hace. Se puede concluir que un poco más de la mitad de los estudiantes no reflexiona sobre los problemas de su entorno y por lo tanto no propone soluciones para ello.

Con respecto a la pregunta, si los estudiantes consideran que los conocimientos adquiridos en clase los forman profesionalmente como agente de cambio para desarrollar su entorno sociocultural, el $61 \%$ de los estudiantes afirma que a veces o casi nunca los conocimientos recibido los forman como agente de cambio, mientras que el $39 \%$ considera que casi siempre o siempre los conocimientos llegan a ser importantes en su desarrollo personal y mediante ello pueden cambiar su entorno sociocultural. A partir de ello podemos inferir que los profesores o los docentes no imparten los conocimientos necesarios para que los estudiantes sean agentes de cambio en su entorno sociocultural.

En referencia a la pregunta, si el profesor usa diferentes estrategias para conseguir que los estudiantes desarrollen opinión propia, análisis y solución de los problemas de su entorno sociocultural, el $74 \%$ de los estudiantes refirieron que a veces o casi nunca el docente tiene estrategias para conseguir el desarrollo del pensamiento 
crítico, por otro lado, el $26 \%$ de los estudiantes consideró que los profesores sí tienen estrategias de enseñanza para desarrollar el pensamiento crítico. Se puede interpretar que muchos docentes no tienen estrategias metodológicas para desarrollar el pensamiento crítico en sus estudiantes.

En cuanto a la pregunta si el profesor se preocupa por los estudiantes que no relacionan sus propuestas artísticas con los problemas de su entorno, el 74\% refirió que a veces o casi nunca el profesor tiene la preocupación de relacionar las propuestas artísticas con los problemas del entorno del estudiante, en cambio, el $26 \%$ contestó que siempre o casi siempre el profesor tiene la preocupación de relacionar las propuestas artísticas con los problemas del entorno del estudiante. De acuerdo con lo expuesto, se deduce que los estudiantes no relacionan sus propuestas artísticas con su medio sociocultural, dejando de lado los problemas sociales que le atañen.

Con respecto a la pregunta, si el profesor cambia de estrategias de forma permanente con el fin que todos los estudiantes puedan tomar decisiones propias en la construcción de sus propuestas artísticas, el 77\% considera que el profesor a veces o casi nunca cambia de estrategias a fin de propiciar que el estudiante tome decisiones propias en la construcción de su propuesta artística. Por otro lado, el $23 \%$ de los estudiantes considera que el profesor siempre o casi siempre cambia de estrategias de enseñanza para que sus estudiantes desarrollen ideas propias. Al respecto, se considera que los docentes carecen de estrategias para desarrollar el pensamiento crítico en los estudiantes.

A la pregunta, si el profesor promueve la investigación, el 53\% de los estudiantes señaló que a veces o casi nunca el profesor promueve proyectos de investigación, por el contrario el $47 \%$ contestó que sí, de lo que podemos inferir que en la mayoría de los casos no se promueve el desarrollo de proyectos ni la investigación. Por lo tanto, no hay un desarrollo del pensamiento crítico.

En referencia a la pregunta, si el profesor utiliza otros medios artísticos para desarrollar el pensamiento crítico en la sesión de clase, el $65 \%$ de los estudiantes manifestó que a veces o casi nunca se da esta iniciativa por parte del profesor, el $35 \%$ de los estudiantes señaló que sí. De lo cual, se puede deducir que los docentes no hacen una conexión de las propuestas artísticas con otras manifestaciones de arte, con lo cual se ve limitada las posibilidades creativas de los estudiantes. 
En cuanto a la pregunta si el profesor promueve el desarrollo de valores a través del conocimiento de otras manifestaciones artísticas, el $71 \%$ de los estudiantes afirmó que el profesor no promueve el desarrollo de valores. Por otro lado, el $29 \%$ contestó que el promueve sí promueve valores teniendo como recurso otras manifestaciones artísticas. Al respecto, se interpreta que en su gran mayoría los profesores no promueven valores en sus alumnos ni los aproximan a otras manifestaciones artísticas.

Con respecto a la pregunta, si el profesor promueve el diálogo y acepta debatir las diferentes opiniones en clase, el 58\% de los estudiantes manifestó que el docente no propicia el diálogo ni el debate, mientras que un $42 \%$ de los estudiantes contestó que siempre o casi siempre esto ocurre. Por lo expuesto, se concluye que el docente no promueve el diálogo ni el debate entre los estudiantes durante el proceso de realización de sus trabajos.

A la pregunta, si el profesor promueve el trabajo en equipo y permite a los estudiantes sustentar conjuntamente sus propuestas artísticas, el 55\% de los estudiantes, contestó que a veces o casi siempre el profesor promueve el trabajo en equipo y la sustentación respectiva de sus trabajos. Por otro lado, el $45 \%$ de los estudiantes manifestó que siempre o casi siempre el profesor promueve estas actividades. Al respecto, se puede deducir que no es frecuente el trabajo en equipo en la sesión de clase, tampoco es frecuente que los estudiantes comuniquen y sustenten los resultados obtenidos en sus propuestas artísticas.

En referencia a la pregunta, si el profesor interactúa con los estudiantes propiciando el intercambio de información y aceptando la opinión de los estudiantes, el $52 \%$ de los estudiantes refiere que a veces o casi nunca se produce este intercambio de información y de opiniones, mientras el $48 \%$ de los estudiantes afirma que el docente sí propicia estos intercambios. Por lo tanto, interpretamos que en la mayoría de las veces, no hay intercambio de ideas en la sesión de clase, debido a que el docente rara vez interactúa con los estudiantes.

En cuanto a la pregunta, si el profesor promueve las propuestas artísticas a partir de su entorno, el 58\% de los estudiantes refirió que a veces o casi nunca el profesor incentiva la realización de los trabajos artísticos en relación a su entorno, mientras que el $42 \%$ de los estudiantes afirmas que sí. De acuerdo a lo expuesto, se deduce que en la mayoría de los casos el profesor no incentiva al estudiante a relacionar su obra artística con entorno. 


\section{Análisis de los resultados de la guía de observación de clase.}

La guía de observación de clase fue aplicada a dos sesiones de clase, una sesión por docente, en los cursos de Pintura I y Dibujo III. Estas fueron ejecutadas con el fin de evidenciar in situ las estrategias empleadas por el docente para desarrollar el pensamiento crítico en los estudiantes, estas guías tienen a modo de referencia una lista de aspectos a evaluar, adicionalmente se registraron todas las actividades del docente y de los estudiantes en la sesión de clase para luego ser analizadas e interpretadas. Los resultados del análisis son los siguientes.

En la sesión de clase correspondiente al primer docente se observó que los estudiantes se presentan a tiempo para la toma de asistencia. Con respecto al segundo docente, la toma de asistencia no se lleva a cabo porque los estudiantes llegan tarde, algunos incluso con más de dos horas de tardanza, lo cual evidencia el poco entusiasmo por el curso.

Se observó que el primer docente inicia su clase con un resumen de la sesión anterior y presenta el tema a tratar, rescatando saberes previos y propiciando el diálogo. En contraste, el segundo docente no realiza un resumen de la clase anterior y no recoge los saberes previos

Durante la observación, se evidenció que ambos docentes hacen un uso adecuado de las tecnologías de la información y comunicación, ambos presentaron diapositivas y tuvieron un fácil manejo de estas. En el caso del segundo docente las diapositivas contenían excesivo texto, lo cual dificultaba la lectura y por ende, el procesamiento del mismo.

Con respecto al manejo del contenido, ambos docentes demostraron un dominio total de la materia dictada, en el primer caso, los estudiantes tienen un rol activo, participando a través de preguntas o dando opiniones, no es necesario que el profesor los incite a ello. Por el contrario, en el segundo caso, se evidenció que los estudiantes tienen un rol pasivo, se limitan a tomar nota y solo participan cuando el docente hace preguntas en relación al tema en cuestión, incluso algunos estudiantes se distraen por el uso excesivo de sus dispositivos móviles.

En ambos casos se evidenció que los docentes presentan imágenes y videos para reforzar la clase y ofrecer ejemplos o referencias que servirán para el desarrollo del trabajo a realizar en la sesión de clase. El primer docente presenta los requerimientos, 
los parámetros y los materiales necesarios para realizar dicho trabajo. El segundo docente, también realiza estas indicaciones pero hace más regulaciones, limitando la creatividad y el pensamiento crítico del estudiante.

Una vez iniciado el trabajo aplicativo, ambos docentes asisten a cada estudiante para verificar, orientar y escuchar las propuestas, además, en ambos casos, se evidencia el respectivo asesoramiento con respecto al empleo correcto de los materiales. En relación al primer docente, los estudiantes son dinámicos y se apoyan entre ellos. Por el contrario, en el segundo caso, los estudiantes trabajan individualmente y no son empáticos.

Durante la realización de las actividades, ambos docentes fomentan el respeto y sus opiniones tienen en cuenta la sensibilidad de los estudiantes y a su vez incentivan el compromiso con el curso; el segundo docente además fomenta la investigación, facilita un sitio web en el cual se pueden hallar referentes para su propuesta, al mismo tiempo se evidenció que los alumnos no visitaron dicha página.

Se observó en ambos casos, que los docentes evalúan los trabajos concluidos. El primer docente no solo evalúa, incentiva la autoevaluación y la metacognición a través de preguntas para averiguar los logros alcanzados y las dificultades que se presentaron durante el proceso de creación. El segundo docente, solo evalúa los trabajos y no comunica a los estudiantes los logros alcanzados.

Las clases observadas, evidencian que no hay una metodología para desarrollar el pensamiento crítico. Si bien, con el primer docente, las clases son más abiertas y participativas, las propuestas artísticas se limitan a los aspectos técnicos, haciendo que carezcan de contenido y relación con su entorno. De igual manera, el segundo docente limita el desarrollo de las propuestas, pues todos los trabajos son similares entre sí y además se parecen a los ejemplos proporcionados por el docente.

Finalmente, se evidencia que ambos docentes cierran la sesión de clase solicitando los materiales que serán empleados en la próxima clase. El primer docente motiva a sus estudiantes a mejorar su aprendizaje, brinda tics para trabajar de forma más eficiente. Por otro lado, se evidencia que el segundo docente no motiva a sus estudiantes. 


\section{Presentación de los resultados según las categorías emergentes}

Luego de realizar el análisis y procesar los datos, es decir la codificación y categorización de la información, se agruparon y determinaron las estrategias apriorísticas y categorías emergentes que surgieron durante el proceso.

La información recogida a través de la entrevista evidencia que para los docentes es importante que los estudiantes desarrollen el pensamiento crítico en sus propuestas artísticas, de la triangulación de los datos recogidos a través de los instrumentos de observación, encuesta y entrevista, hemos encontrado diez categorías sumativas: bajo desarrollo de pensamiento crítico, formulación y reformulación de problemas, habilidades de indagación, apertura mental, diálogo reflexivo, hábito de lectura, base gnoseológica, conceptualización axiológica, entorno socio cultural y motivación por el aprendizaje. De las categorías sumativas antes señaladas tenemos cuatro emergentes: bajo crítico de pensamiento crítico, apertura mental, motivación por el aprendizaje y hábitos de lectura. 
Bajo desarrollo del pensamiento crítico

Los docentes afirman que los estudiantes presentan un bajo nivel d pensamiento crítico. El $52 \%$ de los estudiantes manifiesta que los docentes no desarrollan el pensamiento crítico en las sesiones de clase. Según Priestley (1996), el pensamiento crítico es la manera como procesamos la información, para desarrollar en el estudiante capacidades de indagación, comprensión, creación de conocimiento

y además, el manejo de la información de forma correcta.

Formulación y reformulación de problemas os docentes manifestaron la importancia que tiene en el pensamiento crítico la formulación y reformulación de problemas; los estudiantes deben saber detectar problemas en su entorno, plantearlos y formularlos de problemas en su entorno, plantearlos y formularlos de manera científica y metodológica. Muñoz (2011), afirma que la formulacion del problema consiste en identificarlo, delimitarlo, determinar el objeto de estudio y finalmente
plantearlo.

\section{Falta de apertura mental en los estudiantes} Según Obradors (2007), la apertura mental es una característica semejante a la flexibilidad, que inicia la creatividad y la búsqueda constante de mejorar. De acuerdo con esto, obstinarse con ideas o actitudes sobre una cuestión limita I exploración del individuo. Por lo tanto, la apertura mental es una noción que le permite al creador, a partir de la curiosidad y el interés, dar un paso más allá, en su necesidad de superar todo tipo de obstáculos.

Carencia de hábito de lectura en los estudiantes De las entrevistas con los docentes se pudo constatar que la lectura es una herramienta vital en el desarrollo del pensamiento crítico y autoaprendizaje. Igualmente manifestaron la importancia de la ectura en la creación de las propuestas artísticas de los estudiantes, debido a la necesidad de contar con una base de conocimientos y cultura que enriquezca dichas propuestas.

\section{Conceptualización axiológica}

En las entrevistas se evidenció que la conceptualización axiológica es un requisito necesario para el desarrollo del pensamiento crítico. Casillas y Santini (2006), afirman que la conceptualización axiológica es una expresión mental producida para representar las cualidades principales de los individuos y las clases de valor.

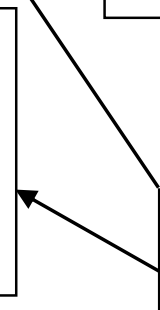
4
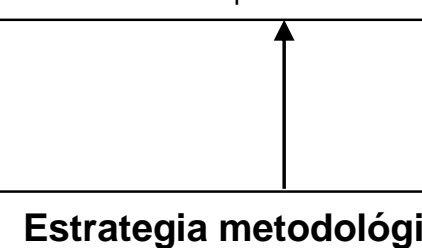
Estrategia metodológica para contribuir al desarrollo del pensamiento crítico en los estudiantes de la especialidad de pintura de una institución educativa de arte de Lima

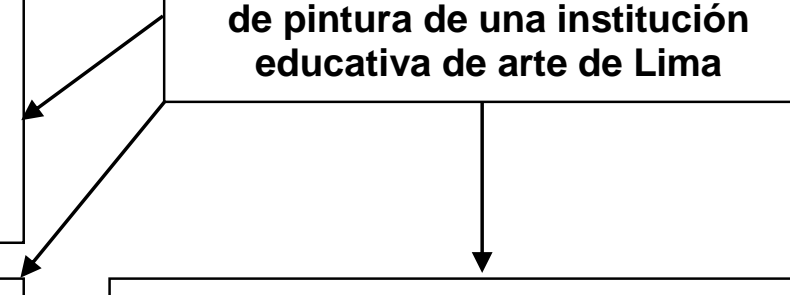

Entorno socio cultural

Giraldo (2015), afirma que el entorno sociocultural es un conjunto de factores que rodean al sujeto durante su vida, conjunto de factores que rodean al sujeto durante su vida, lo cual influye en su evolución personal y colectiva. Es una relación de ida y vuelta, donde las personas influyen y son influenciadas por el contexto. La clase social, la cultura y la ideología son factores importantes que determinan el entorno socio cultural.

\section{Habilidades de indagación}

Los docentes otorgan importancia a la habilidad de indagación, debido a que los estudiantes pueden buscar información, referentes, sitios web, bibliografía destacada y veraz. Echeverría (2005), sostiene que la habilidad de indagación consiste en hacer preguntas y explorar con facilidad; quien indaga, tiene atención u objetivo de conocer algo; es decir, quiere ahondar sobre un tema, enriquecer sus saberes y adquirir nuevos conocimientos.

Figura 1. Categorías emergentes y alternativas, elaboración propia (2019). 


\section{Bajo desarrollo del pensamiento crítico.}

De acuerdo a las entrevistas realizadas, los docentes afirma que los estudiantes presentan un bajo nivel de pensamiento crítico, también señalan que esta capacidad reflexiva es sumamente necesaria para la formación del artista. Al mismo tiempo, el 52\% de los estudiantes manifiestan que los docentes no desarrollan el pensamiento crítico en las sesiones de clase.

Según Priestley (1996), el pensamiento crítico es la manera como procesamos la información, para desarrollar en el estudiante capacidades de indagación, comprensión, creación de conocimiento y además, el manejo de la información de forma correcta. Al respecto, en la observación de clase no se evidenció que los estudiantes tengan las capacidades antes señaladas, por el contrario, los estudiantes tienen un rol pasivo en las sesiones de clase.

Por lo tanto, es necesario elaborar estrategias de enseñanza para incrementar los niveles de pensamiento crítico que le permitan al estudiante generar propuestas artísticas con contenido estético y social.

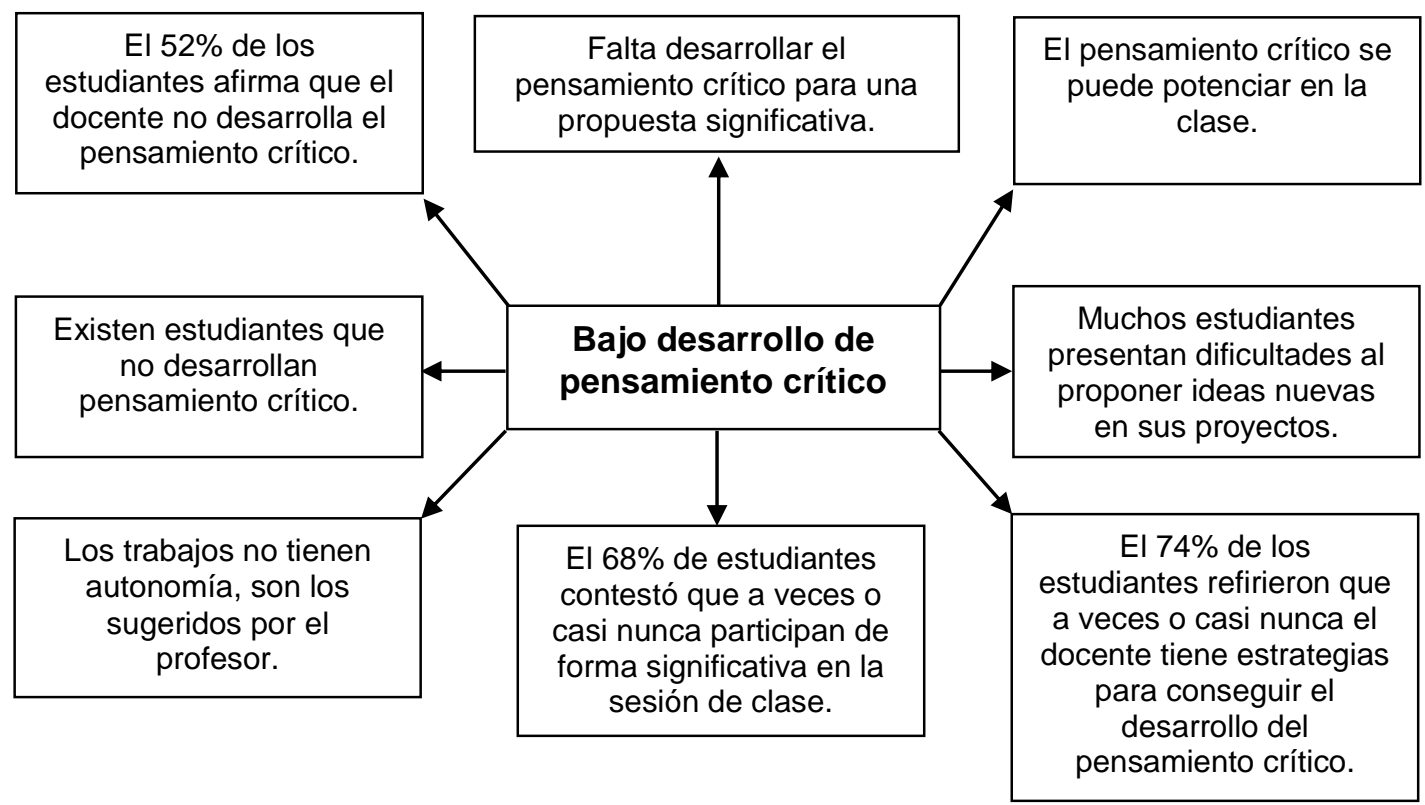

Figura 2. Categoría emergente bajo desarrollo de pensamiento crítico, elaboración propia (2019). 


\section{Falta de apertura mental en los estudiantes.}

Según Obradors (2007), la apertura mental es una característica semejante a la flexibilidad, que incita la creatividad y la su búsqueda constante de mejorar. De acuerdo con esto, obstinarse con ideas o actitudes sobre una cuestión, limita la exploración del individuo. Por lo tanto, la apertura mental es una noción que le permite al creador, a partir de la curiosidad y el interés, dar un paso más allá, en su necesidad de superar todo tipo de obstáculos.

En este sentido, se evidenció que los estudiantes no se involucran con el conocimiento impartido en clase, ni expresan libremente sus pensamientos o pareceres, tomando como cierto sin ningún cuestionamiento la información brindada por el docente. Lo mencionado, se refleja en las propuestas artísticas de los estudiantes.

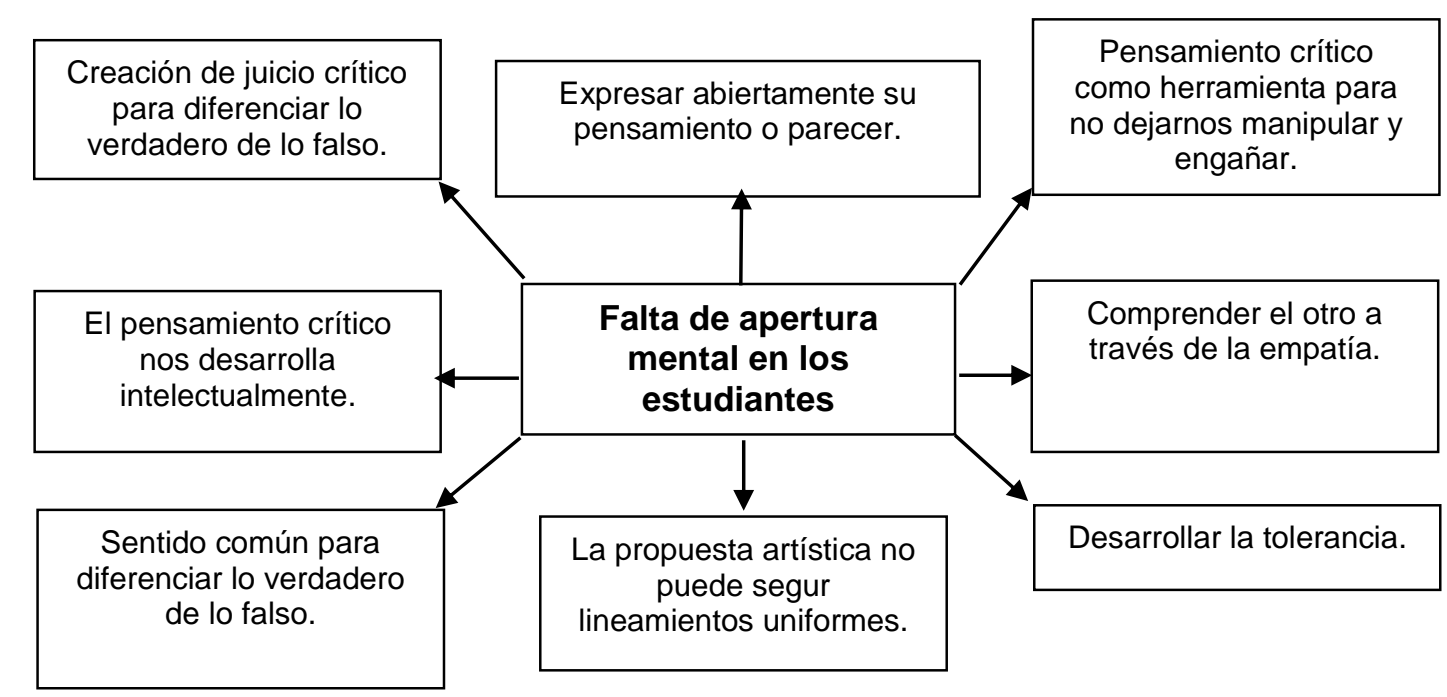

Figura 3. Categoría emergente falta de apertura mental en los estudiantes, elaboración propia (2019).

\section{Falta de motivación por el aprendizaje en los estudiantes.}

La motivación es importante en el proceso de enseñanza aprendizaje, para lo cual el docente debe contar con estrategias que permitan involucrar al estudiante de manera efectiva en la construcción de nuevos conocimientos. Díaz y Hernández (1999), refieren que la motivación posibilita al estudiante a alcanzar sus objetivos y metas, saber cómo resolver de manera eficiente las tareas, problemas que se les imparte, manejar conocimientos y saberes previos. 
En la entrevista, los docentes coincidieron que es necesario diseñar estrategias para motivar a los estudiantes a aprender, investigar y cuestionar los conocimientos que se les imparte, con el propósito de desarrollar un pensamiento propio. En este sentido, la motivación es importante puesto que, a través de sus propuestas artísticas, los estudiantes creen conocimientos y conceptos.

En las observaciones de las sesiones de clase, se pudo constatar que existe dificultad por parte del docente en motivar a los estudiantes a participar activamente en la clase, a expresarse con fluidez e intercambiar ideas y opiniones.

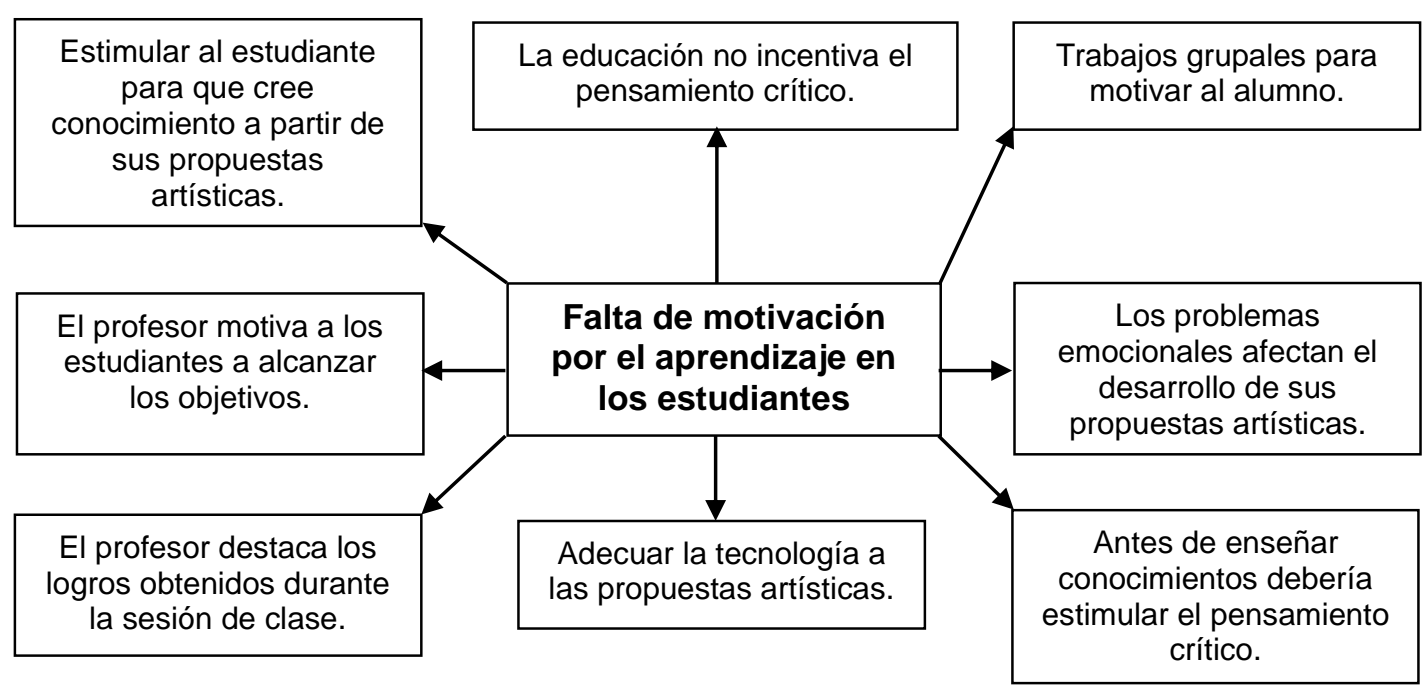

Figura 4. Categoría emergente falta de motivación por el aprendizaje en los estudiantes, elaboración propia (2019).

\section{Carencia de hábito de lectura en los estudiantes.}

De las entrevistas con los docentes se pudo constatar que la lectura es una herramienta vital en el desarrollo del pensamiento crítico y el autoaprendizaje. De manera singular, manifestaron la importancia de la lectura en la creación de las propuestas artísticas de los estudiantes, debido a la necesidad de contar con una base de conocimientos y cultura que enriquezca dichas propuestas.

El Diccionario de Lectura y Términos afines (1985), define hábito de lectura de tres formas distintas: la primera es el uso de la lectura como un ejercicio usual; el segundo, define el hábito de la lectura como un acto repetitivo de libros y textos; y en 
tercer lugar, como la persistencia de una manera específica de leer. Por lo tanto, podemos concluir que el hábito de la lectura implica que los estudiantes busquen siempre y por su propia voluntad materiales de lectura como medio para obtener conocimientos y entretenimiento.

En la observación de las sesiones de clase se evidenció que los docentes no aplican ejercicios de lectura como estrategia para desarrollar el pensamiento crítico en los estudiantes. En cambio, las propuestas se hicieron de manera directa, sin previa investigación, ni lectura de los conceptos que están implicados en el trabajo propuesto.

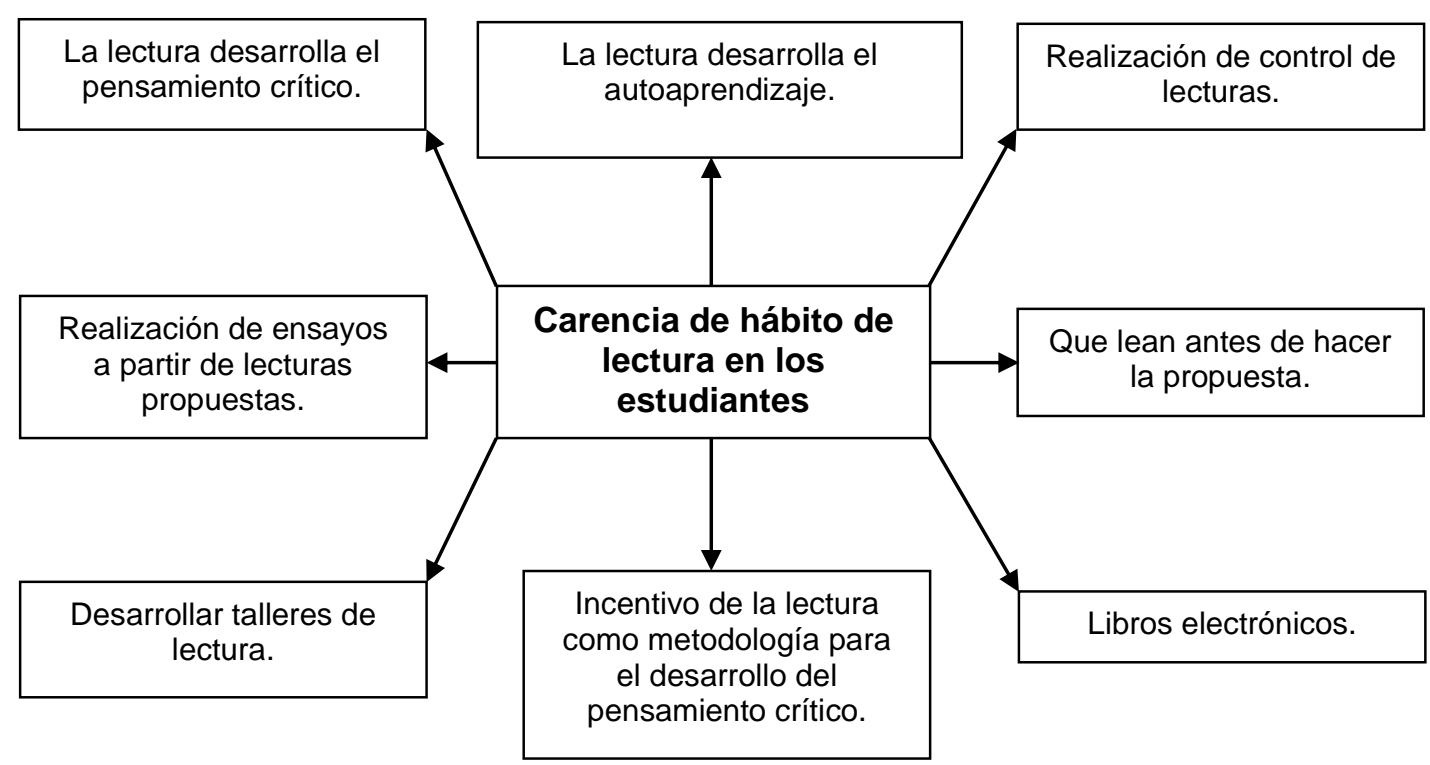

Figura 5. Categoría emergente carencia de hábito de lectura en los estudiantes, elaboración propia (2019).

\section{Conceptualización axiológica.}

En la entrevista a los docentes, se evidenció que la conceptualización axiológica es un requisito necesario para el desarrollo del pensamiento crítico. Casillas y Santini (2006), afirman que la conceptualización axiológica es una expresión mental producida para representar las cualidades principales de los individuos y las clases de valor. Se trata de un proceso en el cual el individuo genera conceptos a partir de la valoración de las cosas, conceptos que deben tener su origen en las vivencias personales, sobre el valor en cuestión, para que sean significativos. 
En la observación de clase se constató que los estudiantes no tienen juicio crítico ya que no pueden diferenciar lo verdadero de lo falso en cuanto a los conocimientos que se les propone, aceptando la información que se les brinda sin ningún cuestionamiento. Al mismo tiempo, el $52 \%$ de los estudiantes manifestó que los docentes no incentivan el cuestionamiento y la autocrítica de sus propuestas artísticas.

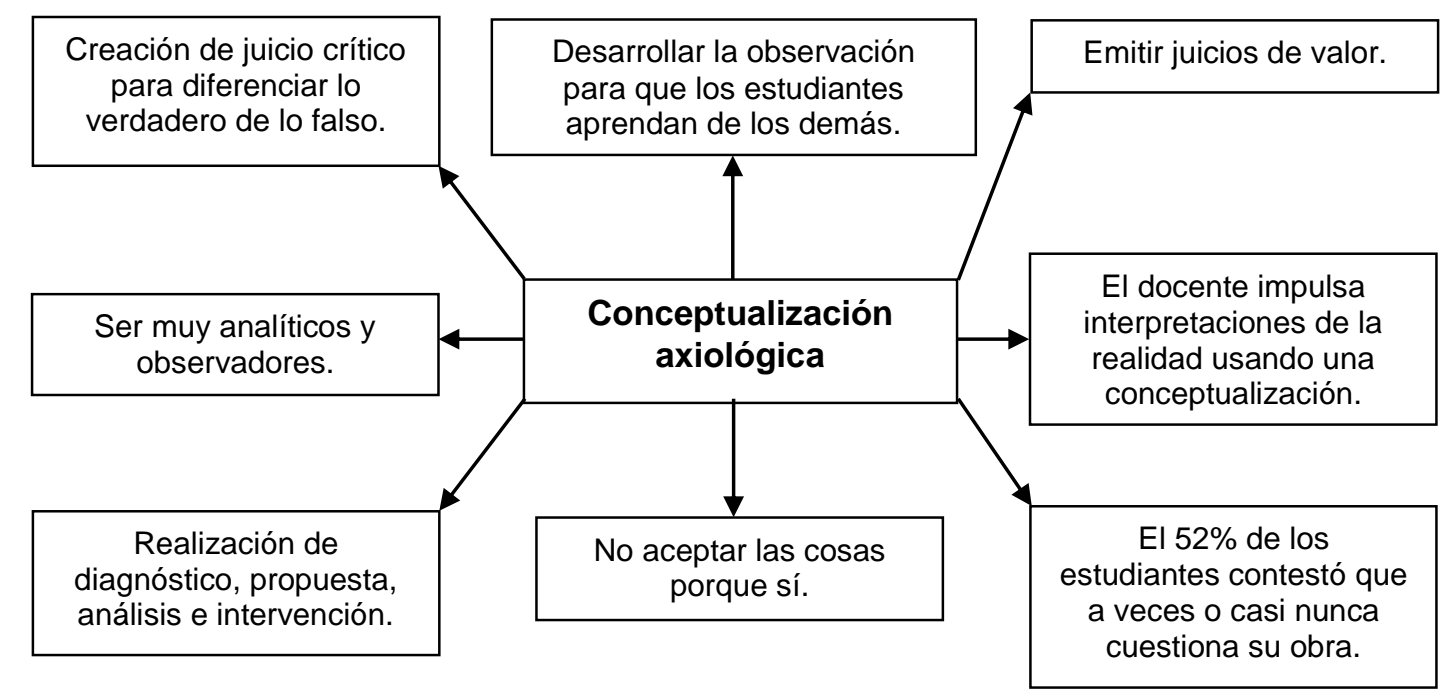

Figura 6. Categoría alternativa conceptualización axiológica, elaboración propia (2019).

\section{Formulación y reformulación de problemas.}

En las entrevistas realizadas a los docentes, se pudo evidenciar la importancia que tiene en el pensamiento crítico la formulación y reformulación de problemas; según ellos, los estudiantes deben saber detectar problemas en su entorno y a su vez, plantearlos y formularlos de manera científica y metodológica.

Muñoz (2011), afirma que la formulación del problema consiste en identificarlo, delimitarlo, determinar el objeto de estudio y finalmente plantearlo. A través de este proceso, se detecta la información necesaria para comprender el significado de los hechos y fenómenos a estudiar, permitiendo valorar sus relaciones y significancias.

Los estudiantes también manifiestan la importancia de formular proyectos para buscar soluciones a problemas de su entorno, a sus propuestas artísticas y a los desafíos de la vida diaria. En la observación de clase, no se pudo constatar que el docente incentive a los alumnos a la investigación y la formulación de problemas. La docente 
(D2) compartió una dirección web para ser investigada por los estudiantes, quienes desestimaron la sugerencia.

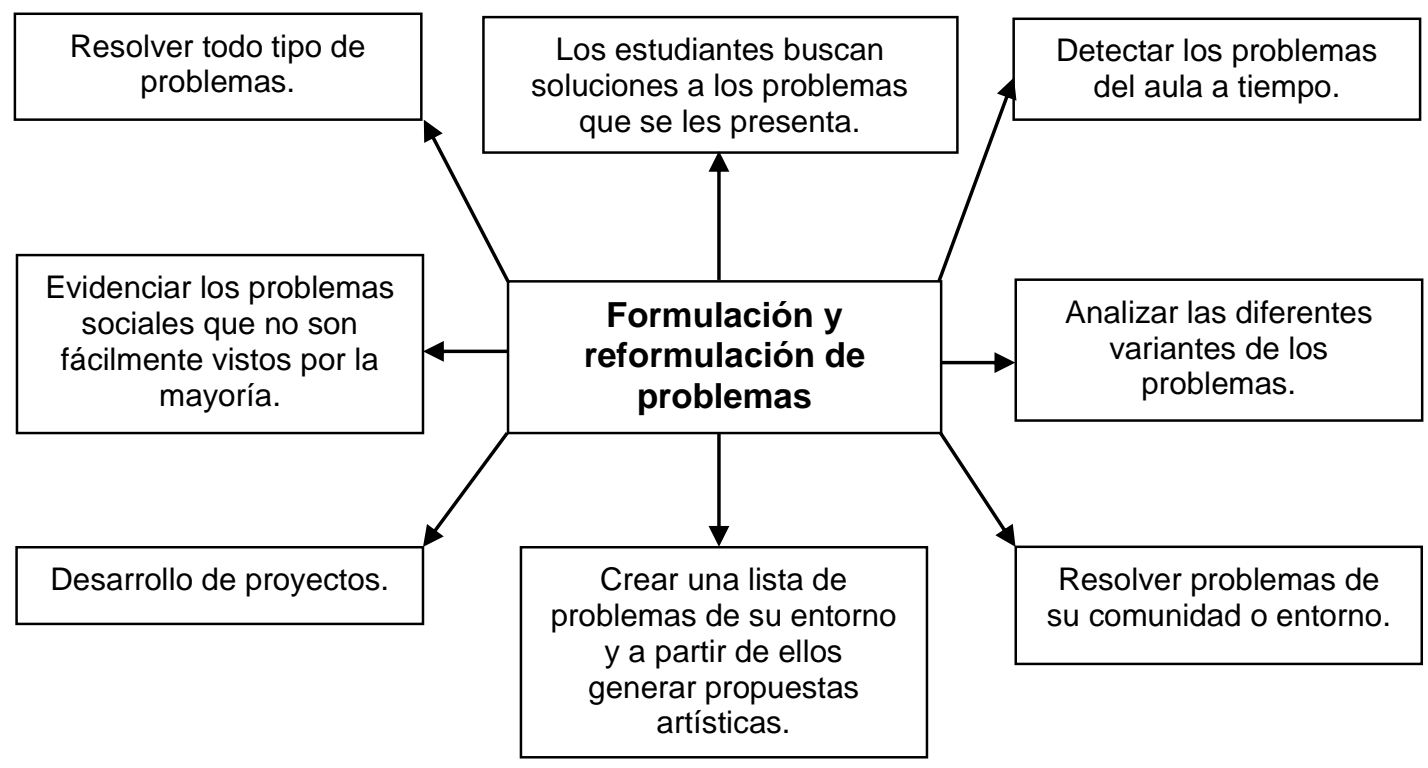

Figura 7. Categoría alternativa formulación y reformulación de problemas, elaboración propia (2019).

\section{Habilidades de indagación.}

Durante la entrevista a los docentes, se pudo constatar la importancia que cada uno le otorga a la habilidad de indagación para poder incrementar el nivel de pensamiento crítico, debido a que uno puede buscar información, referentes, sitios web, bibliografía destacada para desarrollar sus propuestas profesionales.

Al respecto, Echeverría (2005), sostiene que la habilidad de indagación consiste en hacer preguntas y explorar con facilidad; quien indaga, tiene la intención u objetivo de conocer algo; es decir, el indagador quiere ahondar sobre un tema, enriquecer sus saberes y adquirir nuevos conocimientos.

Si bien los docentes manifiestan que la habilidad de indagación es una característica necesaria del pensamiento crítico, no se pudo observar en la sesión de clase, que el docente incentive esta habilidad; por el contrario, los estudiantes aceptan los conocimientos impartidos sin cuestionarlos. 


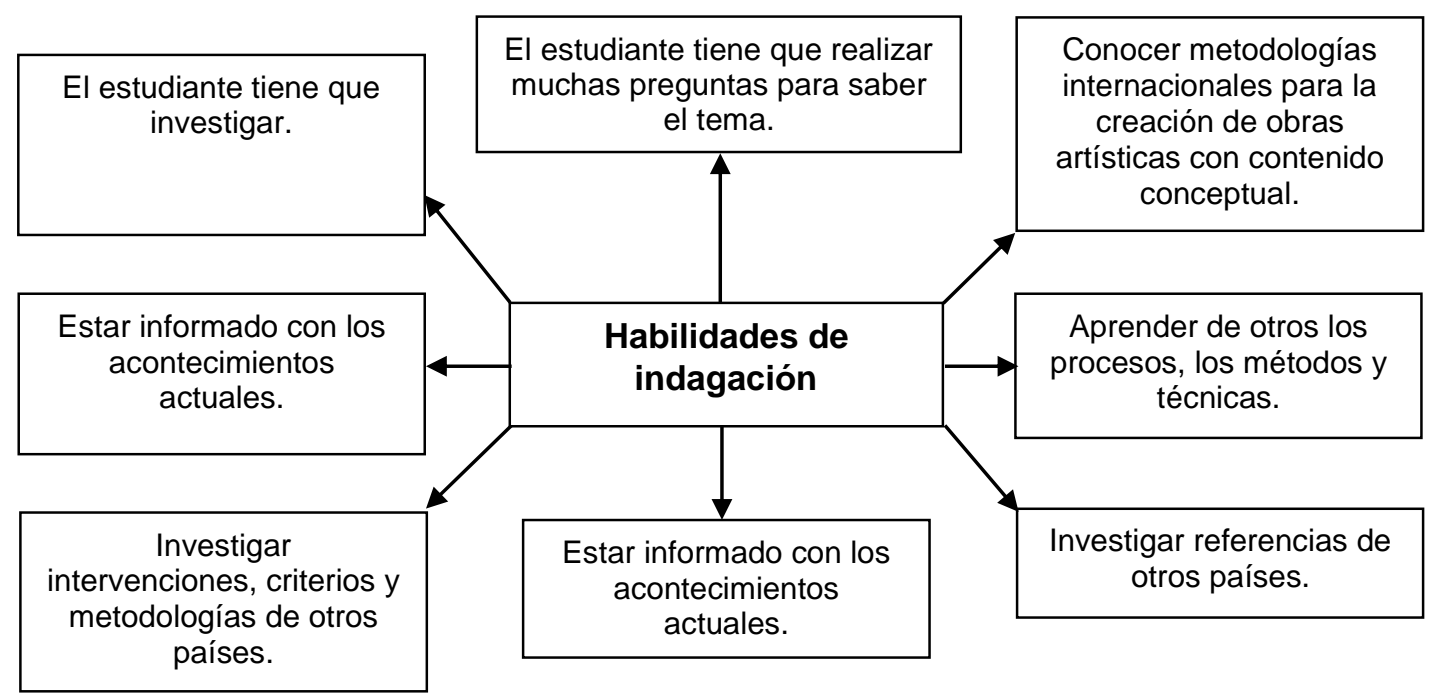

Figura 8. Categoría alternativa habilidades de indagación, elaboración propia (2019).

\section{Diálogo reflexivo.}

Medina, Cruz y Jarauta (2016), sostienen que el diálogo reflexivo es una estrategia usada por el docente para hacer efectivo el proceso didáctico a emplear durante la sesión de clase. No sólo se limita a comunicar al estudiante los conocimientos impartidos, sino a comprender el proceso y justificar porque son necesarios dichos saberes.

En la entrevista y la observación de clase, se evidenció que existe poco diálogo; el docente imparte los saberes y no tiene la preocupación si estos han sido asimilados por los estudiantes, quienes tienen poca participación, limitándose a contestar algunas preguntas que el docente realiza en la clase. Los docentes afirmaron que entre sus estrategias para incrementar el pensamiento crítico están las de promover el diálogo y el debate, ya sea de casos reales para obtener opiniones propias de los estudiantes, lo cual contrastó con la encuesta en la cual ellos manifestaron que el docente no propicia el diálogo ni el debate. Por lo tanto, es necesario diseñar estrategias para el diálogo fluido con los estudiantes. 


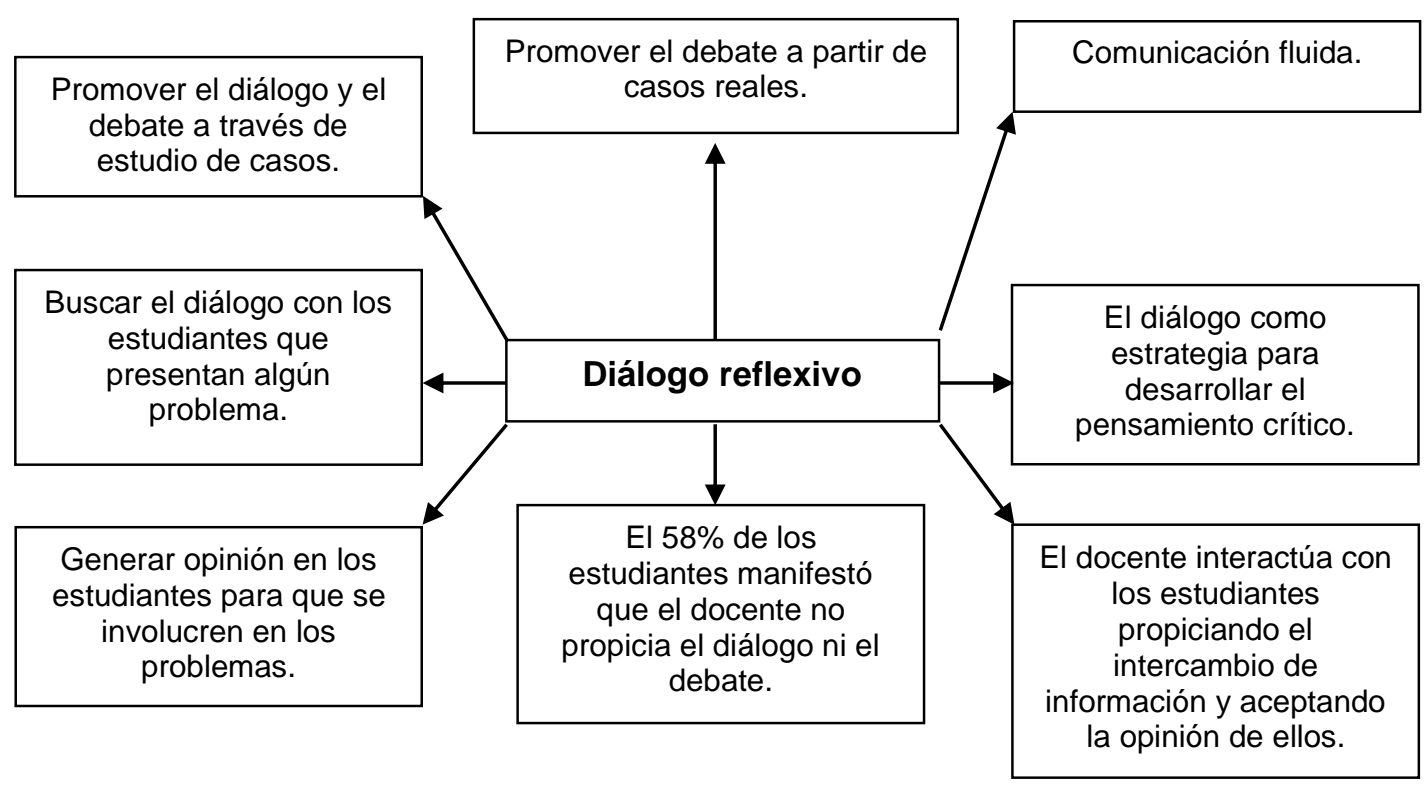

Figura 9. Categoría alternativa diálogo reflexivo, elaboración propia (2019).

\section{Base gnoseológica.}

De las entrevistas a los docentes, se puede colegir que para tener pensamiento crítico se debe tener un bagaje cultural amplio que nos permita analizar problemas o fenómenos que se nos presenta en la vida cotidiana; estos conocimientos sirven como instrumentos de análisis para deducir su veracidad o falsedad.

En las propuestas artísticas, además del procedimiento técnico, es importante el concepto que se quiere transmitir, este concepto puede ser conocimientos o soluciones a problemas existentes en su entorno; las propuestas artísticas no pueden carecer de contenido conceptual, por lo cual es importante que los estudiantes de arte posean una base gnoseológica. Al respecto, Fallas y Cárdenas (2006), refieren que a partir de un enfoque gnoseológico, se entiende que el arte es una técnica de la observación con una lectura de la realidad.

En los resultados del cuestionario a los estudiantes se evidencia la necesidad por parte de ellos de adquirir diversos conocimientos, tales como filosofía, psicología, antropología, literatura y cine. Los estudiantes deben conocer su entorno cultural, sus tradiciones e historia para formar una identidad sólida. Esta base de conocimientos permite sustentar la propuesta artística; además, evita la manipulación y la generación de propuestas carentes de contenido. 


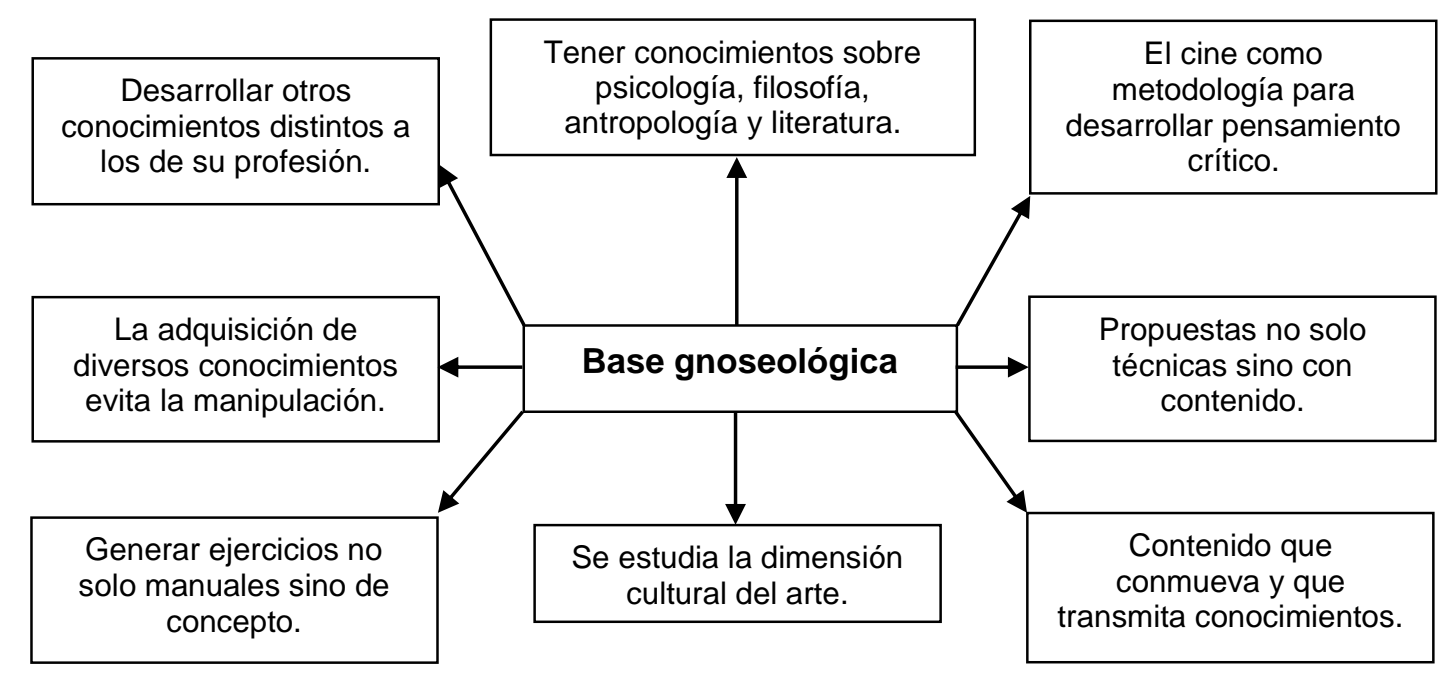

Figura 10. Categoría alternativa base gnoseológica, elaboración propia (2019).

\section{Entorno socio cultural.}

El arte está vinculado con su contexto social y es una forma de expresarlo y crear emociones para poder comprender lo que sucede a nuestro alrededor. Los docentes entrevistados reconocieron que los artistas deben estar vinculados con su entorno, y a partir de ello generar propuestas artísticas. Sin embargo, esto no ocurre en la realidad, por el contrario, los estudiantes buscan referentes externos o movimientos artísticos en boga, con lo cual, sólo generan propuestas artísticas sin contenido conceptual.

Giraldo (2015), el entorno sociocultural es un conjunto de factores que rodean al sujeto durante su vida, lo cual influye en su evolución personal y colectiva. Es una relación de ida y vuelta, donde las personas influyen y son influenciadas por el contexto. La clase social, la cultura y la ideología son factores importantes que determinan el entorno socio cultural.

Los docentes manifestaron que las propuestas artísticas deben partir de su contexto socio cultural para estar vinculadas a los problemas existentes y no resueltos; estas propuestas permiten expresar los sentimientos, las emociones y la manera de concebir el mundo y la vida. Además, los docentes afirmaron que los estudiantes estas descontextualizados de su medio por buscar referentes de realidades opuestas. Por el contrario, los estudiantes afirmaron que los docentes no incentivan la relación entre sus propuestas y su entorno socio cultural. 


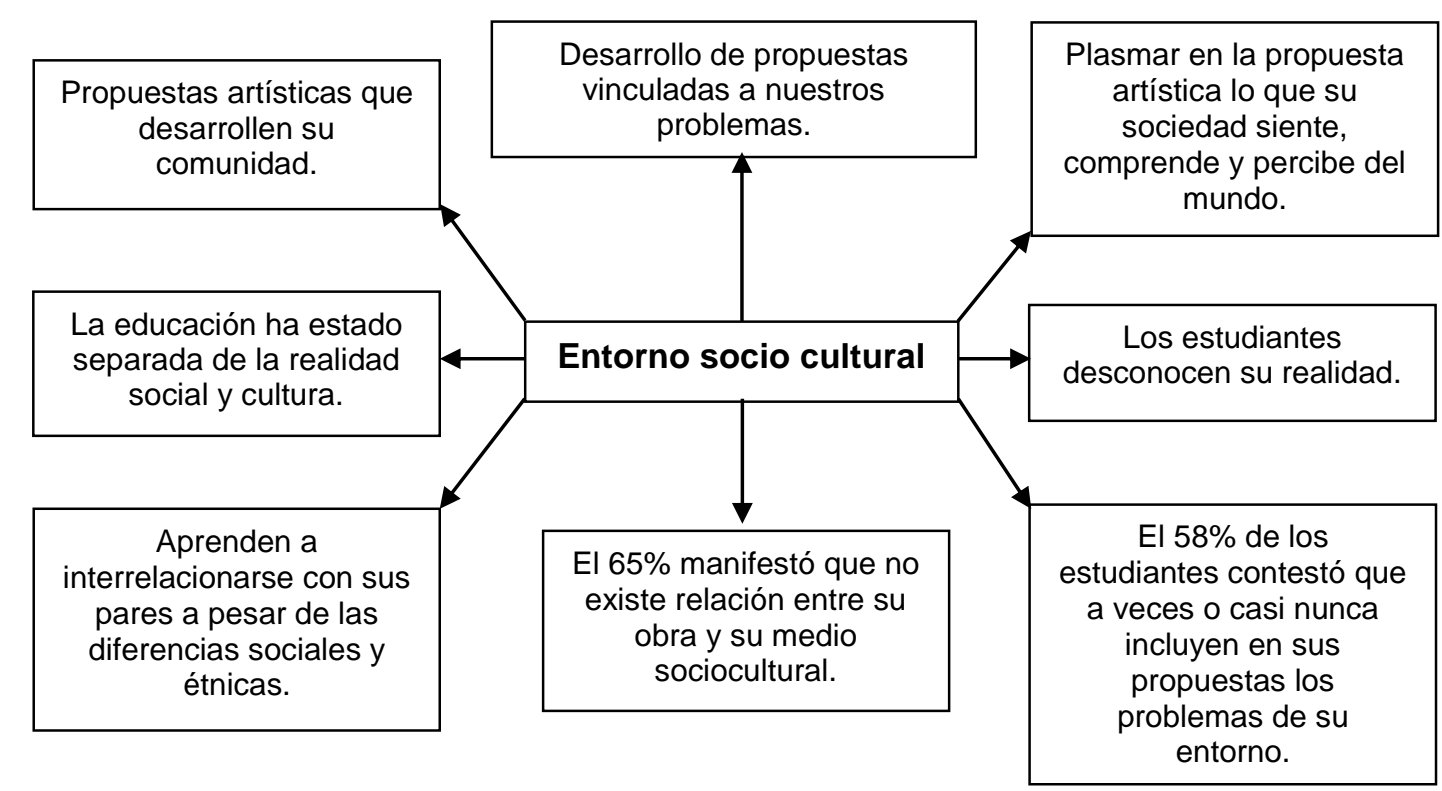

Figura 11. Categoría alternativa entorno socio cultural, elaboración propia (2019).

\section{Conclusiones aproximativas al estudio de campo}

Luego de procesar y triangular la información recogida en el campo mediante los instrumentos respectivos, se obtuvieron los datos que permiten conocer el estado actual del nivel del pensamiento crítico en los estudiantes del curso de Pintura I, así como las estrategias empleadas por el docente para el desarrollo de esta capacidad. Se hallaron cuatro categorías emergentes, bajo nivel de pensamiento crítico, falta de apertura mental, falta de motivación por el aprendizaje y carencia de hábito de lectura. A partir de estos resultados, se establece una estrategia metodológica debidamente sustentada que permita al estudiante desarrollar su capacidad de pensamiento crítico. 


\section{Capítulo III}

\section{Modelación y validación de la propuesta}

Como resultado de la investigación sobre el nivel de pensamiento crítico se propone una estrategia metodológica para mejorar esta capacidad en los estudiantes del curso de Pintura I de una institución pública de arte de Lima. Esta herramienta integra los distintos procesos y fases relacionadas con la enseñanza aprendizaje de los estudiantes.

Los datos señalados anteriormente permitirán modelar una propuesta para el desarrollo del pensamiento crítico; al respecto, Martínez y Calva (2005), afirman que la modelación es un método de estudio para explicar y comprender los fenómenos de la realidad; es decir, es una imitación o reproducción de las estructuras, funcionamiento y relaciones de los elementos de los fenómenos estudiados. La estrategia metodológica elaborada a partir de la modelación es una herramienta pedagógica que le sirve al docente para mejorar el nivel de pensamiento crítico en los estudiantes, lo cual se verá reflejado en sus propuestas artísticas.

\section{Objetivo de la propuesta}

El propósito de la estrategia metodológica es contribuir al desarrollo del pensamiento crítico en los estudiantes de la asignatura de Pintura I de la especialidad de Pintura de una institución educativa de arte de Lima.

\section{Justificación de la propuesta}

A partir de los resultados obtenidos de la investigación de campo, se determinó diseñar una estrategia metodológica que sirva de ayuda para mejorar los diversos aspectos que enmarcan el pensamiento crítico en los estudiantes. Con esta estrategia mejorará el nivel de enseñanza aprendizaje en las áreas de: discusión, motivación por el aprendizaje, hábitos de lectura y apertura mental.

Los estudiantes y los docentes del curso están relacionados por el objetivo en común de crear nuevas propuestas artísticas, que incluyen lo conceptual, una relación con su entorno con el fin de interpretar y resolver problemas y con el desarrollo de una técnica para poder expresar los dos puntos antes señalados. En la actualidad, el artista 
debe adaptarse a los cambios constantes de la estructura social, incrementando su nivel técnico e ideológico, para lo cual necesita el pensamiento crítico. Es necesario artistas que puedan interpretar su entorno para alcanzar una propuesta que nos defina como sociedad.

\section{Fundamentos de la propuesta}

La estrategia metodológica propuesta está orientada a desarrollar el pensamiento crítico en los estudiantes de arte. A continuación se detallan los fundamentos científicos sobre los cuales se apoya la propuesta, estos enfoques son: enfoque sociocultural, filosófico, psicológico, pedagógico y curricular.

\section{Fundamento socioeducativo}

La propuesta está dirigida a los estudiantes de pintura del tercer ciclo de una institución educativa pública de arte ubicada en el centro histórico de Lima. La institución cuenta con cinco facultades: pintura, escultura, grabado, restauración y educación artística. Sus estudiantes provienen de distintas regiones del Perú y sus egresados desempeñan su profesión a nivel nacional. Entre los principios educativos de la institución, se encuentra el aprendizaje por competencias. Además, su currículo está centrada en los estudiantes, tanto a nivel conceptual, procedimental y valores. Dentro de su maya curricular, tiene la asignatura de pensamiento crítico como una competencia más a alcanzar.

La población estudiantil del ciclo 2019-1 de la carrera de la pintura, tiene alrededor de 230 estudiantes, de los cuales 84 cursan el tercer ciclo y están divididos en dos grupos. Los docentes encargados de la asignatura Pintura I son artistas plásticos profesionales con experiencia empírica, pero sin formación docente. La institución cuenta con aulas amplias acondicionadas para el desarrollo de propuestas artísticas, laboratorios, centro de información, biblioteca, servicio psicológico y social.

Los estudiantes provienen de un estrato socioeconómico de clase media baja y popular, familias que esperan una rápida reinserción laboral de sus hijos en la economía, el promedio de edad de los estudiantes fluctúa entre los 17 y 25 años, promedio en el cual puede ser desarrollado el pensamiento reflexivo y crítico (Feldman, Martorell y Papalia; 2012). 


\section{Fundamento filosófico}

La propuesta descansa sobre postulados filosóficos de una educación humanística que exige el desarrollo del pensamiento crítico. Savater (2004), sostiene que el acto de enseñar a quien no sabe o aprender de otros, genera un vínculo importante para el establecimiento de la humanidad, el vínculo humano es la fuente más valiosa de conocimiento.

Stemberg (1985) y Dewey (1916), afirman que el pensamiento crítico es una serie de procesos mentales que pueden ser usados para tomar decisiones, aprender nuevos conceptos, resolver nuevos problemas. El conocimiento filosófico y científico serán considerados verdaderos en función de su observación y comprobación. Al respecto, se aprecia que el docente puede promover todos los aspectos antes mencionados para el desarrollo de la reflexión crítica. Entre las estrategias a emplear se encuentran: el diálogo inteligente, la participación activa en el aula, argumentar, aprender a aprender.

Es necesario que los estudiantes de arte posean pensamiento crítico para poder dotar a sus obras contenidos filosóficos y conceptos de otras índoles, para procurar la creación de una pintura nacional y mejorar sus condiciones económicas, sociales, políticas y culturales. La fundamentación filosófica en la estrategia metodológica proporciona ventajas respecto al desarrollo de habilidades como: pensamiento crítico, argumentación y sustentación de las ideas en base a fuentes fidedignas. Además, proporciona el sustento ético al desempeño artístico, al bienestar humano y el uso racional de los recursos y del planeta.

\section{Fundamento psicológico}

La fundamentación psicológica se propone desde el pensamiento de Vygotsky, quien afirma que el aprendizaje se produce en la sociedad como consecuencia de las relaciones interpersonales en los diversos contextos, lo cual se materializa en formas de comunicación y diálogo (Mingrone, 2007).

Arancibia, Herrera y Strasser (2008), citan a Ausubel, Novak y Hanesian (1978), quienes sostienen que el aprendizaje significativo tiene una base psicológica en cuanto analiza los procesos individuales en el aprendizaje, las dinámicas personales ocurridas durante este aprendizaje, así como las condiciones demandadas para el aprendizaje.

Goleman (1998), sostiene que para el desarrollo del individuo en su entorno es necesario poseer habilidades relacionadas a la inteligencia emocional; habilidades tales 
como: motivación, empatía, autorregulación y autoconocimiento. El logro de estas habilidades se manifiesta en los estudiantes en actividades colaborativas, iniciativa propia en el aula, habilidades para investigar; como consecuencia, los estudiantes incrementarán sus niveles de pensamiento crítico.

\section{Fundamento pedagógico}

La propuesta se encuentra dentro del paradigma cognitivista desarrollada por Piaget, Ausubel y Bruner referidos al funcionamiento de la mente y la adquisición de conocimientos. Ausubel (1983), nos propone el aprendizaje significativo para relacionar las ideas nuevas o aprendizajes nuevos con algún aspecto existente o relevante en la estructura cognitivista del estudiante; estos pueden ser: una imagen, un símbolo, un concepto, una leyenda, una noticia o cualquier otra proposición (Harlen, 2007; Zubiría, 2013). La propuesta se fundamenta en la pedagogía crítica, ya que esta promueve el incremento de habilidades de pensamiento crítico, lo cual permitirá a los estudiantes no solo resolver problemas en cuanto a su creación artística, sino a su vez ser agentes de cambio creando nuevas visiones de pintura y reafirmando una identidad nacional.

Entre los roles del docente, se encuentra la problematización de situaciones reales vinculadas a ellos, de tal forma se obliga a los estudiantes a pensar, razonar y tener opiniones propias acerca de los orígenes, situaciones y formas de resolver dichos problemas. Por lo tanto, es necesario el diálogo entre el docente y el estudiante para incentivar el desarrollo de la conciencia crítica.

El modelo educativo de institución de arte en la cual se realizó la investigación tiene como principio pedagógico el aprendizaje por competencias. Al respecto, Tobón (2006) manifiesta que las competencias se focalizan en aspectos específicos que integran los conocimientos, las destrezas y habilidades y los valores y actitudes, en el desempeño de la actividad profesional.

Por otro lado, la propuesta se basa en la didáctica desarrolladora de Castellanos (2005) y Silvestre \& Zilberstein (2001) para quienes los nuevos aprendizajes deben tener un potencial que transforme e impulse a los estudiantes hacia niveles superiores y al mismo tiempo busquen y apliquen los nuevos conocimientos, aprendan argumentación, generación de puntos de vista propios, sepan discutir y resuelvan problemas de su entorno; todo lo antes señalado, se encuentra en el proceso de enseñanza aprendizaje, dirigido a que los conocimientos sean para toda la vida, formando a un persona integral, autodeterminado, capaza de transformarse y transformar su realidad. 


\section{Fundamento curricular}

El diseño de la estrategia metodológica propuesta se basa en la normatividad y lineamientos expuestos en el artículo $\mathrm{N}$. .5 de la Ley Universitaria 30220.donde se puede apreciar entre los principios que rigen las universidades el espíritu crítico y una investigación relacionada a su contexto social. Como consecuencia, los profesionales serán formados de una manera integral y con responsabilidad social de acuerdo a las exigencias de desarrollo del país.

Por otro lado, los egresados de esta institución, según la malla curricular deberían poseer las siguientes habilidades; participa activa y efectivamente en la creación de conocimientos, propone, plantea, formula y resuelve problemas de su entorno, es responsable y ético. Es un buen comunicador y tiene la facultad de aprender a aprender En tal sentido, el estudiante debe incrementar sus niveles de pensamiento crítico para mejorar sus condiciones, sus competencias, ser sujeto de cambio y poder reinsertarse en el mercado laboral.

\section{Diseño de la propuesta metodológica}

La estrategia metodológica para desarrollar el pensamiento crítico en estudiantes de la asignatura de Pintura del tercer ciclo de una institución de arte pública de Lima, se construye a partir de una propuesta diseñada sobre fundamentos socioculturales, filosóficos, psicológicos, pedagógicos y curriculares antes mencionados. La propuesta se realizó para orientar a los docentes de dicha asignatura durante el proceso de enseñanza aprendizaje con la finalidad de incrementar el nivel de pensamiento crítico en sus estudiantes y que represente un aporte significativo en la obtención de propuestas artísticas.

\section{Esquema teórico-funcional de la propuesta de la estrategia metodológica}

En la figura se muestra el modelo teórico funcional que sintetiza el funcionamiento de la propuesta por medio de un esquema que contiene una entrada y una salida, las cuales representan el problema y su respectiva solución. El modelo se elaboró a partir de la información obtenida en el diagnóstico de campo, del cual se obtuvieron cuatro categorías emergentes: bajo nivel de pensamiento crítico, apertura mental, motivación 
por el aprendizaje y hábitos de lectura. Del análisis de los resultados obtenidos a partir de los instrumentos, se concluye que el nivel de desarrollo del pensamiento crítico en los estudiantes es desigual, por consiguiente, es necesario mejorarlo.

La propuesta busca incrementar el nivel de pensamiento crítico en los estudiantes, que conlleva a que logren ser agentes de cambio, constructores de su propio conocimiento, capaces de trabajar de forma colaborativa y de resolver problemas. Al respecto, Jones e Idol (1990), afirman que el propósito de la educación no se basa en procurar que el estudiante acumule conocimientos de campos especializados, sino el de lograr que adquiera autonomía intelectual. 


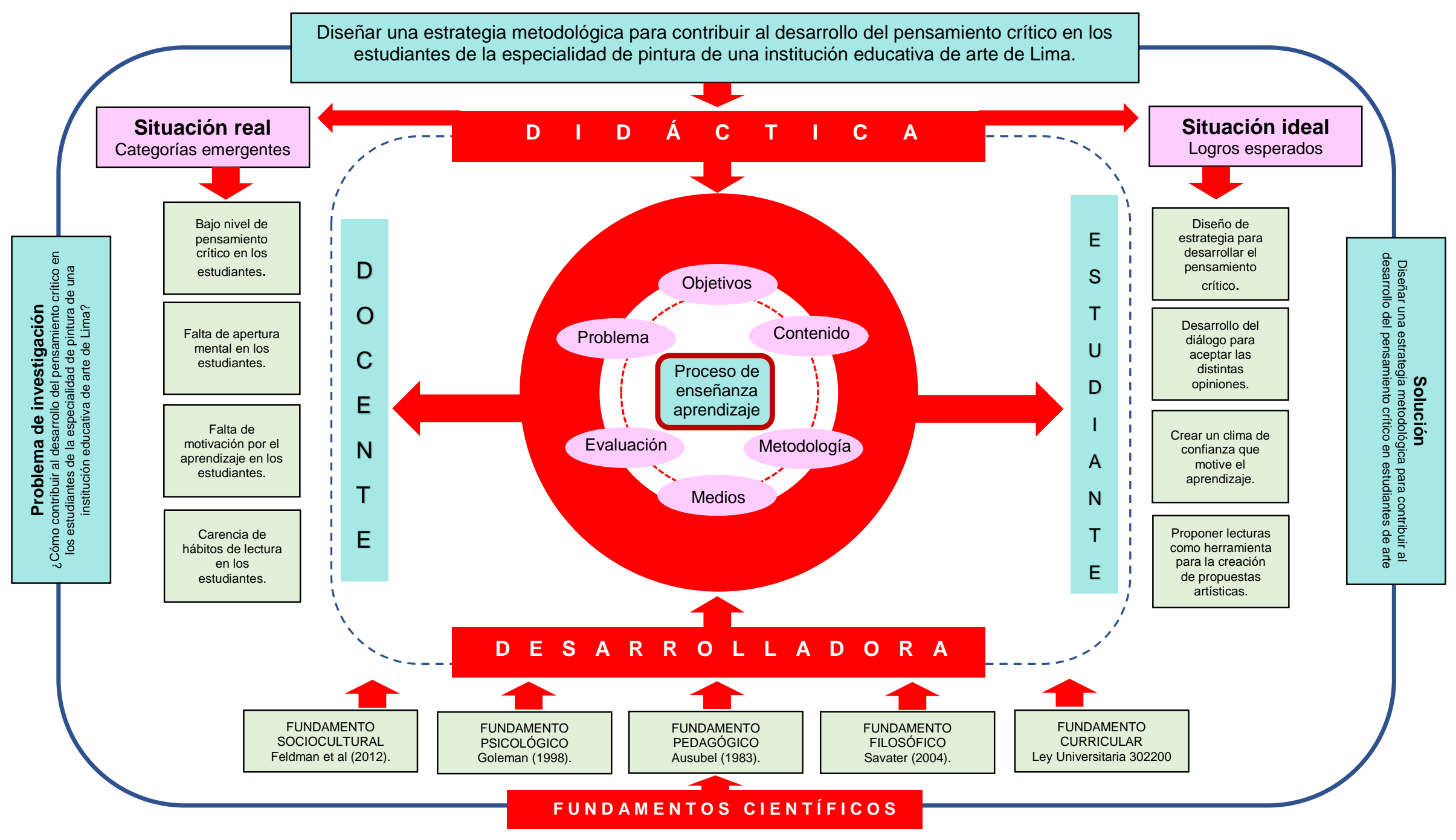

Figura 12. Diseño analógico de la propuesta de la estrategia metodológica, elaboración propia (2019). 


\section{Modelo de pensamiento crítico}

El pensamiento crítico es una capacidad que se puede desarrollar durante el proceso de enseñanza-aprendizaje, para la presente investigación se ha tomado el modelo de la Viterbo University, el cual se adapta al curso de Pintura I.

La Viterbo University establece cinco etapas, las cuales están diseñadas para activar el pensamiento, tomar acciones, desarrollar conocimientos para obtener una conducta externa; es decir, tener un juicio propio sobre los hechos de su contexto (Campos, 2007). Este modelo presenta las siguientes etapas:

Recoger información, etapa en la cual el estudiante descubre un problema y se cuestiona sobre este, la calidad del pensamiento determina la calidad de las preguntas. El estudiante debe prestar atención a sus argumentos y tener un juicio valorativo sobre ellos, debe responder a las siguientes interrogantes: ¿Qué, quién, cuándo, donde, por qué y cómo?, ¿Cuáles son los hechos importantes?, ¿Cuál es el problema?

Comprender la información, para entender lo que se dice, los fenómenos y los hechos de la realidad. Para ello, el estudiante debe hacer uso de sus conocimientos previos y relevantes en el momento de seleccionar la información, la que debe ser clara y precisa. Asimismo, debe diferenciar opiniones, evidencias, alternativas, hechos, valores y sentimientos.

Analizar la información, para descomponer los elementos del problema propuesto por el docente, poder identificar su ordenamiento y funcionamiento, como se desenvuelven estas partes y donde se pueden encontrar el origen del problema. En esta etapa se formulan las siguientes interrogantes: ¿Cómo separo los componentes principales?, ¿cuáles son los errores y las limitaciones?, ¿qué relaciones existen entre sus componentes?, ¿cuán verás y confiable es la información?

Llegar a conclusiones, para arribar a resultados, o integrar todas las ideas en un conocimiento nuevo, que permita dar solución al problema propuesto. Esta etapa se relaciona con el cómo formula sus conclusiones, las generaliza, corrige conocimientos previos, realiza interpretaciones y establece soluciones. Evaluar conclusiones, en esta última etapa se evalúan las soluciones, se comprueba la calidad del razonamiento y se busca una relación con el entorno. En esta etapa, se comprueba la relevancia de las soluciones halladas, se buscan otras alternativas, se comprueba la consistencia, limitaciones y certezas de los resultados. 


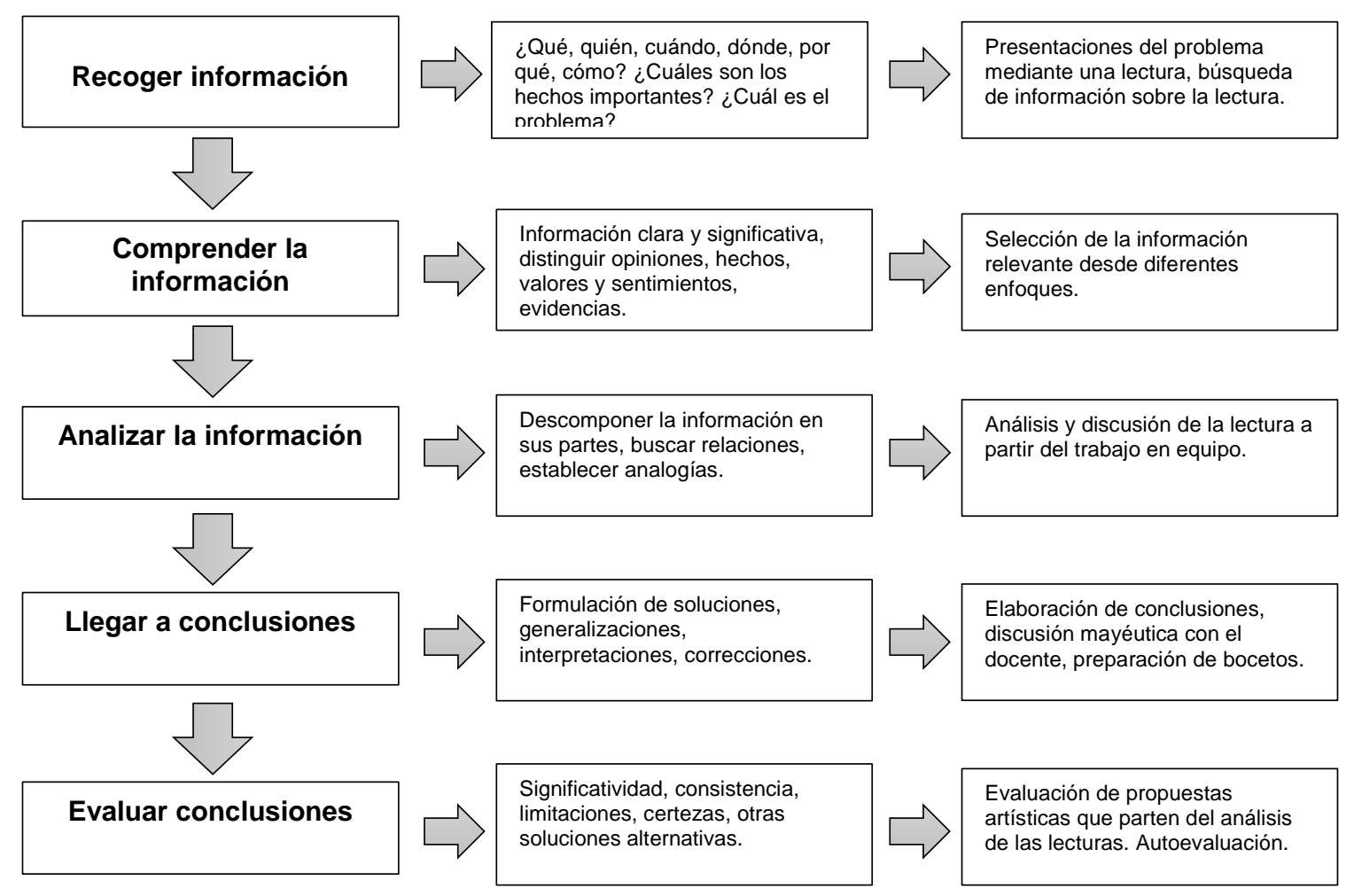

Figura 13. Modelo de pensamiento crítico de Viterbo Univeristy, elaboración propia a partir del modelo de Viterbo University (Campos, 2007).

\section{Organización de la unidad didáctica 1 de la asignatura Pintura I}

A continuación se representa la estructura de la unidad didáctica número uno de la asignatura de Pintura I que se tiene en cuenta la organización y el diseño de clases propuesta como se evidencia en la tabla 1.

Tabla 1

Dosificación del sistema de clases correspondiente a la unidad 1

\begin{tabular}{|c|c|c|c|c|c|c|}
\hline $\begin{array}{c}\text { Sesión de } \\
\text { aprendizaje }\end{array}$ & Métodos & Competencias & Capacidades & Conocimientos & $\begin{array}{c}\text { Valores a } \\
\text { formar }\end{array}$ & Indicadores \\
\hline $\begin{array}{l}1 . \\
\text { El espectro } \\
\text { visible. } \\
\text { Color y } \\
\text { subjetividad. } \\
\text { Color luz y color } \\
\text { pigmento. }\end{array}$ & $\begin{array}{l}\text { Método de } \\
\text { casos y } \\
\text { problémico. }\end{array}$ & $\begin{array}{l}\text { Comprender, } \\
\text { analizar y } \\
\text { reflexionar a } \\
\text { través de } \\
\text { experiencias y } \\
\text { materiales: } \\
\text { pigmentos, } \\
\text { diluyentes, } \\
\text { solventes y } \\
\text { otros materiales }\end{array}$ & $\begin{array}{l}\text { Reconoce y } \\
\text { describe los } \\
\text { materiales de } \\
\text { la técnica del } \\
\text { óleo. } \\
\text { Maneja y } \\
\text { emplea } \\
\text { adecuadament } \\
\text { e las }\end{array}$ & $\begin{array}{l}\text { De qué está } \\
\text { hecha la pintura. } \\
\text { Técnica de la } \\
\text { pintura. } \\
\text { Soportes de la } \\
\text { pintura e } \\
\text { imprimaciones. } \\
\text { La bidimensión } \\
\text { y la ilusión de la } \\
\text { tridimensión. }\end{array}$ & $\begin{array}{l}\text { Responsabilid } \\
\text { ad, } \\
\text { laboriosidad, } \\
\text { honestidad. }\end{array}$ & $\begin{array}{l}\text { Demuestra el } \\
\text { interés por } \\
\text { conocer los } \\
\text { diversos } \\
\text { soportes e } \\
\text { imprimaciones } \\
\text { en la técnica } \\
\text { del óleo. }\end{array}$ \\
\hline
\end{tabular}




\begin{tabular}{|c|c|c|c|c|c|c|}
\hline & & auxiliares. & imprimaciones & & & \\
\hline $\begin{array}{l}2 . \\
\text { La línea. } \\
\text { La imagen y el } \\
\text { volumen. } \\
\text { El lenguaje } \\
\text { pictórico. }\end{array}$ & & $\begin{array}{l}\text { Utiliza la línea y } \\
\text { la perspectiva } \\
\text { en la creación } \\
\text { de imágenes. } \\
\text { Realiza } \\
\text { bodegones. } \\
\text { Compone } \\
\text { aplicando las } \\
\text { leyes de la } \\
\text { Gestalt sus } \\
\text { propuestas } \\
\text { artísticas. }\end{array}$ & $\begin{array}{l}\text { soportes. } \\
\text { Mezcla } \\
\text { correctamente } \\
\text { los pigmentos. } \\
\text { Realiza } \\
\text { estudio del } \\
\text { bodegón. }\end{array}$ & $\begin{array}{l}\text { La } \\
\text { representación. } \\
\text { Positivo y } \\
\text { negativo. } \\
\text { Reglas de } \\
\text { composición. } \\
\text { Gestalt y } \\
\text { percepción. } \\
\text { La abstracción, } \\
\text { pintura y } \\
\text { música. }\end{array}$ & $\begin{array}{l}\text { Solidaridad, } \\
\text { honestidad, } \\
\text { ética. }\end{array}$ & $\begin{array}{l}\text { Estudiantes } \\
\text { motivados a } \\
\text { aplicar las } \\
\text { leyes de la } \\
\text { Gestalt en la } \\
\text { creación } \\
\text { artística. }\end{array}$ \\
\hline $\begin{array}{l}3 . \\
\text { La imagen y el } \\
\text { plano. } \\
\text { La composición } \\
\text { en la pintura }\end{array}$ & $\begin{array}{l}\text { Método } \\
\text { crítico de } \\
\text { solución de } \\
\text { problemas y } \\
\text { casos } \\
\text { reales. }\end{array}$ & $\begin{array}{l}\text { Ser capaz de } \\
\text { ejecutar una } \\
\text { pintura creativa } \\
\text { y con similitud al } \\
\text { modelo en } \\
\text { referencia. } \\
\text { Ejecuta técnicas } \\
\text { básicas para la } \\
\text { creación de un } \\
\text { lenguaje propio. }\end{array}$ & $\begin{array}{l}\text { Pinta al óleo } \\
\text { paisajes. } \\
\text { Da dimensión } \\
\text { social al } \\
\text { espacio. } \\
\text { Reconoce } \\
\text { lugares } \\
\text { sagrados y } \\
\text { espirituales. }\end{array}$ & $\begin{array}{l}\text { Volumen, forma, } \\
\text { plano y } \\
\text { pincelada. } \\
\text { El espacio. } \\
\text { Paisaje urbano y } \\
\text { rural. }\end{array}$ & $\begin{array}{l}\text { Responsabilid } \\
\text { ad, ética, } \\
\text { solidaridad, } \\
\text { laboriosidad }\end{array}$ & $\begin{array}{l}\text { Interés y } \\
\text { destreza que } \\
\text { presentan los } \\
\text { estudiantes en } \\
\text { la realización } \\
\text { de una pintura } \\
\text { de paisaje. }\end{array}$ \\
\hline $\begin{array}{l}4 . \\
\text { La } \\
\text { representación. } \\
\text { Lo figurativo y } \\
\text { simbólico. }\end{array}$ & & $\begin{array}{l}\text { Maneja la } \\
\text { proporción de } \\
\text { las formas y los } \\
\text { valores tonales } \\
\text { en la creación } \\
\text { de propuestas } \\
\text { pictóricas. } \\
\text { Pinta e } \\
\text { interpreta la } \\
\text { figura humana. }\end{array}$ & $\begin{array}{l}\text { Pinta } \\
\text { representacion } \\
\text { es de la figura } \\
\text { humana. } \\
\text { Valora las } \\
\text { formas } \\
\text { teniendo en } \\
\text { cuenta la luz y } \\
\text { la oscuridad. }\end{array}$ & $\begin{array}{l}\text { El cuerpo } \\
\text { personal y el } \\
\text { cuerpo social. } \\
\text { Materialidad del } \\
\text { cuerpo. } \\
\text { Las formas } \\
\text { simbólicas y de } \\
\text { representación } \\
\text { del cuerpo. } \\
\text { El claroscuro. } \\
\text { La forma y la } \\
\text { luz. }\end{array}$ & $\begin{array}{l}\text { Responsabilid } \\
\text { ad, } \\
\text { solidaridad, } \\
\text { puntualidad, } \\
\text { tolerancia. }\end{array}$ & $\begin{array}{l}\text { Motivación por } \\
\text { la aplicación } \\
\text { de los } \\
\text { elementos de } \\
\text { la composición } \\
\text { en la pintura } \\
\text { de la figura } \\
\text { humana. }\end{array}$ \\
\hline $\begin{array}{l}5 . \\
\text { Formas } \\
\text { expandidas e } \\
\text { ideas. } \\
\text { Lo geométrico y } \\
\text { la abstracción. }\end{array}$ & $\begin{array}{l}\text { Método } \\
\text { problémico, } \\
\text { Investigativo } \\
\text { y decisorio. }\end{array}$ & $\begin{array}{l}\text { Realiza pinturas } \\
\text { al óleo } \\
\text { abstractas. } \\
\text { Domina la } \\
\text { perspectiva de } \\
\text { color y maneja } \\
\text { las armonías de } \\
\text { color en sus } \\
\text { creaciones. } \\
\\
\text { Interpreta al } \\
\text { través del color } \\
\text { su entorno } \\
\text { social. }\end{array}$ & $\begin{array}{l}\text { Realiza } \\
\text { estudios al } \\
\text { aire libre. } \\
\text { Maneja } \\
\text { técnicas de } \\
\text { pintura } \\
\text { abstracta } \\
\text { como el action } \\
\text { painting. } \\
\text { Realiza } \\
\text { abstracciones } \\
\text { a partir de su } \\
\text { entorno social. }\end{array}$ & $\begin{array}{l}\text { La abstracción } \\
\text { contemporánea. } \\
\text { La abstracción y } \\
\text { lo espiritual. } \\
\text { La sociedad y la } \\
\text { problemática } \\
\text { contemporánea. } \\
\text { Técnicas mixtas. }\end{array}$ & $\begin{array}{l}\text { Responsabilid } \\
\text { ad, } \\
\text { honestidad, } \\
\text { solidaridad. }\end{array}$ & $\begin{array}{l}\text { Aplica con } \\
\text { éxito las } \\
\text { diferentes } \\
\text { técnicas } \\
\text { mixtas en sus } \\
\text { propuestas } \\
\text { artísticas. }\end{array}$ \\
\hline
\end{tabular}

Fuente: Elaboración propia a partir del silabo de la asignatura Pintura I (2019). 


\section{Diseño didáctico de la propuesta}

Para la estrategia metodológica propuesta, se tuvo en cuenta la didáctica desarrolladora, enunciada por Zilberstein y Olmedo (2015), Molina (2014) y Castellanos et al. (2002). En la sesión de clase se evidencia como y de qué forma se adecua la relación entre las categorías didácticas y el proceso de enseñanza, los que se dan en un proceso dialéctico.

Uno de los principales intereses para el docente de arte, en su gestión educativa, es el futuro desempeño profesional en las propuestas artísticas de sus estudiantes. Al respecto, Molina (2014), sostiene que un profesional es competente para su desempeño, así como competitivo en el mercado laboral, si es apoyado por los cuatro saberes de Delors: aprender a conocer, aprender a ser, aprender a hacer y aprender a convivir; en otras palabras, la educación tiene que abarcar la dimensión técnica y la dimensión ética.

El proceso de enseñanza-aprendizaje es un sistema planificado, organizado, sistemático y contrastado que tiene como función la formación total de la personalidad del estudiante; en el intercambio que se da en el proceso de enseñanza aprendizaje se crean relaciones sociales y comunicativas entre el docente y los educandos, estableciéndose relaciones entre las categorías didácticas, (Molina, 2014; Addine, 2008).

\section{Categorías didácticas}

La categoría didáctica problema se contempla en la fase inicial del diseño y al momento de ejecutar la propuesta; en la cual el docente, considerando el modelo educativo de una escuela de arte, el perfil del egresado, el sílabo del curso pertinente y las competencias técnicas y éticas dirige su diseño para la organización, la ejecución y comprobación del proceso de enseñanza aprendizaje, para transformar el bajo nivel de pensamiento crítico en los estudiantes.

El objetivo de esta categoría es que rige y constituye el proceso de enseñanza aprendizaje y lo que se desea lograr de los estudiantes. Su adecuada estructuración permite organizar, crear y diseñar las actividades del docente y del estudiante para revertir el problema encontrado de bajos niveles pensamiento crítico.

El objetivo es la siguiente categoría didáctica que rige el proceso de enseñanza aprendizaje y lo que se desea lograr con los estudiantes. Su acertada formulación 
permite establecer las actividades del docente y del estudiante que va a revertir el problema. La redacción de los objetivos se deben diseñar en función de los estudiantes como realizadores de las tareas y actividades de aprendizaje en la clase, y debe mantener la unidad entre lo cognoscitivo y lo afectivo sobre la base de la didáctica desarrolladora.

En los objetivos se deben señalar claramente las acciones y operaciones para lograr las habilidades deseadas, los conocimientos impartidos, las acciones valorativas y las condiciones y niveles de asimilación, los medios a utilizar. Los objetivos orientan y guían el funcionamiento de las demás categorías y se transforma en un criterio de evaluación de la calidad del proceso al señalar la precisión de la meta deseada o aspirada que se debe alcanzar en la propuesta de dicho proceso para resolver tareas teóricas, prácticas y éticas (Álvarez de Zayars, 1997; Molina, 2014; Zilberstein y Olmedo, 2015).

La categoría de contenidos parte de los objetivos que están definidos en el sílabo de la asignatura, pero su aplicación viene esencialmente de la propuesta, la cual consiste en proponer la lectura de obras literarias a fin de que los estudiantes analicen los personajes, el contexto y reconozcan la visión social, psicológica, filosófica y antropológica, que derive en la producción de una pintura en estilo propio; posteriormente, los estudiantes realizarán un video o instalación a partir de la lectura.

No se trata de realizar un trabajo informativo o ilustrativo sobre un tema, sino de interpretar el tema de forma amplia, de manera que esto implique una reflexión y el desarrollo del pensamiento crítico. De esta manera, se muestra el proceso mental de los estudiantes frente a un tema controvertido.

La propuesta, contribuirá a la formación socio humanista del estudiante, al involucrar datos de la lectura, análisis e interpretación a propuestas artísticas con contenido conceptual y ético. Esta situación motiva al estudiante porque su trabajo tiene un sustento real que puede valorar y que es producto de su esfuerzo y su trabajo académico.

La categoría contenidos teóricos y prácticos de la asignatura Pintura I, contribuye al cumplimiento del perfil del egresado mediante el desarrollo de las competencias generales como el pensamiento crítico y las específicas que son propias de la especialidad. De esta manera, la formación del estudiante de arte es integral. 
La categoría métodos de enseñanza, como lo afirman Zilberstein y Olmedo (2015), constituye un sistema de acciones que rige y regula la actividad del docente y los estudiantes en función de lograr los objetivos. Su ejecución debe ser creativa, nunca separada del contexto en el cual se desarrolla, debe atender a los contenidos de la asignatura; es decir, no utilizar procedimientos, para desarrollar una capacidad en sí, sino por una demanda real en el proceso enseñanza aprendizaje, respetando la dualidad, instrucción y educación.

La elección de los métodos, técnicas y procedimientos, están en estrecha relación con los objetivos deseados y con las características del contenido. Molina (2014), sostiene que los métodos de enseñanza deben promover activamente la participación de los estudiantes para que este método tenga resultados favorables. Los contenidos conceptuales se pueden enseñar a través de métodos expositivos con técnicas de pensamiento crítico como la mayéutica y a dialéctica.

En la propuesta metodológica basada en la didáctica desarrolladora del arte (actividad profesional relacionada con su entorno real y ético), las acciones a realizar del método propuesto están comprendidas en el aprendizaje de resolución de problemas, para que los estudiantes tengan la oportunidad de pensar y desarrollar el pensamiento crítico. Este método de aprendizaje aproxima a los estudiantes a su contexto y a su futura vida profesional, desarrolla competencias genéricas que favorecen el pensamiento crítico, la autodirección y el trabajo en equipo (Olivares y Heredia, 2012).

En una universidad privada del norte de México, se realizó un proyecto educativo interdisciplinario con la colaboración de los departamentos de filosofía y artes visuales. En este proyecto se aplicó la metodología de aprendizaje por resolución de problemas, se propone una dinámica grupal para que los estudiantes consigan la autorreflexión. A partir del análisis de textos sobre la corriente filosófica existencialista, se elaboraron propuestas pictóricas, producciones de videos, instalaciones y performances (Fernández \& Sañudo; 2014).

La experiencia educativa diseñó actividades que a su vez fomentan el pensamiento crítico y la actividad artística a partir de la contribución interdisciplinaria. Se solicitó a los estudiantes que plasmen en un dibujo o pintura la interpretación o el análisis de la lectura sugerida relacionándola con su contexto actual, para después en grupos de tres a cuatro estudiantes complementen la experiencia interdisciplinaria con la elaboración de un video, una representación teatral o instalación. 
La secuencia de acciones o procedimientos que realizan los estudiantes en el método propuesto se configuran en la siguiente tabla.

Tabla 2

Secuencia de procedimientos en el método propuesto

\begin{tabular}{|c|c|}
\hline Motivación & $\begin{array}{l}\text { El docente enfatiza la importancia del método de resolución de problemas en el } \\
\text { desempeño profesional como medio a realizar propuestas artísticas. Además, destaca } \\
\text { el trabajo grupal y colaborativo como un medio creativo. } \\
\text { El docente hace hincapié en la importancia del método de resolución de problemas, } \\
\text { como un instrumento para desarrollar el pensamiento crítico y el beneficio de esta } \\
\text { capacidad alcanzar las competencias requeridas en la educación superior y en el } \\
\text { desempeño profesional. }\end{array}$ \\
\hline $\begin{array}{l}\text { Definición del } \\
\text { problema }\end{array}$ & $\begin{array}{l}\text { El establecimiento y la identificación de los requerimientos o necesidades indicadas por } \\
\text { el docente y/o los estudiantes de una situación problemática. Se señala y se determina } \\
\text { la relevancia del problema. } \\
\text { El planteamiento formal del problema con objetivos claros y con un lenguaje preciso y } \\
\text { exacto. } \\
\text { La creación de criterios a lograr, son las especificaciones que indican cual es la solución } \\
\text { a alcanzar y cumplir para que la propuesta sea exitosa. } \\
\text { Debe promover entre los estudiantes a la toma de decisiones acertadas. } \\
\text { Se finaliza con una pregunta abierta a los estudiantes, para motivar el diálogo y crear un } \\
\text { clima propicio que estimule la creación. }\end{array}$ \\
\hline $\begin{array}{l}\text { Recolección de } \\
\text { información }\end{array}$ & $\begin{array}{l}\text { Antes de avanzar en el proceso de creación de la propuesta artística, es necesario } \\
\text { recabar toda la información posible relacionada al problema. Las dificultades } \\
\text { presentadas y el tiempo invertido en la investigación son retribuidos con creces en las } \\
\text { etapas siguientes de la propuesta. } \\
\text { La mayoría de las veces, la información recogida nos aproxima a los fenómenos } \\
\text { relacionados al problema para poder redefinirlos. }\end{array}$ \\
\hline $\begin{array}{l}\text { Generación de } \\
\text { múltiples } \\
\text { soluciones }\end{array}$ & $\begin{array}{l}\text { La articulación de los saberes previos, las nuevas ideas, los métodos y herramientas } \\
\text { para obtener soluciones se conoce como síntesis. } \\
\text { Los conocimientos y la práctica del estudiante tienen un rol destacado en esta etapa; sin } \\
\text { embargo, es la actitud de los estudiantes lo indispensable en la resolución del problema } \\
\text { planteado presentando diversas soluciones y bocetos artísticos. }\end{array}$ \\
\hline $\begin{array}{l}\text { Análisis y } \\
\text { selección de la } \\
\text { solución }\end{array}$ & $\begin{array}{l}\text { Es necesario analizar las alternativas de solución al problema para determinar la que } \\
\text { mejor cumpla con los criterios de logro, lo cual se efectúa a través del diálogo, creando } \\
\text { un clima de confianza y motivación. Para lograr construir una propuesta artística los } \\
\text { estudiantes deben aplicar los conocimientos teóricos a las alternativas indicadas por el } \\
\text { docente. } \\
\text { Cada propuesta artística debe ser estudiada con los tipos de análisis adecuadas a cada } \\
\text { una de ellas, contrastando cada alternativa de solución con los criterios definidos al } \\
\text { proponer el problema. Al finalizar el proceso de presentación de soluciones, se tiene que }\end{array}$ \\
\hline
\end{tabular}




\begin{tabular}{|l|l|}
\hline Validación & escoger la mejor de ellas, con el propósito de concretarla en una propuesta artística. \\
\hline $\begin{array}{l}\text { Documentación y } \\
\text { presentación oral } \\
\text { un jurado de expertos en arte, al finalizar el semestre académico. }\end{array}$ & $\begin{array}{l}\text { Documentar el proceso es una actividad importante ya que permite a otros estudiantes } \\
\text { a entender cómo se alcanza a desarrollar propuestas artísticas con contenido y a su vez } \\
\text { creativas. También permite el uso correcto de las técnicas, los materiales y realización } \\
\text { de bocetos o propuestas de solución. La propuesta artística exige un informe final de } \\
\text { las actividades del proceso, al elaborar este informe de manera consciente y reflexiva el } \\
\text { estudiante ejercita la habilidad de argumentación y sustentación de conceptos; además, } \\
\text { se propicia el debate entre los estudiantes, lo cual permite el desarrollo del pensamiento } \\
\text { crítico. }\end{array}$ \\
\hline
\end{tabular}

Fuente: Elaboración propia (2019).

Una estrategia está compuesta por un conjunto de técnicas y actividades específicas que el docente emplea para alcanzar el objetivo del método de resolución de problemas y un óptimo proceso de enseñanza-aprendizaje. Entre las técnicas más utilizadas figuran: la mayéutica, el aprendizaje colaborativo, diagrama de flujos, informe técnico, crítico y reflexivo, mapas cognitivos, informe oral, debate e investigación. Estas técnicas pueden ser utilizadas en cualquier momento y más de una vez. El docente apoya en todo momento a los estudiantes para una óptima aplicación de dichas técnicas.

Con respecto a las lecturas como herramienta para la creación de propuestas artísticas, los estudiantes recibirán orientaciones para un análisis e interpretación de forma crítica y reflexiva. Los estudiantes deben incorporar las interpretaciones solicitadas por el docente, desde el análisis: filosófico, psicológico, literario, socio-antropológico; estos análisis pueden ser abordados todos en conjunto o los que considere el docente. Además, se realizará un informe final que incluye la descripción del proceso, interpretaciones, bocetos, conclusiones y un registro fotográfico de la propuesta artística. Este informe debe presentarse con una redacción clara y lógica, con lo cual se incentiva la lectura y el pensamiento crítico.

Mediante una rúbrica, el docente evaluará el trabajo final, desde las interpretaciones de la lectura, el informe y la propuesta artística. El foco de atención es la interpretación de la lectura aplicada a la propuesta artística para la toma de conciencia de los estudiantes.

Con respecto a la motivación por el aprendizaje, que es una categoría emergente del estudio de campo, se propone crear un clima de confianza. De la Torre (2010), sostiene que se trata de un clima propicio para un aprendizaje relevante y satisfactorio, 
con aportación y participación en la producción de conocimientos, con un alto nivel de compromiso y cumplimiento de las tareas encomendadas, realizadas con esfuerzo y dedicación. Al respecto, se crea en el aula un clima de confianza para obtener mejores propuestas de interpretación y artísticas de los estudiantes, quienes participan de forma voluntaria.

La apertura mental es otra categoría emergente, para la cual se propone el diálogo como herramienta, que en el proceso de enseñanza aprendizaje promueve el acercamiento del docente a los estudiantes, estableciendo vínculos de incuestionable valor en la formación del carácter profesional del educando. Fisher (2013), afirma que el diálogo en la sesión de clase hace visible el pensamiento y el aprendizaje, por lo que es necesario estimularlo en clase para desarrollar la inteligencia. Asimismo, el diálogo obliga a traducir y expandir los pensamientos en palabras. De esta manera, se propiciará el diálogo en referencia a las interpretaciones de las lecturas y los bocetos generados a partir de ellas; las propuestas mencionadas serán ampliadas, enriquecidas y modificadas mediante el diálogo socrático.

La categoría medios de enseñanza, como lo sostiene Bravo (2004), es un conjunto de instrumentos o canales por el que fluye la comunicación entre docentes y estudiantes. Los medios de enseñanza son recursos instrumentales que facilitan la transmisión de los conocimientos, afectan directamente la relación entre profesores y alumnos y tienen sentido en el proceso de enseñanza-aprendizaje. La aplicación de la didáctica desarrolladora en el curso de Pintura I, busca promover el acercamiento del estudiante al futuro ejercicio de su profesión, por lo que es necesario seleccionar cuidadosamente los medios de enseñanza para cada sesión.

En la propuesta se emplearán los siguientes medios, multimedia, pc, internet, teléfonos celulares y medios audiovisuales, con los cuales los estudiantes tendrán a su disposición las lecturas, los análisis y los referentes para encontrar soluciones al problema planteado en la sesión de clase.

La categoría evaluación debe ser integral, holística y libre, no se mide únicamente la capacidad memorística o intelectual de la persona que aprende, además, es necesario medir su sensibilidad, su discernimiento, la consistencia de sus acciones, su coherencia, la aplicación de lo aprendido y su comportamiento ético y estético. Tan fundamental como el conocimiento teórico, es garantizar las actitudes de los estudiantes para su ejercicio profesional (Franco, 2006). En consecuencia, la evaluación es una actividad que 
mide la calidad del aprendizaje integral, efectuado en los estudiantes y deberá ser contrastado con los objetivos planteados para el proceso de enseñanza-aprendizaje.

En la propuesta, la evaluación se centra en la aplicación de lo aprendido y el nivel de pensamiento crítico alcanzado en la realización de sus creaciones artísticas. La evaluación de las competencias específicas está incluida en el sílabo de la asignatura Pintura I, el cual tiene sus propios criterios de evaluación. Ambas evaluaciones, desde un punto de vista pedagógico, proveen al docente una herramienta para reevaluar y reorientar el proceso de enseñanza-aprendizaje. Las actividades de evaluación se señalan en el siguiente cuadro:

Tabla 3

Actividades de evaluación

\begin{tabular}{|c|c|}
\hline ¿Qué evaluar? & $\begin{array}{l}\text { El nivel de pensamiento crítico del estudiante al trabajar en su propuesta artística y } \\
\text { al sustentarla. }\end{array}$ \\
\hline ¿Para qué evaluar? & $\begin{array}{l}\text { Evaluar para que el estudiante tenga un instrumento que mida su progreso en el } \\
\text { proceso educativo y su habilidad de aplicación del pensamiento crítico en la } \\
\text { resolución de problemas relacionados a su contexto, a través de propuestas } \\
\text { artísticas. }\end{array}$ \\
\hline ¿Cuándo evaluar? & $\begin{array}{l}\text { La evaluación es formativa durante todas las sesiones de clase, ya que permite un } \\
\text { juicio valorativo del desarrollo del proceso de manera individual y grupal, lo que } \\
\text { permite seguir detenidamente los niveles alcanzados del pensamiento crítico y al } \\
\text { mismo tiempo permite al docente realizar una rápida retroalimentación. La } \\
\text { evaluación sumativa se realizará al final del proceso. }\end{array}$ \\
\hline ¿Cómo evaluar? & $\begin{array}{l}\text { La evaluación formativa es mediante la mediación cognitiva durante el proceso de } \\
\text { creación de las obras artísticas, su contenido y la explicación de estas, así como las } \\
\text { reflexiones que le produzca su trabajo artístico. La evaluación sumativa se realizará } \\
\text { con el uso de rúbricas de los trabajos finales presentados en el cierre del proceso. }\end{array}$ \\
\hline ¿Quiénes evalúan? & $\begin{array}{l}\text { La evaluación se desarrolla con la participación de los estudiantes y el docente, } \\
\text { quienes son los protagonistas del proceso de enseñanza-aprendizaje. Se fomentará } \\
\text { la heteroevaluación, la coevaluación y autoevaluación. La evaluación sumativa final } \\
\text { del semestre se realizará por juicio de expertos, es decir, un jurado formado por } \\
\text { profesores de pintura. }\end{array}$ \\
\hline
\end{tabular}

Fuente: elaboración propia (2019). 
La categoría de organización, según Zilberstein y Olmedo (2015), responde a la interrogante ¿Cómo organizar el proceso de enseñanza-aprendizaje? En este contexto las formas de organización son el soporte en el que se desarrolla dicho proceso, en el cual están implicados el docente, el estudiante, la institución, la familia y la comunidad. De acuerdo a lo expuesto, los protagonistas de la sesión de clase se comprometen a aprender juntos y realizar un trabajo en equipo, es necesario que el docente cree un clima de confianza para que los estudiantes se sientan motivados, activen su participación en la generación de conocimientos, y se impliquen o involucren en la sesión de clase; para ello, el docente debe construir lazos afectivos para lograr un aprendizaje significativo y el desarrollo del pensamiento crítico.

El docente organiza la clase en función de la metodología basada en problemas, la cual estimula el pensamiento y el correcto manejo de las emociones y sentimientos de los estudiantes, al aplicar sus propuestas artísticas. En la propuesta, se propicia la creación artística a partir de lecturas detonantes del pensamiento crítico. De esta forma, los estudiantes arriban a conclusiones, interpretaciones y conceptos que serán aplicados en la propuesta artística, todo esto bajo la mediación del docente. El grupo decide cómo realizar los debates, sus procedimientos para adoptar decisiones para la elaboración de sus propuestas. El diálogo y la comunicación dentro del equipo y del docente con el equipo son elementos clave en este proceso; puesto que, se busca no solo el logro de las metas académicas sino además la mejora de las relaciones sociales y por ende el desarrollo del pensamiento crítico.

Sobre el rol del docente, Egido (2007), afirma que este no es una fuente de información, por lo contrario, pasa a tener un papel como facilitador del conocimiento, lo cual es indispensable en nuestros días. En tal sentido, el docente debe tener un rol dinámico, debe dominar su tema y saber explicar claramente la situación problémica, los aprendizajes esperados y las competencias a alcanzar. Además, el docente requiere manejar técnicas de trabajo grupal, generando un espacio efectivo para promover la capacidad del pensamiento crítico. Por último, no menos importante es su rol de tutor, en el cual realiza asesorías de forma individual o grupal en el momento requerido.

Ser pensador crítico es una de las habilidades que debe tener el docente, ya que debe formular interrogantes adecuadas a partir de las interpretaciones generadas por los estudiantes sobre las lecturas seleccionadas. A través de las preguntas el docente estimula el razonamiento, la crítica, el cuestionamiento y la capacidad de análisis. El docente proporciona lecturas cuestionadoras que son interpretadas por los estudiantes 
desde diferentes perspectivas, de estas interpretaciones se genera el diálogo mayéutico, la discusión y el debate. De esta manera se arriba a una conclusión, la cual es necesaria para el desarrollo de la propuesta artística.

En tal sentido, la labor docente exige crear un clima adecuado y sostenido para la motivación de los estudiantes, propiciando un cambio en ellos, el trabajo colaborativo y el óptimo aprendizaje de la asignatura. El docente en su rol pedagógico no solo debe desarrollar lo cognitivo, su trabajo incluye lo afectivo, lo volitivo y lo emocional, que son fuerzas internas que movilizan a los estudiantes a relacionar lo aprendido con la realidad.

El estudiante en educación superior genera su propio conocimiento, asume un rol interactivo, espontáneo y crítico que no se limita a ser un simple espectador, sino por lo contrario, es activo y decidido. El docente debe tener un papel mediador para que el estudiante elija y planifique sus conocimientos, sea autónomo, capaz de pensar críticamente y por sí mismo. De esta manera, el estudiante puede adquirir nuevas competencias para adaptase a un mundo en constante cambio (Prieto, Mijares y Llorent, 2014). De lo cual se puede colegir, que el estudiante se hace cargo de su propio aprendizaje; es decir, desarrolla la capacidad del autoaprendizaje y aumenta su compromiso respecto a las actividades específicas para solucionar los problemas propuestos.

Otro aspecto que caracteriza el rol del estudiante es el factor motivacional, indispensable para el desarrollo social y la asimilación de valores y normas que le permite al estudiante tomar decisiones y adquirir una forma de pensar, sentir y hacer propias. Además, debe sentir pasión por su profesión, ser capaz de resolver problemas y entender las ideas y conceptos proporcionados por el docente.

Por otro lado, es necesario que el estudiante desarrolle sus capacidades colaborativas, ya que el aprendizaje es social y debe estar dispuesto a escuchar ideas de otros y articularlas adecuadamente a los nuevos conocimientos. La empatía es otra de las características del estudiante, mediante la cual puede aceptar opiniones que no considere tan válidas y aprender de los demás en el modo de ser, pensar y sentir, con la finalidad de enriquecer sus conocimientos. El estudiante de ser consiente que el éxito debe ser grupal y no limitarse únicamente a lo personal.

La comunicación, entre otras de las características del rol del estudiante, es importante y necesaria para crear un clima en el cual se garantice el aprendizaje y el desarrollo del pensamiento crítico. La propuesta fomenta el trabajo en equipo, que 
fortalece la comunicación, el intercambio de información, la ayuda mutua y la retroalimentación. De esta manera, los estudiantes mejoran su desempeño, su habilidad de análisis, de síntesis, con lo cual son capaces de arribar a conclusiones y reflexiones que se reflejan en la propuesta artística. Por lo tanto, la comunicación aporta a la metacognición, como proceso de reflexión, del cómo se hace, qué se hace, porqué se hace y los resultados esperados.

Por último, hay que añadir la capacidad del pensamiento crítico, la cual es estimulada por el docente a través de los contenidos de la asignatura empleando la metodología propuesta. Al finalizar el curso, el estudiante debe haber desarrollado sus capacidades intelectuales para tener diferentes miradas y enfoques a los problemas de su contexto.

\section{Desarrollo e implementación de la estrategia metodológica para contribuir en el desarrollo del pensamiento crítico en los estudiantes de la asignatura de Pintura I en la carrera de artista profesional}

La propuesta responde a cumplir con el tercer objetivo de la investigación, al respecto se ha diseñado una guía metodológica cimentada en el método de resolución de problemas y en el modelo de pensamiento crítico de Viterbo University. La guía está formada por conceptos, orientaciones y etapas para la implementación de la estrategia propuesta y de las sesiones de clase desarrolladas, la cual responde a los resultados encontrados en el estudio de campo.

\section{Lineamientos y orientaciones metodológicas para la elaboración de las sesiones de clase.}

El proceso de enseñanza-aprendizaje del curso Pintura I se realizará a través de sesiones de clase, en talleres acondicionados para esta asignatura. La propuesta será implementada en sesiones teóricas prácticas de aprendizaje y cubre dos sesiones de clase para implementar la guía metodológica y resolver el bajo nivel de pensamiento crítico en los estudiantes. La propuesta basada en la didáctica desarrolladora tiene el enfoque socio formativo y plantea un problema a resolver, el cual está relacionado con su contexto y el trabajo en equipo, estos están constituidos por cuatro o cinco estudiantes.

La primera sesión es sumamente importante ya que en ella se orienta y se establece una guía de acción para la ejecución de la estrategia. Se establecen las 
siguientes actividades para la siguiente sesión. En el inicio, se motiva a los estudiantes, relacionando la asignatura con su contexto y la relevancia de esta en su formación académica.

A continuación, se rescata saberes previos y los estudiantes exponen las que expectativas que tienen del curso. Luego, se define el pensamiento crítico y se presenta el modelo de pensamiento crítico de Viterbo University, también se presenta las fases del método de resolución de problemas y las normas, compromisos, responsabilidades de los estudiantes para el trabajo en equipo. Seguidamente, se presenta el modelo de evaluación de la propuesta artística y del informe que este conlleva.

En el desarrollo de la sesión de clase se exponen los conocimientos correspondientes a la sesión, según el sílabo. El docente establece el problema a través de una lectura por equipo para su interpretación desde diferentes ópticas del conocimiento humano. El estudiante busca información relevante respecto a la lectura y la interpretación desde distintos enfoques, luego seleccionará la información relevante para la solución del problema. La sesión de clase se cierra con una exposición por equipo, de las interpretaciones y los bocetos realizados a partir de las lecturas propuestas.

En la segunda sesión de clase, al igual que la anterior, se motiva desde el inicio a los estudiantes a encontrar soluciones a los problemas propuestos, en esta etapa se muestra imágenes de pinturas con contenido que permita vislumbrar el pensamiento crítico, a partir de su identificación se rescata los saberes previos. Luego que el docente expone los conocimientos correspondientes, los estudiantes elaboran las conclusiones del problema propuesto en la primera sesión, estas serán expuestas y dialogadas con el docente. Finalmente, los estudiantes proceden a realizar sus bocetos, los cuales son sustentados por ellos y con la mediación del docente seleccionan uno, que servirá para la elaboración de su propuesta artística.

En la tercera sesión de clase, con los bocetos seleccionados en la sesión anterior, los estudiantes proceden a realizar sus pinturas. En esta etapa, el docente asesora de forma individual sobre la técnica, procedimientos y otros aspectos necesarios para la elaboración del trabajo, así como inculca valores y relaciona su trabajo como un promotor de cambios en su contexto. Por último, los estudiantes preparan un informe sobre su proceso, el cual será expuesto en la sesión de clase. 


\section{Validación de la estrategia metodológica propuesta}

Para efectos de validar la propuesta metodológica diseñada que pretende desarrollar el pensamiento crítico en los estudiantes de la asignatura de Pintura I de la carrera de artes visuales de una institución educativa de arte de Lima, se usó la técnica de juicio de expertos, para realizar la consultar sobre la validación de la estrategia, por medio de fichas de evaluación. Los expertos consultados fueron seleccionados por su experiencia académica, exitoso desempeño profesional y experiencia en pedagogía.

\section{Características de los especialistas.}

Los expertos seleccionados para validar la propuesta metodológica fueron tres docentes, quienes tienen una amplia carrera profesional y los grados académicos y científicos que les da autoridad para validar con rigor el contenido científico de la propuesta metodológica. A continuación, se detallan los datos de los especialistas.

Tabla 4

Especialistas seleccionados para la validación de la propuesta

\begin{tabular}{|c|c|c|c|c|}
\hline Nombre & $\begin{array}{c}\text { Grado } \\
\text { Académico }\end{array}$ & $\begin{array}{l}\text { Especialidad } \\
\text { profesional }\end{array}$ & Ocupación & $\begin{array}{c}\text { Años de } \\
\text { Experiencia }\end{array}$ \\
\hline $\begin{array}{l}\text { Cruzata Martínez, Alejandro } \\
\text { Goñi Cruz, Fernando } \\
\text { Velázquez Tejada, Miriam }\end{array}$ & $\begin{array}{l}\text { Doctor } \\
\text { Doctor } \\
\text { Doctora }\end{array}$ & $\begin{array}{l}\text { Ciencias Pedagógicas } \\
\text { Docente Física-Matemática } \\
\text { Educación }\end{array}$ & $\begin{array}{l}\text { Docente superior } \\
\text { Docente superior } \\
\text { Docente superior }\end{array}$ & $\begin{array}{l}25 \text { años } \\
17 \text { años } \\
24 \text { años }\end{array}$ \\
\hline
\end{tabular}

Fuente: Staff de investigadores USIL.

\section{Valoración interna y externa}

En el proceso de evaluación interna y externa se diseñaron dos fichas de validación cada una con diez criterios y sus respectivos indicadores cuantitativos y cualitativos. Desde el punto de vista cualitativo, los expertos señalaron su valoración en cada uno de los ítems referidos en la ficha de validación. La valoración que asignaron cada uno de ellos se encuentra entre los márgenes de uno a cinco puntos, estos se presentan de la siguiente manera: deficiente (1 punto), bajo (2 puntos), regular (3 puntos), buena (4 puntos), muy buena (5 puntos).

En consecuencia, en cada ficha de evaluación se podría obtener hasta cincuenta puntos, lo cual daría entre ambas fichas un total de cien puntos, el puntaje está clasificado desde deficiente hasta muy bueno, lo cual se puede apreciar detalladamente en la siguiente tabla. 
Tabla 5

Tabla de Valoración

\begin{tabular}{|l|l|}
\hline $0-25$ & Deficiente \\
\hline $26-50$ & Baja \\
\hline $51-70$ & Regular \\
\hline $71-85$ & Buena \\
\hline $86-100$ & Muy buena \\
\hline
\end{tabular}

Fuente: Ficha de valoración de la propuesta metodológica USIL (2019).

Para analizar la opinión cualitativa fue necesario un juicio crítico de la propuesta examinada considerando las dimensiones de los aspectos positivos, negativos y sugerencias. En la primera ficha de valoración interna, el especialista juzga el contenido de la propuesta como la factibilidad de aplicación de los resultados propuestos; asimismo, la calidad de la propuesta para ser aplicada por otros docentes, la posibilidad de aplicar esta propuesta en otros contextos similares; la correspondencia con las necesidades sociales e individuales que se presentan en la actualidad; congruencia entre el resultado propuesto y el objetivo señalado en la investigación, novedad en el uso de los conceptos y procedimientos de la propuesta metodológica.

Además, este proceso implica valorar si la propuesta tiene fundamentos educativos, curriculares y pedagógicos acertados, detallados y precisos. Valorar la contextualización de la propuesta en función a la realidad y el nivel de precisión, coherencia, certeza y fácil implementación de sus objetivos, con un plan de acción de lo general a lo particular, son otros criterios evaluados por los expertos.

La segunda ficha corresponde a la valoración externa, la cual incluye los siguientes criterios: claridad, objetividad, actualidad, organización, suficiencia, intencionalidad, consistencia, coherencia, pertinencia de la propuesta y si la metodología responde al diagnóstico de campo. Luego de la valoración de los expertos se obtuvieron los siguientes resultados numéricos expuestos en la siguiente tabla:

Tabla 6

Especialistas seleccionados para la validación de la propuesta

\begin{tabular}{|l|l|c|c|c|}
\hline \multicolumn{1}{|c|}{ Nombre } & \multicolumn{1}{|c|}{$\begin{array}{c}\text { Grado } \\
\text { Académico }\end{array}$} & $\begin{array}{c}\text { Validación } \\
\text { interna }\end{array}$ & Validación externa & Validación final \\
\hline Cruzata Martínez, Alejandro & Doctor & 40 & 40 & 80 \\
Goñi Cruz, Fernando & Doctor & 41 & 39 & 80 \\
Velázquez Tejada, Miriam & Doctora & 46 & 46 & 92 \\
\hline Promedio & & 42 & 42 & 84 \\
\hline
\end{tabular}

Fuente: Elaboración propia a partir de la ficha de validación de la propuesta metodológica USIL (2019). 
De los resultados obtenidos a partir de la valoración de expertos, podemos concluir que la propuesta está considerada como buena. Por tanto, la propuesta metodológica posee una validez interna y externa que hace posible su aplicación en las asignaturas de Pintura de las diversas escuelas de arte con rango universitario de Lima. Las fichas de valoración se muestran en el anexo. 


\section{Conclusiones}

\section{Primera:}

La propuesta de una estrategia metodológica permitirá incrementar los niveles de pensamiento crítico en los estudiantes en los estudiantes de arte, esto debido a que la propuesta mencionada aborda los distintos aspectos y dimensiones que están presenten durante el desarrollo de la carrera, con lo cual se cumplió el objetivo general propuesto en la investigación.

\section{Segunda:}

Se cumplió con éxito la realización de la primera tarea científica, para ello se utilizaron técnicas e instrumentos de recolección de datos en la unidades de análisis, el posterior análisis de estos datos permitió obtener un diagnóstico detallado del estado actual del desarrollo del pensamiento crítico, se pudo evidenciar cuales son las principales falencias presentes en los estudiantes y así enfocarse en la propuesta de solución para subsanar estas carencias.

\section{Tercera:}

Se sistematizaron los fundamentos teóricos y prácticos de la estrategia metodológica para desarrollar el pensamiento crítico, para ello se recurrió al planteamiento y estudio de las categorías apriorísticas, vistas desde la perspectiva de los autores de base; seguido, se sistematizaron, mediante proceso de triangulación y codificación, aquellas categorías emergentes pertinentes para el proceso de investigación, en consecuencia se cumplió con la segunda tarea científica.

\section{Cuarta:}

Para la modelación de la propuesta se consideraron aquellos criterios identificados durante el desarrollo de la investigación, así como los fundamentos de criterio de expertos, la propuesta contiene elementos relacionados entre sí, siguiendo fases secuenciales involucradas en el pensamiento crítico de los estudiantes, se consideraron las implicancias teóricas, metodológicas y prácticas de la propuesta, de esta forma se cumplió con la tercera tarea científica propuesta en la investigación. 


\section{Quinta:}

Para el desarrollo de la propuesta se identificó las potencialidades curriculares de validez de la misma, los actores involucrados en la propuesta son los estudiantes de arte y docentes del curso, así como el contexto en el cual se desarrolla el proceso de enseñanza aprendizaje, adicional a ello, la propuesta cuenta con una validación interna y externa respaldada por expertos en el tema, en consecuencia, la cuarta tarea científica de la investigación fue realizada con éxito. 


\section{Recomendaciones}

\section{Recomendación 1:}

Seguir investigando, perfeccionando las competencias de los docentes, no dejar de capacitarse para desarrollar el pensamiento crítico en la carrera de Artes Visuales; para lo cual se debe promover talleres de capacitación tanto en el pensamiento crítico como en la metodología de aprendizaje basada en proyectos.

\section{Recomendación 2:}

Aplicar la propuesta diseñada en esta investigación en todos los cursos de pintura de la carrera de Artes Visuales, dado que el pensamiento crítico es una capacidad necesaria que debe acompañar a los estudiantes en toda su carrera profesional, para dotar de contenido sus propuestas artísticas.

\section{Recomendación: 3:}

Los docentes al aplicar la metodología problemática deben relacionarla con el contexto de los estudiantes, lo cual permite tener una visión y opinión propia de los problemas de su entorno, encontrando soluciones y ser agente transformador de su realidad.

\section{Recomendación 4:}

El pensamiento crítico debe ser promovido de manera trasversal, en todos los estudiantes de la carrera de Artes Visuales, exponiendo sus ventajas en el aspecto profesional y personal. 


\section{Referencias}

Addine, F. (2008). La didáctica. Una visión histórica desde su desarrollo en el Varona. La Habana: Universidad Pedagógica Enrique José Varona. Recuperado de http://www. Reda lyc.org/pdf/3606/360635567006.pdf

Águila, E. (2014). Habilidades y estrategias para el desarrollo del Pensamiento crítico y creativo en alumnado de la Universidad de Sonora (Tesis doctoral). Recuperado de https://issuu.com/miguelcastromattos/docs/unlock____guila_2014_habilidade

Alejo L. (2017). El pensamiento crítico en estudiantes del grado de maestro/a en educación primaria desde la didáctica de las ciencias sociales (Tesis doctoral). Recuperada de https://riuma.uma.es/xmlui/bitstream/handle/10630/15997/TD_ALEJO_LOZANO_Laura .pdf?sequence $=1$ \&isAllowed $=y$

Alfonso R. (2001). Historia de la teoría y la crítica literaria en Estados Unidos. Madrid: Verbum.

Álvarez de Zayas, R. (1997). Hacia un currículum integral y contextualizado. La Habana: Académica. Recuperado de https://es.scribd.com/doc/132548798/Libro-Rita-m-Alvarez

Amo, J. (1993). Elementos de teorías de las artes visuales. Cuestiones sobre dibujo y pintura. Madrid: Servicio de publicaciones de la Universidad de Castilla-La Mancha.

Angvik, B. (1999). La ausencia de la forma da forma a la crítica que forma el canon literario peruano. Lima: Fondo Editorial de la Pontificia Universidad Católica del Perú.

Arancibia, V. Herrera, P. y Strasser, K. (2008). Manual de psicología educacional. Santiago de Chile: Ediciones Universidad Católica de Chile.

Bautista, G. Borges, F. \& Forés, A. (2006). Didáctica universitaria en entornos virtuales de enseñanza-aprendizaje. Madrid: Narcea.

Báez, J. (2007). Investigación cualitativa. Madrid: ESIC

Bernal, B. (2008). El arte como acontecimiento: Heidegger-Kandinsky. Medellín: Universidad de Antioquia.

Bidegain, G. (2010). La Utopía de Tomás Moro: una sociedad disciplinada. Revista Pléyade, 3,6, 2-26.

Blanco, A. (2016). Desarrollo y Evaluación de Competencias en Educación Superior. Madrid: Narcea.

Prieto, M. Mijares, B. \& Llorent, V. (2014). Roles del docente y del alumno universitario desde las perspectivas de ambos protagonistas del hecho educativo. Venezuela: REDHECS. Recuperado de https://helvia.uco.es/bitstream/handle/10396/14970/ROLES\%20DEL\%20 DOCENTE\%20Y\%20DEL\%20ALUMNO\%20UNIVERSITARIO\%20DESDE\%20LAS\%2 OP ERSPECTIVAS\%20DE\%20AMBOS\%20PROTAGONISTAS\%20DEL\%20HECHO \%20EDUCATIVO\%20_\%20Prieto\%2C\%20Venezuela\%20_\%20REDHECS.pdf?seque nce $=1$ \&isAllowed $=y$ 
Bolo, K. (2017). La filosofía y el pensamiento crítico desde un enfoque pragmático: el caso de su aplicación en la educación superior en Lima (Tesis de maestría).

Recuperada de

http://cybertesis.unmsm.edu.pe/bitstream/handle/cybertesis/6700/Bolo_rk.pdf?sequenc $\mathrm{e}=1$ \&isAllowed $=y$

Bravo, J. (2004). Los medios de enseñanza: clasificación, selección y aplicación. España: Píxel-Bit. Revista de Medios y Educación.

Casillas, M. y Santini, L. (2006). Modelo educativo. Universidad Intercultural. México: Coordinación General de Educación Intercultural Bilingüe.

Campos, A. (2007). Pensamiento crítico. Técnicas para su desarrollo. Bogotá: Magisterio.

Campos, Y (2018). Estrategias de enseñanza aprendizaje. Recuperado de http://www.camposc.net/0repositorio/ensayos/00estrategiasenseaprend izaje.pdf

Capacho, J. (2011). Evaluación del aprendizaje en espacios virtuales. Barranquilla: Universidad del norte; Grupo Ibáñez.

Carretero, M. (2005). Constructivismo y educación. México: Progreso.

Castellanos, D. (2005). Estrategias para promover el aprendizaje desarrollador en el contexto escolar. Recuperado de http://www.cubaeduca.cu/medias/pdf/5171.pdf

Castellanos, D. (2002). Aprender y Enseñar en la Escuela. Recuperado de http://www.cubaeduca.cu/media/www.cubaedua.cu/medias/pdf/5171.pdf

Colmenares, I. (2018). El dibujo artístico para el desarrollo del pensamiento crítico (Tesis de maestría). Recuperada de http://www.riuc.bc.uc.edu.ve/bitstream/123456789/7312/1/TEG\%20COLMENARES\%2 OISABELA.2018.pdf

Contreras, J. (1990). Enseñanza, currículum y profesorado. Introducción crítica a la didáctica. Madrid: Akal.

De-Juanas, A. (2013). Cuestionar las evidencias, educar en la reflexión. Revista internacional de ciencias del deporte, 9, 33, 298-300.

De La Torre, S. (2010). Estrategia didáctica en el aula. Buscando la calidad y la innovación. Madrid: Universidad Nacional de Educación a Distancia.

Delors, J. (1996). La educación encierra un tesoro. Informe a la Unesco de la Comisión internacional sobre la educación para el siglo XXI. Paris: Unesco. Recuperado de http://www.unesco.org/education/pdf/DELORS S.PD

Descartes, R. (2010). El discurso del método. Ecuador: JG

Dewey, J. (1916). Democracy and Education. Recuperado de https://en.wikisourse.org /wiki/ Democracy_cnd_Education.

Díaz, F. \& Hernández, G. (1999). Estrategias docentes para un aprendizaje significativo. México: McGraw Hill.

Díaz, F. \& Hernández, G. (2010). Estrategias docentes para un aprendizaje significativo. 
Interpretación constructivista. México: McGraw Hill.

Díaz, G. (2012). Las estrategias metodológicas y la actitud crítica en los estudiantes ingresantes de la Facultad de Educación de la Universidad Nacional de San Marcos (Tesis de maestría). Lima: Universidad Nacional Mayor de San Marcos.

Díaz, V. (2009). Metodología de la investigación científica y bioestadística. Santiago de Chile: Ril Editores.

Echeverría, R. (2005). Ontología del lenguaje. Buenos Aires: Granica.

Egido, I. (2007). El aprendizaje basado en problemas como innovación docente en la universidad: Posibilidades y limitaciones. Revista Educación y futuro. España:

Profesores de la Universidad Autónoma de Madrid y Sevilla.

Ennis, R. (1996). Critical Thinking Dispositions: Their Nature and Assessability. Recuperado de http://faculty.education.illinois.edu/rhennis/documents/TheNatureofCriticalThinkin 5171 1 000.pdf

Espíndola, J. \& Espíndola, M. (2005). Pensamiento crítico. México: Pearson Education.

Facione, P. (1990). Critical Thinking: A Statement of Expert Consensus for Purposes of Educational Assesment and Instruction. Research Findings and Recommendations. Fullerton: California Academic Press. Recuperado de https://pdfs.semanticscholar.org /75ec/bd5ec433f20dff5fc2e8894a0b1e7107d505.pdf?_ga=2.78751508.1483732974.15 70469437-1923564374.1570469437

Fallas, L. \& Cárdenas, L. (2006). El diálogo con los griegos. Bogotá: San Pablo.

Feldman, R. Martorell, G. y Papalia, D. (2012). Desarrollo humano. México: McGrawHill/Interamericana Editores.

Fernández, M. \& Sañudo, M. (2014). Expresando la existencia. El pensamiento crítico por medio del arte. Revista Innovación educativa, 14, 66, 91-102.

Fisher, R. (2013). Diálogo creativo. Hablar para pensar en el aula. Madrid: Morata.

Fiske, E. (2000) Informe final Foro Mundial sobre la Educación Dakar Senegal. Paris: Unesco.

Flórez, J. (2007). Constructivismo y educación virtual. Sevilla: Lulu.

Fowler, B. (2002). La taxonomía de Bloom y el pensamiento crítico. Missouri: Longview Community College. Recuperado de http://eduteka.icesi.edu.co/articulos/taxonomiabloom -pensamiento-critico

Franco, Z. (2006). La evaluación ética en la educación para el desarrollo humano. Manizales: Universidad de Caldas.

García, L., Ruiz y García (2016). Claves para la educación. Actores, agentes y escenarios en la sociedad actual. Madrid: Narcea.

García, X \& Puig, J. (2007). Las siete competencias básicas para educar en valores. Barcelona: Graó. 
Garzón, A. \& Garcés J. (1989). Hacia una conceptualización del valor. En Rodríguez, A. \& Seoane, J. (Eds) Creencias, actitudes y valores (365-407) España: Alambra.

Giraldo, M. (2015). UF1947: Contextualización del tiempo libre infantil y juvenil en el entorno social. Madrid: Elearning.

Goleman, D. (1998). La práctica de la inteligencia emocional. Barcelona: Kairós.

Gómez, M; Deslauriers, J y Alzate, M (2010). Cómo hacer tesis de maestría y doctorado Investigación, escritura y publicación. Bogotá: Ecoe.

Gromi, A. (2013). Didáctica de las operaciones mentales. Madrid: Narcea.

Guevara F. (2016). Pensamiento crítico y su relación con el desempeño docente en el décimo ciclo de pregrado, de Educación de la Universidad Nacional Mayor de San Marcos (Tesis de maestría). Recuperada de http://cybertesis.unmsm.edu.pe/bitstream/handle/cybertesis /6399/Guevara_df.pdf?sequence=1

Hernández, C. \& Guárate, A. (2017). Modelos didácticos. Para situaciones y contextos de aprendizaje. Madrid: Narcea.

Herrero, J. (2018). Elementos del pensamiento crítico. Instituto Universitario de Investigación en Estudios Latinoamericanos. Madrid: Ediciones Jurídicas y sociales.

Harlen, W. (2007). Enseñanza y aprendizaje de las ciencias. Madrid: Morata.

Harris, T. Hodges, R. (1985). Diccionario de lectura y términos afines. Madrid: Fundación Germán Sánchez Ruipérez.

Jeter, L. (2013). Métodos de enseñanza. Madrid: Editorial Vida.

Jones, B. \& Idol, L. (1990). Dimensions of thinking and cognitive instruction. New Yersey: Lawrence Erlbaum.

Julien, G. (2007). La comunicación niños-adultos. Cómo ayudarles a expresar y cómo aprender a escuchar. Madrid: Narcea.

Kurfiss, J. (1988). Critical Thinking: Theory, Research, Practice, and Possibilities. ASHEERIC Higher Education Report No 2. Washington DC: Association for the Study of Higher Education. Recuperado de files.eric.ed.gov/fulltext/ED304041.pdf

Lanuez, M. Martínez, M. y Pérez, V. (2008). La investigación educativa en el aula. La Habana: Pueblo y Educación.

Lavín S., Del Solar S. (2000). El proyecto educativo institucional como herramienta de transformación de la vida escolar. Santiago de Chile: LOM.

Lentini, L. et al. (1986). Arte y Crítica en el siglo XX. San José: Universidad Estatal a Distancia.

León, F. (2014). Sobre el pensamiento reflexivo también llamado pensamiento crítico. Revista Propósitos y Representaciones, 2, 1, 161-214. 
Lorenzo, N. \& Pla, M. (2001). Teoría de la enseñanza. Modelos aplicados al proceso de enseñanza-aprendizaje. Madrid: Universidad Nacional de Educación a Distancia.

Macías, M. (2014). Evaluación del proceso enseñanza aprendizaje en formación profesional para el empleo. Madrid: Elearning.

Martínez, F y Calva J (2005). Memoria del XXIII coloquio de investigación bibliotecológica de la información: problemas y métodos de investigación en bibliotecología e información. Una perspectiva interdisciplinaria. México: Universidad Nacional Autónoma de México.

Maurial, I. (2015). Tomás de Aquino y las cinco vías de la existencia de Dios. Lima: Consensus. Recuperado de fdefunife.edu.pe/publicaciones/revistas/consensus/volumen 20/Consensus\%2020_1/Cap.\%206.pdf

Medina, A. (2009). Didáctica general. Madrid: Pearson Education.

Medina, A., Domínguez, C. y De La Herrán, G. (2014). Fronteras en la investigación didáctica. Madrid: Universidad Nacional de Educación a Distancia.

Medina, J., Cruz, L., Jarauta, B. (2016) S./T. Revista de Educación №374, OctubreDiciembre 2016. España: Ministerio de Educación, cultura y deporte.

Melchor, L. (2017). Portafolio digital estudiantil en el desarrollo del pensamiento crítico en la asignatura dibujo en los estudiantes del primer ciclo del programa de artes plásticas y visuales de la Escuela Nacional Superior Autónoma de Bellas Artes del Perú (Tesis de maestría). Lima: Universidad Peruana Cayetano Heredia.

Meneses, G. (2007). El proceso de enseñanza aprendizaje. El acto didáctico. Cataluña: Universitat Rovira i Virgili.

Mingrone, P. (2007). Metodología del estudio eficaz. Buenos Aires: Bonum.

Ministerio de Educación del Perú. (2014). Ley Universitaria. Ley $N^{\circ} 30220$. Recuperado de http://www.minedu.gob.pe/reforma-universitaria/pdf/ley_universitaria.pdf

Molina, A (2014). Didáctica de la Ingeniería. Fundamentos teóricos y metodológicos. La Habana: Congreso Internacional de Educación Superior. Recuperado de beduniv.reduniv.edu. $\mathrm{cu} / \mathrm{fetch}$. php?data $=355 \&$ type $=$ pdf\&id $=2968 \mathrm{db}=0$

Mora, A. (2015). Habilidades y estrategias para el desarrollo del Pensamiento crítico y creativo en alumnado de la Universidad de Sonora (Tesis de maestría). Recuperada de

https://repository.unilibre.edu.co/bitstream/handle/10901/8334/TRABAJO\%20DE\%20G RADO\%20CD.pdf?sequence $=1$ \&isAllowed $=y$

Motta, N. (2017). Resiliencia, actitud creativa hacia las actividades académicas y habilidad del pensamiento crítico de los estudiantes del primer ciclo de la Escuela Académico Profesional de Educación de la Facultad de Educación de la Universidad Nacional Mayor de San Marcos (Tesisdemaestría).Recuperadadehttp://cybertesis.unmsm.edu.pe/bitstream/handle/cyb ertesis/7067/Motta_cn.pdf?sequence=1\&isAllowed=y 
Muñoz, C. (2011). Cómo elaborar y asesorar una investigación de tesis. México: Pearson Educación.

Ñaupas, H., Mejía, E., Novoa, E. y Villagómez, A. (2014). Metodología de la investigación cuantitativa-cualitativa y redacción de la tesis. Bogotá: Ediciones de la U.

Nuñez, F. et al. (2018). Factores de éxito de los estudiantes universitarios y herramientas para conseguirlo. Madrid: Egregius.

Obradors, M. (2007). Creatividad y generación de ideas. Barcelona: Universidad Autónoma de Barcelona.

Olivares, S. \& Heredia, Y. (2012). Desarrollo del pensamiento crítico en ambientes de aprendizaje basado en problema en estudiantes de educación superior. Revista Mexicana de Investigación Educativa, 54, 17, 759-778.

Ontoria, A., et al (2017). Mapas conceptuales. Una técnica para aprender. Madrid: Narcea.

Ospina, J. (2006). La motivación, motor del aprendizaje. Bogotá: Revista Ciencias de la Salud, 4, 158-160. Recuperado de https://www.redalyc.org/pdf/562/56209917.pdf

Patiño, H. (2014). Desarrollo del pensamiento crítico (versión electrónica). Revista Nueva Época, 64, 3-9.

Pimienta, J. (2012). Estrategias de enseñanza-aprendizaje. México: Pearson Educación.

Paul R y Elder L. (2003). La mini guía para el Pensamiento crítico Conceptos y herramientas. Fundación para el pensamiento crítico. Recuperado de http://epo86neza.com/comunica dos/ comunicado11.pdf.

Prada, M. (2011). El oficio del filósofo y la técnica. Bogotá: Universidad Pedagógica Nacional.

Priestley, M. (1996). Técnicas y estrategias del pensamiento crítico. México: Trillas.

Quiróz, M. (2003). Aprendizaje y comunicación en el siglo XXI. Bogotá: Editorial Norma.

Ramírez, A. (2007). Estrategias de aprendizaje y comunicación. Bogotá: Universidad Cooperativa de Colombia, primera edición.

Real Academia Española. (2014). Diccionario de la lengua española (23. ${ }^{a}$ ed.). Recuperado de https://www.rae.es/diccionario-de-la-lengua-espanola/la-23a-edicion2014

Rodríguez, A. Cañarte, J., Pibaque, M. De Acuña, R. Pionce, A. Caicedo, C. (2017). Estrategia metodológica utilizando técnicas para desarrollar la comprensión lectora en inglés en los estudiantes del nivel superior. Madrid: 3ciencias.

Rodríguez, G. (2018). Pensamiento crítico en alumnos de nivel superior medio (Tesis de maestría). México: Universidad Nacional Autónoma de México.

Rojas, R. (2002). Investigación social. Teoría y praxis. México: Plaza y Valdés. 
Rozitchner A. (2012). Ganas de vivir. La filosofía del entusiasmo. Buenos Aires: Editorial Sudamericana.

Rué, J. (2009). El aprendizaje autónomo en educación superior. Madrid: Narcea.

Salanova M, Grau, Cifre, Llorens y García-Renedo (2004) Nuevos horizonte en la investigación sobre la autoeficacia. Publicaciones de la Universitat Jaume.

Sánchez M. (2006). Investigación cualitativa en educación Hacia la generación de la teoría a través del proceso analítico. Valdivia: Universidad Austral de Chile.

Savater F. (2004). El valor de educar. Madrid: Ariel S.A.

Scott, C. (2015). El futuro del aprendizaje 3. ¿Qué tipo de pedagogías se necesitan para el siglo XXI? París: Unesco.

Silvestre, O. \& Zilberstein, J. (2001). Enseñanza y aprendizaje desarrollador. Instituto central de ciencias pedagógicas. La Habana: Instituto Central de Ciencias Pedagógicas. Recuperado de file//C:/Users/MANUEL/Downloads/ENSE\%C3\%91ANZA\%20Y\%20APRENDIZAJE\% DESARROLLADOR.pdf

Stemberg, R. (1986). Critical Thinking: Its mature, measurement and improvement. Washington DC: National Institute of Education. Recuperado de https://files.eric.ed.gov /fulltext/ED272882.pdf

The University of New Mexico Catalog. (2005). College of Nursing. Recuperado de https://registrar.unm.edu/UNM\%20Catalog/2005-06Catalog.pdf

Tobón, S. (2006). Aspectos básicos de la formación basada en competencias. Talca: Proyecto Mesesup. Recuperado de http://maristas.org.mx/gestion/web/doctos/aspectos básicos formación competencias.pdf.

Touriñán, J. (2010). Artes y Educación. Fundamentos de Pedagogía Mesoaxiológica. La Coruña: Gesbiblo.

Turner, D. (2015). Teoría y práctica de la Educación. México: Siglo XXI.

Utrilla, P. (2008). El pensamiento de Duns Escoto en la cultura de su tiempo. Revista Teológica Limense, 2008, 3, 323-354.

Valero, J. (2003). La escuela del yo quiero. México: Progreso.

Velázquez, M. (2014). Propuesta metodológica dirigida a la competencia comunicativa en la construcción de textos escritos en los estudiantes de sexto grado en la educación primaria. (Tesis doctoral). Florida: Pontificia Universidad Católica Americana de los Estados Unidos.

Zabalza, M. (2004). La enseñanza universitaria. El escenario y sus protagonistas. Madrid: Narcea. 
Zátonyi M. (2002). Una Estética del arte y el diseño de la imagen y el sonido. Buenos Aires: Kliczkowski.

Zilberstein, J. y Olmedo, S. (2015). Didáctica desarrolladora: posición desde el enfoque histórico cultural. Revista Educacao e Filosofía Uberlandia. Recuperado de http://www.seer.ufu.r/ index.php /EducacaoFilosofia/article/viewFile/28056/1767

Zubiría, J. (2013). ¿Cómo diseñar un currículo por competencias? Fundamentos, lineamientos y estrategias. Bogotá: Magisterio Editorial. 
ANEXOS 
MATRIZ METODOLÓGICA

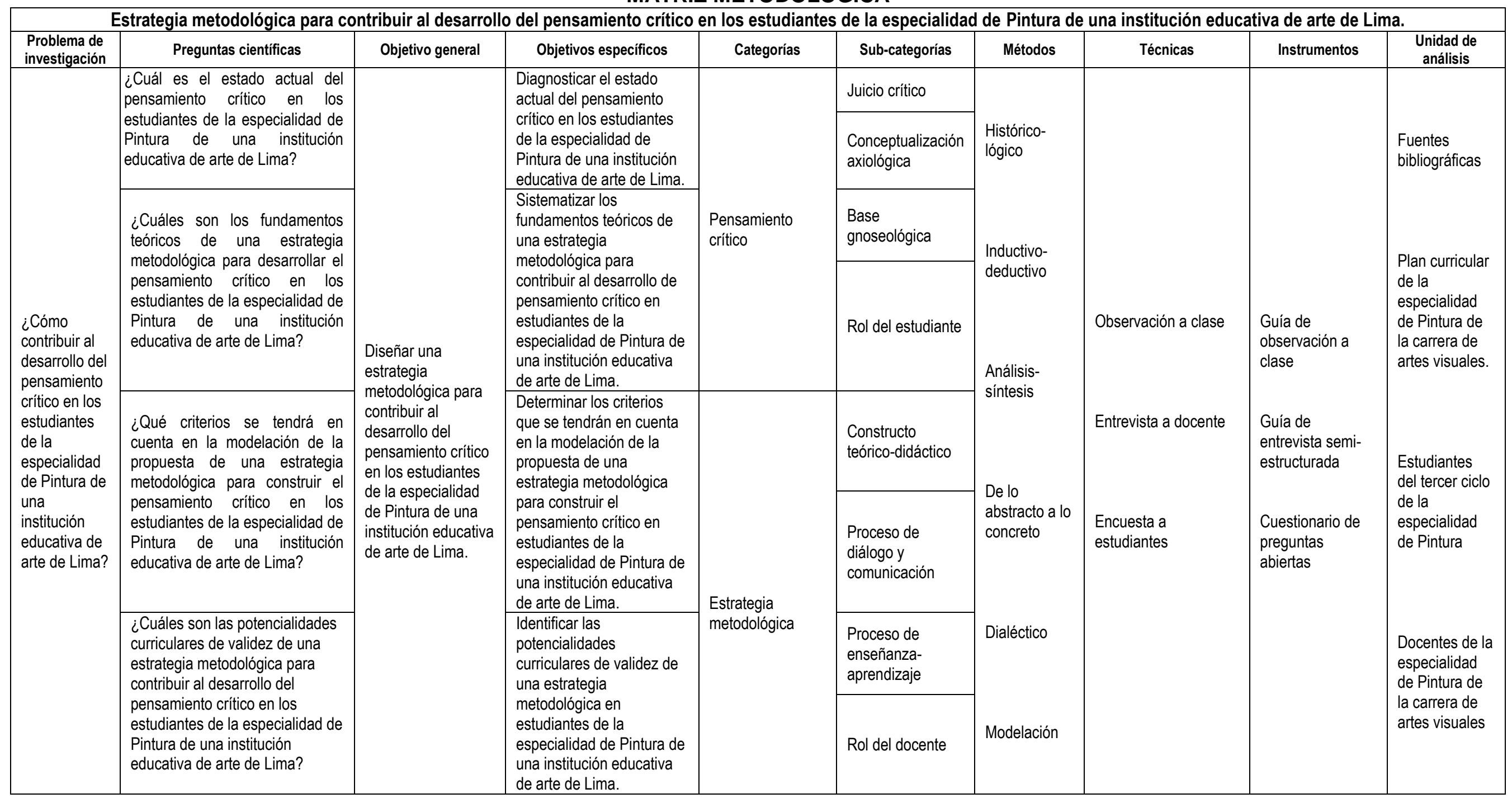




\section{MATRIZ DE CATEGORIZACIÓN}

Estrategia metodológica para contribuir al desarrollo del pensamiento crítico en los estudiantes de la especialidad de Pintura de una institución educativa de arte de Lima.

\begin{tabular}{|c|c|c|c|c|c|c|}
\hline $\begin{array}{l}\text { Problema de } \\
\text { investigación }\end{array}$ & Preguntas cientificas & $\begin{array}{l}\text { Objetivo } \\
\text { general }\end{array}$ & $\begin{array}{l}\text { Objetivos } \\
\text { especificos }\end{array}$ & Categorias principales & Subcategorias aprioristicas & Indicadores por subcategorias \\
\hline \multirow{24}{*}{ 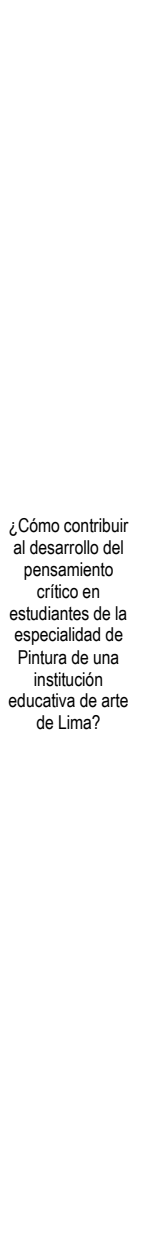 } & \multirow{6}{*}{$\begin{array}{l}\text { ¿Cuál es el estado } \\
\text { actual del pensamiento } \\
\text { crítico en los } \\
\text { estudiantes de la } \\
\text { especialidad de Pintura } \\
\text { de una institución } \\
\text { educativa de arte de } \\
\text { Lima? }\end{array}$} & \multirow{24}{*}{$\begin{array}{l}\text { Diseñar una } \\
\text { estrategia } \\
\text { metodologicaca } \\
\text { para contribuir } \\
\text { al desarrollo } \\
\text { del } \\
\text { pensamiento } \\
\text { critico en los } \\
\text { estudiantes de } \\
\text { la especialidad } \\
\text { de Pintura de } \\
\text { una institución } \\
\text { educativa de } \\
\text { arte de Lima. }\end{array}$} & \multirow{6}{*}{$\begin{array}{l}\text { Diagnosticar el estado } \\
\text { actual del } \\
\text { pensamiento oritico en } \\
\text { los estudiantes de la } \\
\text { especialidad de } \\
\text { Pintura de una } \\
\text { institucion educativa } \\
\text { de arte de Lima. }\end{array}$} & \multirow{12}{*}{ 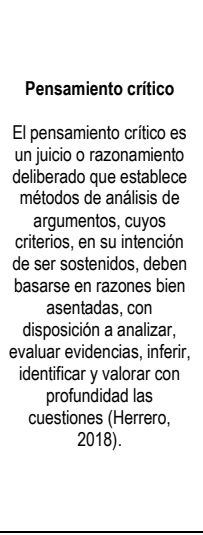 } & \multirow{3}{*}{ 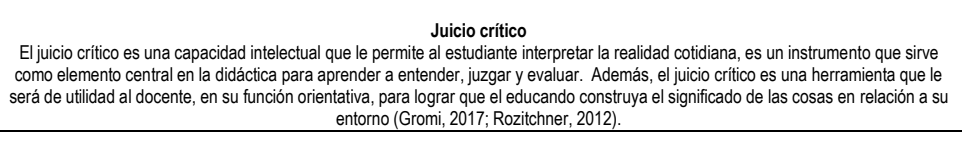 } & Interpreta I a realidad differenciando o 0 verdadero y $\mathrm{l}$ falso. \\
\hline & & & & & & Aprende entender, juzgar y evaluar los conocimientos adquiridos. \\
\hline & & & & & & Construye significados de los hechos y la relación con su entorno. \\
\hline & & & & & \multirow{3}{*}{ 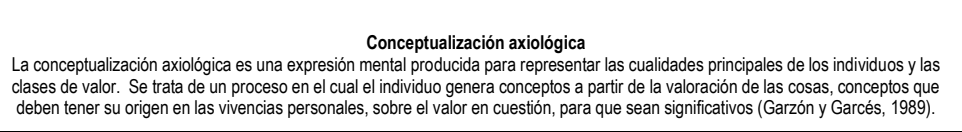 } & Desarrolla valores humanos para la comprensión de su contexto. \\
\hline & & & & & & Genera conceptos de valoración de las cosas para dar su debida importancia. \\
\hline & & & & & & Identifica valores significativos y relevantes para la interpretación de los fenómenos de su entorno. \\
\hline & \multirow{6}{*}{ 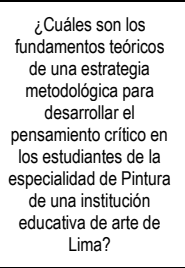 } & & \multirow{6}{*}{ 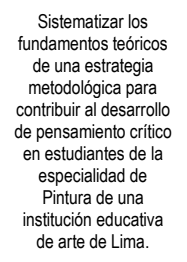 } & & \multirow{3}{*}{ 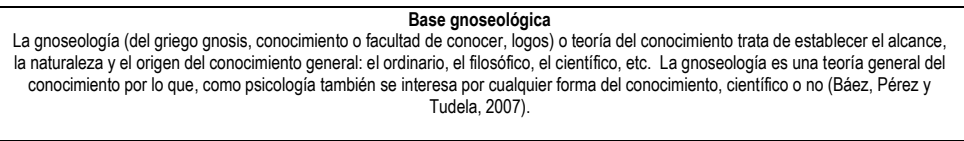 } & Construye soluciones a problemas en base a conocimientios sólidos. \\
\hline & & & & & & Conoce la naturaleza, el origen y los alcances de los conocimientos adquiridos. \\
\hline & & & & & & Adquiere todo tipo de conocimiento. \\
\hline & & & & & \multirow{3}{*}{ 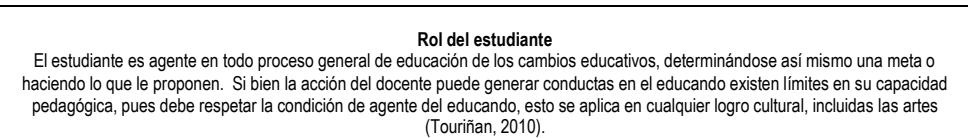 } & Desarrolla su proceso de aprendizaje determinándose metas. \\
\hline & & & & & & Expresa ideas concretas y acertadas y participa de la construcción de su conocimiento. \\
\hline & & & & & & Propone acciones para su formación como agente de cambio de su entorno. \\
\hline & \multirow{6}{*}{ 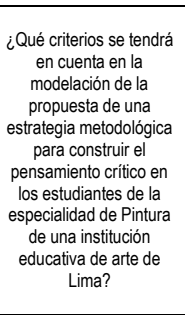 } & & \multirow{6}{*}{ 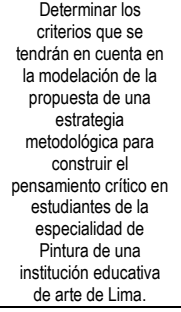 } & \multirow{12}{*}{ 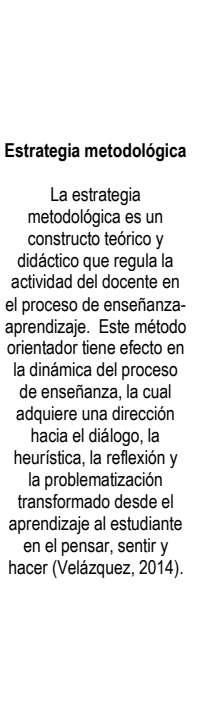 } & \multirow{3}{*}{ 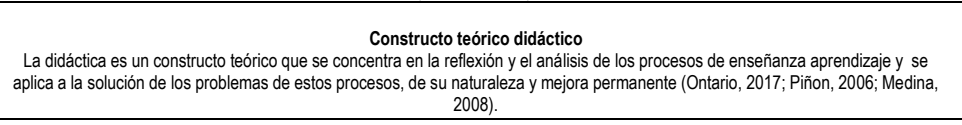 } & Usa herramientas didácticas para la elaboración de sus clases. \\
\hline & & & & & & Analiza el proceso de enseñanza aprendizaje para detectar problemas en este proceso. \\
\hline & & & & & & Propone soluciones y mejoras permanentes en el proceso de enseñanza y aprendizaje. \\
\hline & & & & & \multirow{3}{*}{ 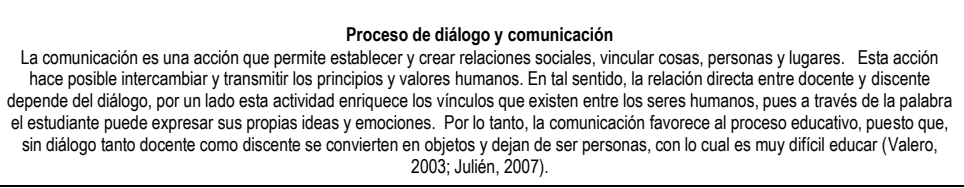 } & El docente promueve el diálogo y la comunicación en el aula. \\
\hline & & & & & & Propone intercambio de conocimientos, valores en el aula. \\
\hline & & & & & & Estimula el dialogo para que expresen sus propias ideas y emociones. \\
\hline & \multirow{6}{*}{ 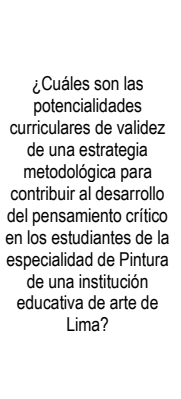 } & & \multirow{6}{*}{$\begin{array}{l}\text { Identificar las } \\
\text { potencialidades } \\
\text { curciculares devalidez } \\
\text { de una estrategia } \\
\text { metodologica en } \\
\text { estudiantel de la } \\
\text { especialidad de } \\
\text { Pintura de una } \\
\text { institución educativa } \\
\text { de arte de Lima. }\end{array}$} & & \multirow{3}{*}{ 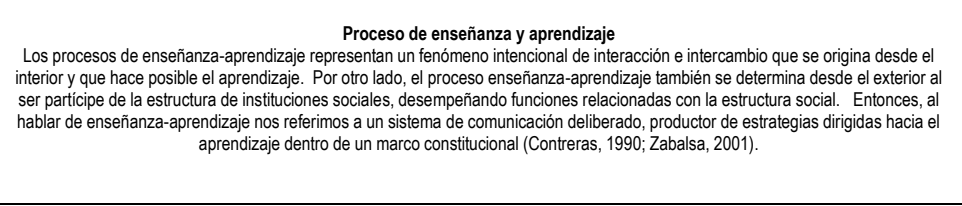 } & Interactúa con los estudiantes para un intercambio de conocimientios. \\
\hline & & & & & & Aplica métodos y estrategias que promueven el aprendizaje significativo. \\
\hline & & & & & & Promueve la investigación o producción de conocimientos. \\
\hline & & & & & \multirow{3}{*}{ 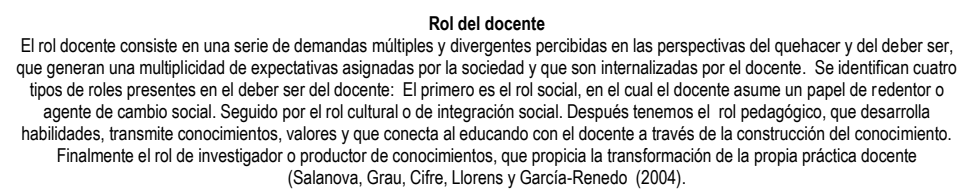 } & Asume el rol de agente de cambio social. \\
\hline & & & & & & Aplica métodos y estrategias que promueven el aprendizaje significativo. \\
\hline & & & & & & Promueve la investigación o producción de conocimientos. \\
\hline
\end{tabular}




\section{GUIA DE ENTREVISTA SEMI-ESTRUCTURADA}

\section{Datos Informativos:}

Entrevistador :

Lugar y Fecha :

Duración

Entrevistado :

Objetivo: Conocer el estado actual del pensamiento crítico, su enseñanza y aprendizaje de los estudiantes de la especialidad de pintura de una institución educativa de arte de Lima.

1. Además de la exposición del curso, es decir del temario pertinente. ¿Qué otras competencias o habilidades desarrolla en la sesión de clase durante el proceso enseñanza aprendizaje?

2. ¿De qué forma cree usted que se puede enseñar pensamiento crítico en la sesión de clase durante el proceso enseñanza aprendizaje?

3. ¿Cómo cree usted que fuera de la sesión de clase los alumnos pueden desarrollar pensamiento crítico o cree que solo el profesor puede desarrollarlo?

4. ¿Cree usted que es importante desarrollar el pensamiento crítico en los alumnos? ¿Por qué?

5. ¿De qué manera usted desarrolla valores humanos en la sesión de clase a través del curso que imparte?

6. ¿Cree usted que los estudiantes valoran, evalúan, juzgan e investigan conocimientos que usted les imparte en la sesión clase?

7. ¿Cómo promueve usted que los estudiantes expresen sus ideas de forma concreta y acertada participando en la construcción de los nuevos conocimiento?

8. ¿Qué soluciones o mejoras propone usted para mejorar el proceso de enseñanza aprendizaje del pensamiento crítico? 
9. ¿De qué manera usted promueve entre los estudiantes el diálogo y debate de ideas, emociones y soluciones sobre los problemas de la realidad educativa actual?

10. ¿Cómo desarrolla usted el debate, la investigación y las lecturas sobre actualidad política, social, cultural económica en la sesión de clase durante el proceso enseñanza aprendizaje?

11. ¿De las distintas metodologías didácticas que usted aplica para desarrollar pensamiento crítico en el estudiante durante la sesión de clase, cual le ofrece mejores resultados?

12. ¿Cómo usted fomenta las ideas en el estudiante como agente de cambio de la sociedad?

13. ¿Cree usted que los estudiantes reflexionan sobre los problemas de su entorno socio cultural y según lo aprendido buscan soluciones para ellos?

14. ¿Cree usted necesario que el estudiante adquiera todo tipo de conocimientos útiles para su vida cotidiana? ¿Por qué?

15. ¿Mediante qué estrategia metodológica usted detecta y resuelve los problemas que se presentan en la sesión de clase durante el proceso de enseñanza aprendizaje? 


\section{CUESTIONARIO A LOS ESTUDIANTES \\ PARA DETERMINAR EL NIVEL DE PENSAMIENTO CRÍTICO}

\section{Datos Informativos}

Nombre y Apellido

Institución Educativa

Grado / Sección

\section{Objetivo:}

Fecha:

Determinar las estrategias que usa el docente de la especialidad de pintura de una institución educativa de arte de Lima.

Estimado estudiante, la información que nos proveas en el siguiente cuestionario nos ayudará a determinar el nivel de desarrollo de pensamiento crítico en la especialidad de pintura de una institución educativa de arte de Lima, por lo que te pedimos que tus respuestas sean lo más sinceras posibles. Marca solo una de las alternativas de acuerdo a la tabla adjunta. Tienes 30 minutos.

\begin{tabular}{|c|c|c|c|c|}
\hline NUNCA & CASI NUNCA & A VECES & CASI SIEMPRE & SIEMPRE \\
\hline 1 & 2 & 3 & 4 & 5 \\
\hline
\end{tabular}

\begin{tabular}{|c|c|c|c|c|c|c|}
\hline & \multirow{3}{*}{ INDICADORES } & \multicolumn{5}{|c|}{ PUNTAJE } \\
\hline & & Nunca & $\begin{array}{c}\text { Casi } \\
\text { nunca }\end{array}$ & A veces & $\begin{array}{c}\text { Casi } \\
\text { siempre }\end{array}$ & Siempre \\
\hline & & 1 & 2 & 3 & 4 & 5 \\
\hline 1. & $\begin{array}{l}\text { ¿Consideras que el pensamiento crítico es una habilidad necesaria } \\
\text { para el artista plástico? }\end{array}$ & & & & & \\
\hline 2. & $\begin{array}{l}\text { ¿En las clases de taller de arte el profesor hace hincapié en el uso } \\
\text { de valores, juicio crítico, conocimiento, referentes e investigación? }\end{array}$ & & & & & \\
\hline 3. & $\begin{array}{l}\text { ¿El profesor impulsa interpretaciones de la realidad diferenciando lo } \\
\text { verdadero de los falso? }\end{array}$ & & & & & \\
\hline 4. & $\begin{array}{l}\text { ¿Entiendes, investigas y evalúas los conocimientos impartidos por } \\
\text { el profesor? }\end{array}$ & & & & & \\
\hline 5. & $\begin{array}{l}\text { ¿Los conocimientos adquiridos en la sesión de clase y las } \\
\text { propuestas artísticas están relacionadas con la construcción de } \\
\text { significados a partir de los hechos de tu medio sociocultural? }\end{array}$ & & & & & \\
\hline 6. & $\begin{array}{l}\text { ¿Los estudiantes construyen soluciones a los problemas propuestos } \\
\text { y de su entorno en base de conocimientos sólidos? }\end{array}$ & & & & & \\
\hline 7. & $\begin{array}{l}\text { ¿El profesor genera un análisis y valoración de su entorno } \\
\text { estimulando que sea parte de su propuesta artística? }\end{array}$ & & & & & \\
\hline 8. & $\begin{array}{l}\text { ¿El profesor motiva el uso de los referentes de su entorno en su } \\
\text { propuesta artística? }\end{array}$ & & & & & \\
\hline
\end{tabular}




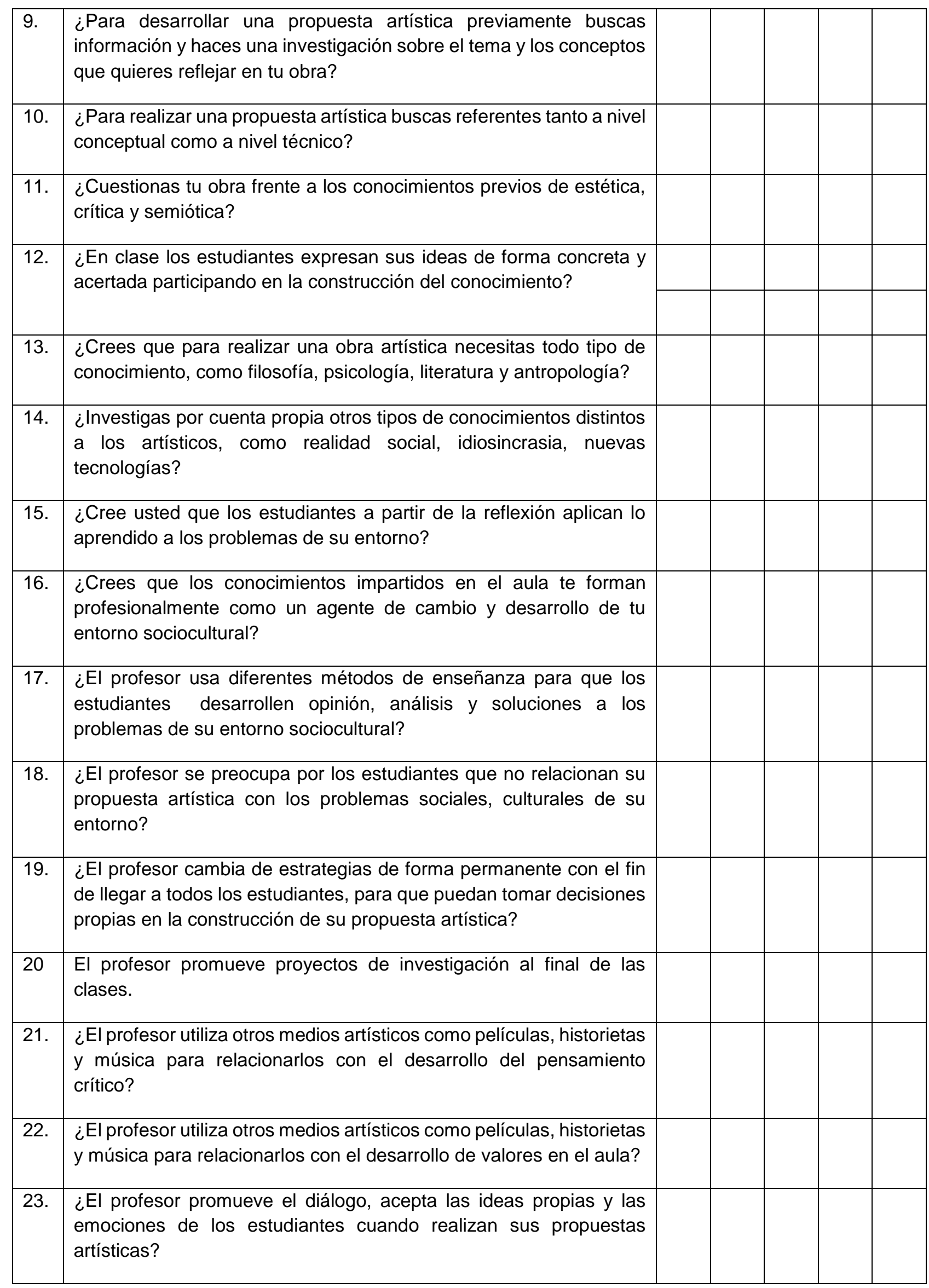




\begin{tabular}{|l|l|l|l|l|l|}
\hline 24. & $\begin{array}{l}\text { ¿El profesor promueve el trabajo en equipos y permite que los } \\
\text { estudiantes comuniquen y sustenten los resultados obtenidos en su } \\
\text { propuesta artística? }\end{array}$ & & & & \\
\hline 25. & $\begin{array}{l}\text { ¿El profesor interactúa con los estudiantes propiciando el } \\
\text { intercambio de información y aceptando la opinión de los } \\
\text { estudiantes? }\end{array}$ & $\begin{array}{l}\text { ¿El profesor promueve la creación de propuestas artísticas creativas } \\
\text { y novedosas basadas en conceptos tomados de su entorno real? }\end{array}$ & & & \\
\hline 26. & & & \\
\hline
\end{tabular}




\section{GUÍA DE OBSERVACIÓN DE UNA SESIÓN DE ENSEÑANZA APRENDIZAJE DEL CURSO DE PINTURA DEL TERCER CICLO}

\section{DATOS GENERALES:}

Observador:

Carrera: Ciclo:

Asignatura:

Tema de la sesión de clase:

Fecha: Horario:

OBJETIVO: Constatar la preparación teórica y didáctica que poseen los docentes sobre el desarrollo de pensamiento crítico en el proceso de enseñanza-aprendizaje en estudiantes de la especialidad de pintura de una institución educativa de arte de Lima.

\begin{tabular}{|l|l|}
\hline $\mathbf{N}^{\mathbf{0}}$ & \multicolumn{1}{|c|}{ ITEMS A OBSERVAR } \\
\hline & INICIO \\
\hline 1 & $\begin{array}{l}\text { Inicia con una situación problemica apoyándose en el uso de videos, multimedia, } \\
\text { una frase, una noticia una anécdota u otros, cuyo contenido se relaciona con el } \\
\text { contenido de la clase, movilizando los saberes previos de los estudiantes a través de } \\
\text { un sistema de preguntas logrando el interés y la motivación inicial. }\end{array}$ \\
\hline 2 & $\begin{array}{l}\text { El diálogo con los estudiantes permite estimular el conflicto cognitivo, a partir del } \\
\text { cual el docente orienta y precisa los objetivos de aprendizaje para la sesión de clase. }\end{array}$ \\
\hline & $\begin{array}{l}\text { DESARROLLO } \\
\text { El docente presenta el contenido demostrando dominio y el empleo de recursos } \\
\text { didácticos que facilitan el rol activo y participativo de los estudiantes que a través } \\
\text { del intercambio expresan libremente sus opiniones, preguntas o juicios respecto al } \\
\text { contenido. }\end{array}$ \\
\hline 4 & $\begin{array}{l}\text { Presenta una situación problémica y a través de preguntas va orientando las acciones } \\
\text { que deben realizar los estudiantes para fomentar el pensamiento crítico en las } \\
\text { propuestas artísticas a desarrollarse. }\end{array}$ \\
\hline $\begin{array}{l}\text { Para orientar a los estudiantes en la solución del problema, el docente explica los } \\
\text { pasos a seguir a través de ejemplos variados contextualizados en la práctica }\end{array}$ \\
\hline 5
\end{tabular}




\begin{tabular}{|c|c|}
\hline & $\begin{array}{l}\text { fesional, solicitando a los estudiantes sus opiniones, los cuales recib } \\
\text { roalimentación permanente. }\end{array}$ \\
\hline 6 & $\begin{array}{l}\text { Luego, presenta otros ejemplos con la finalidad de que los estudiantes asimilen y } \\
\text { comprendan el contenido y desarrollen las habilidades necesarias para lograr el } \\
\text { objetivo de aprendizaje para la sesión. }\end{array}$ \\
\hline 7 & $\begin{array}{l}\text { Seguidamente organiza una serie de actividades grupales con la finalidad de que los } \\
\text { estudiantes puedan aplicar el contenido tratado en clase de manera autónoma } \\
\text { orientados hacia la comprensión y a que apliquen acciones conceptuales, } \\
\text { procedimentales y actitudinales que contribuyen al desarrollo del pensamiento } \\
\text { crítico y al logro de los objetivos de aprendizaje. }\end{array}$ \\
\hline 8 & $\begin{array}{l}\text { El profesor explica la actividad y los criterios con los que serán evaluados los } \\
\text { estudiantes en la sesión de clase. }\end{array}$ \\
\hline 9 & $\begin{array}{l}\text { El profesor utiliza métodos de enseñanza que promueven el rol activo de los } \\
\text { estudiantes para estimular el desarrollo del pensamiento crítico en las propuestas } \\
\text { artísticas a presentar. }\end{array}$ \\
\hline 10 & $\begin{array}{l}\text { Durante la realización de las actividades, el docente fomenta el respeto a las } \\
\text { opiniones de los demás, el profesionalismo, la ética, el compromiso con la profesión, } \\
\text { la actividad creativa y el pensamiento crítico. }\end{array}$ \\
\hline & CIERRE \\
\hline 11 & $\begin{array}{l}\text { Los estudiantes exponen los resultados de los trabajos en equipos y el resto del aula emite } \\
\text { criterios de la calidad del trabajo presentado a través de la autoevaluación, coevaluación y } \\
\text { heteroevaluación. }\end{array}$ \\
\hline 12 & $\begin{array}{l}\text { El docente reconoce los procesos de las actividades y las tareas de aprendizaje, utilizando } \\
\text { un modelo de evaluación que estimula la la metacognición y autorregulación de los } \\
\text { estudiantes. }\end{array}$ \\
\hline 13 & $\begin{array}{l}\text { El profesor destaca los logros de la clase y las actitudes de los estudiantes y motiva a los } \\
\text { demás a seguir mejorando su aprendizaje con acciones concretas para cada equipo e } \\
\text { integrante. }\end{array}$ \\
\hline
\end{tabular}




\section{Ficha para la validación de los instrumentos}

\section{PROGRAMA ACADÉMICO DE MAESTRIA EN EDUCACIÓN EN MENCIÓN DOCENCIA EN EDUCACIÓN SUPERIOR \\ CARTA DE PRESENTACIÓN}

La Molina, 09 de febrero del 2019

\section{Señor:}

\section{Presente:}

Asunto: Validación de instrumento, por criterio de especialista

De mi especial consideración:

Es grato dirigirme a Usted, para expresarle un saludo cordial e informarle que como parte del desarrollo de la tesis del Programa Académico de Maestría en Educación con mención en Docencia en Educación Superior estoy desarrollando el avance de mi tesis titulada: Estrategia metodológica para desarrollar pensamiento crítico en estudiantes de pintura de la Escuela Nacional Superior Autónoma de Bellas Artes del Perú.

Motivo por el cual se hizo necesario la elaboración de una matriz de categorización, construcción del instrumento y ficha de validación.

Por lo expuesto, con la finalidad de darle rigor científico necesario, se requiere la validación de dichos instrumentos a través de la evaluación de Juicio de Expertos. Es por ello, que me permito solicitarle su participación como juez, apelando su trayectoria y reconocimiento como docente universitario y profesional.

Agradeciendo por anticipado su colaboración y aporte en la presente me despido de usted, no sin antes expresarle los sentimientos de consideración y estima personal.

Atentamente;

Gino Sessarego Díaz

PD. Se adjunta:

- Matriz de categorización

- Instrumentos de recolección de la información

- Ficha de validación de instrumento 


\section{CERTIFICADO DE VALIDEZ DE CONTENDO DE LA ENTREVISTA A DOCENTES}

\begin{tabular}{|c|c|c|c|c|c|c|c|c|c|}
\hline \multirow[t]{2}{*}{ № } & \multirow[t]{2}{*}{ Formulación del ítem } & \multicolumn{2}{|c|}{ Pertinencia $^{1}$} & \multicolumn{2}{|c|}{ Relevancia $^{2}$} & \multicolumn{2}{|c|}{$\begin{array}{c}\text { Construcción } \\
\text { gramatical }^{3}\end{array}$} & \multirow[t]{2}{*}{ Observaciones } & \multirow[t]{2}{*}{ Sugerencias } \\
\hline & & $\mathbf{S i}$ & No & $\mathbf{S i}$ & No & Si & No & & \\
\hline 1 & $\begin{array}{l}\text { Además de la exposición del curso, es decir del temario pertinente. ¿Qué } \\
\text { otras competencias o habilidades desarrolla en la sesión de clase durante } \\
\text { el proceso enseñanza aprendizaje? }\end{array}$ & & & & & & & & \\
\hline 2 & $\begin{array}{l}\text { ¿De qué forma cree usted que se puede enseñar pensamiento crítico en } \\
\text { la sesión de clase durante el proceso enseñanza aprendizaje? }\end{array}$ & & & & & & & & \\
\hline 3 & $\begin{array}{l}\text { ¿Cómo cree usted que fuera de la sesión de clase los alumnos pueden } \\
\text { desarrollar pensamiento crítico o cree que solo el profesor puede } \\
\text { desarrollarlo? }\end{array}$ & & & & & & & & \\
\hline 4 & $\begin{array}{l}\text { ¿Cree usted que es importante desarrollar el pensamiento crítico en los } \\
\text { alumnos? ¿Por qué? }\end{array}$ & & & & & & & & \\
\hline 5 & $\begin{array}{l}\text { ¿De qué manera usted desarrolla valores humanos en la sesión de clase } \\
\text { a través del curso que imparte? }\end{array}$ & & & & & & & & \\
\hline 6 & $\begin{array}{l}\text { ¿Cree usted que los estudiantes valoran, evalúan, juzgan e investigan } \\
\text { conocimientos que usted les imparte en la sesión clase? }\end{array}$ & & & & & & & & \\
\hline 7 & $\begin{array}{l}\text { ¿Cómo promueve usted que los estudiantes expresen sus ideas de forma } \\
\text { concreta y acertada participando en la construcción de los nuevos } \\
\text { conocimiento? }\end{array}$ & & & & & & & & \\
\hline 8 & $\begin{array}{l}\text { ¿Qué soluciones o mejoras propone usted para mejorar el proceso de } \\
\text { enseñanza aprendizaje del pensamiento crítico? }\end{array}$ & & & & & & & & \\
\hline 9 & $\begin{array}{l}\text { ¿De qué manera usted promueve entre los estudiantes el diálogo y debate } \\
\text { de ideas, emociones y soluciones sobre los problemas de la realidad } \\
\text { educativa actual? }\end{array}$ & & & & & & & & \\
\hline 10 & $\begin{array}{l}\text { ¿Cómo desarrolla usted el debate, la investigación y las lecturas sobre } \\
\text { actualidad política, social, cultural económica en la sesión de clase } \\
\text { durante el proceso enseñanza aprendizaje? }\end{array}$ & & & & & & & & \\
\hline 11 & $\begin{array}{l}\text { ¿De las distintas metodologías didácticas que usted aplica para } \\
\text { desarrollar pensamiento crítico en el estudiante durante la sesión de clase, } \\
\text { cual le ofrece mejores resultados? }\end{array}$ & & & & & & & & \\
\hline 12 & $\begin{array}{l}\text { ¿Cómo usted fomenta las ideas en el estudiante como agente de cambio } \\
\text { de la sociedad? }\end{array}$ & & & & & & & & \\
\hline 13 & ¿Cree usted que los estudiantes reflexionan sobre los problemas de su & & & & & & & & \\
\hline
\end{tabular}




\begin{tabular}{|l|l|l|l|l|l|l|}
\hline & entorno socio cultural y según lo aprendido buscan soluciones para ellos? & & & & & \\
\hline 14 & $\begin{array}{l}\text { ¿Cree usted necesario que el estudiante adquiera todo tipo de } \\
\text { conocimientos útiles para su vida cotidiana? ¿Por qué? }\end{array}$ & & & & & \\
\hline 15 & $\begin{array}{l}\text { ¿Mediante qué estrategia metodológica usted detecta y resuelve los } \\
\text { problemas que se presentan en la sesión de clase durante el proceso de } \\
\text { enseñanza aprendizaje? }\end{array}$ & & & & & \\
\hline
\end{tabular}

OPINIÓN DE APLICABILIDAD DE LA ENTREVISTA:

Observaciones (precisar si hay suficiencia):

Opinión de aplicabilidad: Aplicable [ ]

\section{Aplicable después de corregir [ ]}

No aplicable [ ]

\begin{tabular}{|l|l|l|l|}
\hline Nombres y Apellidos & & DNI No & \\
\hline Dirección domiciliaria & & Teléfono / Celular & \\
\hline $\begin{array}{l}\text { Título profesional / } \\
\text { Especialidad }\end{array}$ & \multirow{2}{*}{ Firma } & \\
\hline Grado Académico & & & \\
\hline Metodólogo/ temático & & Lugar y fecha & \\
\hline
\end{tabular}

1Pertinencia: El ítem corresponde al concepto teórico formulado.

${ }^{2}$ Relevancia: El ítem es apropiado para representar al componente o dimensión específica del constructo

${ }^{3}$ Claridad: Se entiende sin dificultad alguna el enunciado del ítem, es conciso, exacto y directo

Nota: Suficiencia, se dice suficiencia cuando los ítems planteados son suficientes para medir la dimensión 


\section{CERTIFICADO DE VALIDEZ DE CONTENDO DEL CUESTIONARIO TOMADO A ESTUDIANTES}

\begin{tabular}{|c|c|c|c|c|c|c|c|c|c|}
\hline \multirow[t]{2}{*}{ № } & \multirow[t]{2}{*}{ Formulación del ítem } & \multicolumn{2}{|c|}{ Pertinencia $_{1}$} & \multicolumn{2}{|c|}{ Relevancia $^{2}$} & \multicolumn{2}{|c|}{$\begin{array}{c}\text { Construcción } \\
\text { gramatical }^{3}\end{array}$} & \multirow[t]{2}{*}{ Observaciones } & \multirow[t]{2}{*}{ Sugerencias } \\
\hline & & Si & No & Si & No & Si & No & & \\
\hline 1 & $\begin{array}{l}\text { ¿Consideras que el pensamiento crítico es una habilidad necesaria para } \\
\text { el artista plástico? }\end{array}$ & & & & & & & & \\
\hline 2 & $\begin{array}{l}\text { ¿En las clases de taller de arte el profesor hace hincapié en el uso de } \\
\text { valores, juicio crítico, conocimiento, referentes e investigación? }\end{array}$ & & & & & & & & \\
\hline 3 & $\begin{array}{l}\text { ¿El profesor impulsa interpretaciones de la realidad diferenciando lo } \\
\text { verdadero de los falso? }\end{array}$ & & & & & & & & \\
\hline 4 & $\begin{array}{l}\text { ¿Entiendes, investigas y evalúas los conocimientos impartidos por el } \\
\text { profesor? }\end{array}$ & & & & & & & & \\
\hline 5 & $\begin{array}{l}\text { ¿Los conocimientos adquiridos en la sesión de clase y las propuestas } \\
\text { artísticas están relacionadas con la construcción de significados a partir } \\
\text { de los hechos de tu medio sociocultural? }\end{array}$ & & & & & & & & \\
\hline 6 & $\begin{array}{l}\text { ¿Los estudiantes construyen soluciones a los problemas propuestos y de } \\
\text { su entorno en base de conocimientos sólidos? }\end{array}$ & & & & & & & & \\
\hline 7 & $\begin{array}{l}\text { ¿El profesor genera un análisis y valoración de su entorno estimulando } \\
\text { que sea parte de su propuesta artística? }\end{array}$ & & & & & & & & \\
\hline 8 & $\begin{array}{l}\text { ¿El profesor motiva el uso de los referentes de su entorno en su propuesta } \\
\text { artística? }\end{array}$ & & & & & & & & \\
\hline 9 & $\begin{array}{l}\text { ¿Para desarrollar una propuesta artística previamente buscas información } \\
\text { y haces una investigación sobre el tema y los conceptos que quieres } \\
\text { reflejar en tu obra? }\end{array}$ & & & & & & & & \\
\hline 10 & $\begin{array}{l}\text { ¿Para realizar una propuesta artística buscas referentes tanto a nivel } \\
\text { conceptual como a nivel técnico? }\end{array}$ & & & & & & & & \\
\hline 11 & $\begin{array}{l}\text { ¿Cuestionas tu obra frente a los conocimientos previos de estética, crítica } \\
\text { y semiótica? }\end{array}$ & & & & & & & & \\
\hline 12 & $\begin{array}{l}\text { ¿En clase los estudiantes expresan sus ideas de forma concreta y } \\
\text { acertada participando en la construcción del conocimiento? }\end{array}$ & & & & & & & & \\
\hline 13 & $\begin{array}{l}\text { ¿Crees que para realizar una obra artística necesitas todo tipo de } \\
\text { conocimiento, como filosofía, psicología, literatura y antropología? }\end{array}$ & & & & & & & & \\
\hline
\end{tabular}


14 ¿lnvestigas por cuenta propia otros tipos de conocimientos distintos a los artísticos, como realidad social, idiosincrasia, nuevas tecnologías?

15 ¿Cree usted que los estudiantes a partir de la reflexión aplican lo aprendido a los problemas de su entorno?

¿Crees que los conocimientos impartidos en el aula te forman

16 profesionalmente como un agente de cambio y desarrollo de tu entorno sociocultural?

¿El profesor usa diferentes métodos de enseñanza para que los 17 estudiantes desarrollen opinión, análisis y soluciones a los problemas de su entorno sociocultural?

${ }_{18}$ ¿El profesor se preocupa por los estudiantes que no relacionan su propuesta artística con los problemas sociales, culturales de su entorno? ¿El profesor cambia de estrategias de forma permanente con el fin de

19 llegar a todos los estudiantes, para que puedan tomar decisiones propias en la construcción de su propuesta artística?

20 El profesor promueve proyectos de investigación al final de las clases.

21 ¿El profesor utiliza otros medios artísticos como películas, historietas y música para relacionarlos con el desarrollo del pensamiento crítico?

22 ¿El profesor utiliza otros medios artísticos como películas, historietas y música para relacionarlos con el desarrollo de valores en el aula?

23 ¿El profesor promueve el diálogo, acepta las ideas propias y las emociones de los estudiantes cuando realizan sus propuestas artísticas? $¿$ El profesor promueve el trabajo en equipos y permite que los estudiantes comuniquen y sustenten los resultados obtenidos en su propuesta artística?

25

¿El profesor interactúa con los estudiantes propiciando el intercambio de información y aceptando la opinión de los estudiantes?

26

¿El profesor promueve la creación de propuestas artísticas creativas novedosas basadas en conceptos tomados de su entorno real?

\begin{tabular}{|l|l|l|l|l|l|l|l|}
\hline & & & & & & & \\
\hline \\
\hline$y$
\end{tabular}


OPINIÓN DE APLICABILIDAD DEL CUESTIONARIO:

Observaciones (precisar si hay suficiencia):.

Opinión de aplicabilidad: Aplicable [ ]

Aplicable después de corregir [ ]

No aplicable [ ]

\begin{tabular}{|l|l|l|l|}
\hline Nombres y Apellidos & & DNI No & \\
\hline Dirección domiciliaria & & Teléfono / Celular & \\
\hline $\begin{array}{l}\text { Título profesional / } \\
\text { Especialidad }\end{array}$ & \multirow{2}{*}{ Firma } & \\
\hline Grado Académico & & & \\
\hline Metodólogo/ temático & Lugar y fecha & \\
\hline
\end{tabular}

1Pertinencia: El ítem corresponde al concepto teórico formulado.

${ }^{2}$ Relevancia: El ítem es apropiado para representar al componente o dimensión específica del constructo

${ }^{3}$ Claridad: Se entiende sin dificultad alguna el enunciado del ítem, es conciso, exacto y directo

Nota: Suficiencia, se dice suficiencia cuando los ítems planteados son suficientes para medir la dimensión 


\section{CERTIFICADO DE VALIDEZ DE CONTENDO DE LA OBSERVACIÓN DE CLASE}

\begin{tabular}{|c|c|c|c|c|c|c|c|c|c|}
\hline \multirow[t]{2}{*}{ № } & \multirow[t]{2}{*}{ Formulación del ítem } & \multicolumn{2}{|c|}{ Pertinencia $^{1}$} & \multicolumn{2}{|c|}{ Relevancia $^{2}$} & \multicolumn{2}{|c|}{$\begin{array}{c}\text { Construcción } \\
\text { gramatical }^{3}\end{array}$} & \multirow[t]{2}{*}{ Observaciones } & \multirow[t]{2}{*}{ Sugerencias } \\
\hline & & $\mathbf{S i}$ & No & $\mathbf{S i}$ & No & Si & No & & \\
\hline 1 & $\begin{array}{l}\text { Inicia con una situación problémica apoyándose en el uso de videos, } \\
\text { multimedia, una frase, una noticia una anécdota u otros, cuyo contenido } \\
\text { se relaciona con el contenido de la clase, movilizando los saberes } \\
\text { previos de los estudiantes a través de un sistema de preguntas logrando } \\
\text { el interés y la motivación inicial. }\end{array}$ & & & & & & & & \\
\hline 2 & $\begin{array}{l}\text { El diálogo con los estudiantes permite estimular el conflicto cognitivo, a } \\
\text { partir del cual el docente orienta y precisa los objetivos de aprendizaje } \\
\text { para la sesión de clase. }\end{array}$ & & & & & & & & \\
\hline 3 & $\begin{array}{l}\text { El docente presenta el contenido demostrando dominio y el empleo de } \\
\text { recursos didácticos que facilitan el rol activo y participativo de los } \\
\text { estudiantes que a través del intercambio expresan libremente sus } \\
\text { opiniones, preguntas o juicios respecto al contenido. }\end{array}$ & & & & & & & & \\
\hline 4 & $\begin{array}{l}\text { Presenta una situación problémica y a través de preguntas va orientando } \\
\text { las acciones que deben realizar los estudiantes para fomentar el } \\
\text { pensamiento crítico en las propuestas artísticas a desarrollarse. }\end{array}$ & & & & & & & & \\
\hline 5 & $\begin{array}{l}\text { Para orientar a los estudiantes en la solución del problema, el docente } \\
\text { explica los pasos a seguir a través de ejemplos variados } \\
\text { contextualizados en la práctica profesional, solicitando a los estudiantes } \\
\text { sus opiniones, los cuales reciben retroalimentación permanente. }\end{array}$ & & & & & & & & \\
\hline
\end{tabular}




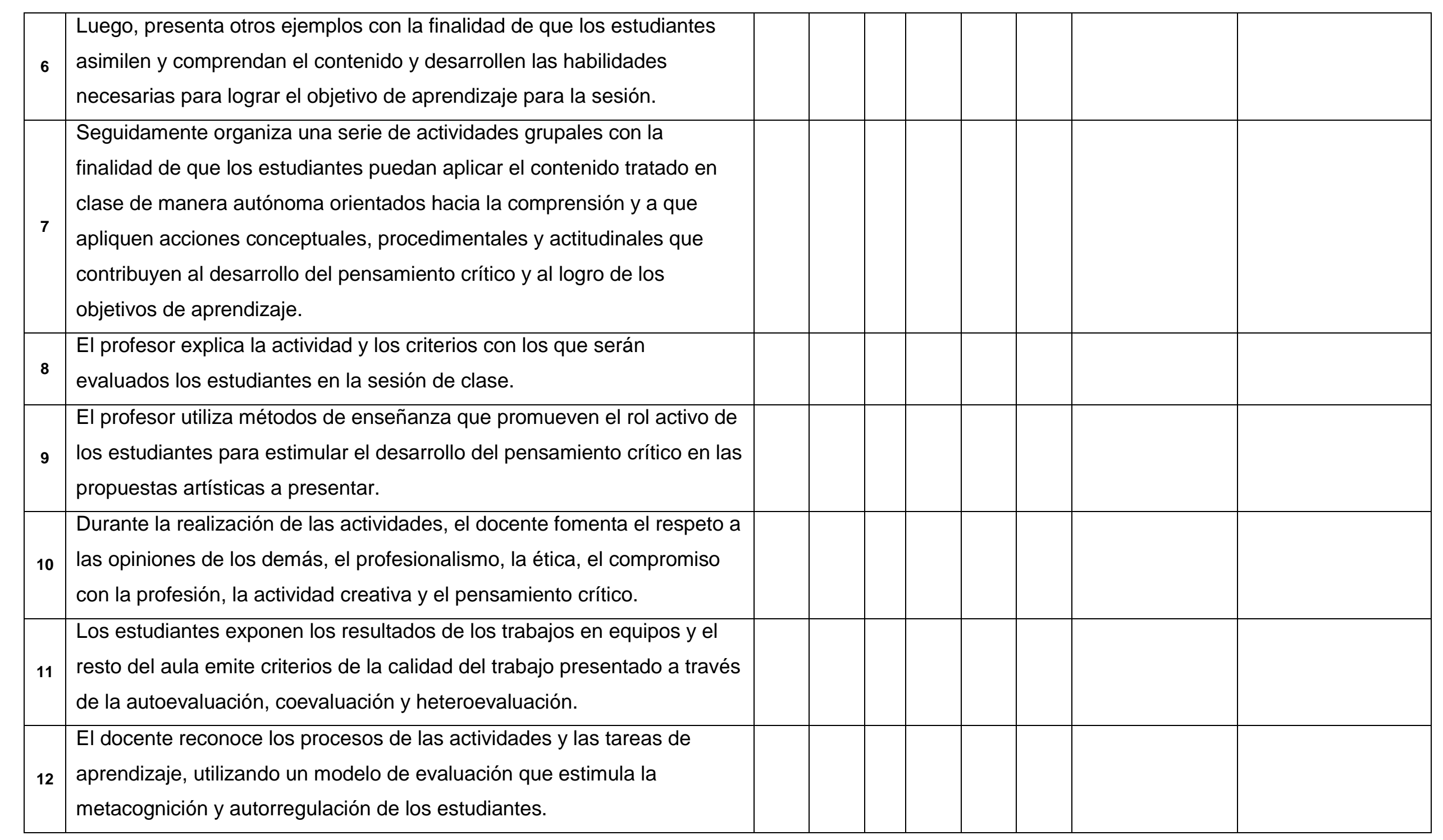


El profesor destaca los logros de la clase y las actitudes de los

estudiantes y motiva a los demás a seguir mejorando su aprendizaje

con acciones concretas para cada equipo e integrante.

\section{OPINIÓN DE APLICABILIDAD DE LA OBSERVACION:}

Observaciones (precisar si hay suficiencia):

Opinión de aplicabilidad: Aplicable [ ]

Aplicable después de corregir [ ]

No aplicable [ ]

\begin{tabular}{|l|l|l|l|}
\hline Nombres y Apellidos & DNI No & \\
\hline Dirección domiciliaria & & Teléfono / Celular & \\
\hline Título profesional / & & \multirow{2}{*}{ Firma } \\
\cline { 1 - 3 } Grado Académico & & & \\
\hline Metodólogo/ temático & Lugar y fecha & \\
\hline
\end{tabular}

1Pertinencia: El ítem corresponde al concepto teórico formulado.

${ }^{2}$ Relevancia: El ítem es apropiado para representar al componente o dimensión específica del constructo

${ }^{3}$ Claridad: Se entiende sin dificultad alguna el enunciado del ítem, es conciso, exacto y directo

Nota: Suficiencia, se dice suficiencia cuando los ítems planteados son suficientes para medir la dimensión. 


\section{Validación de instrumentos}

\section{Especialista 1}

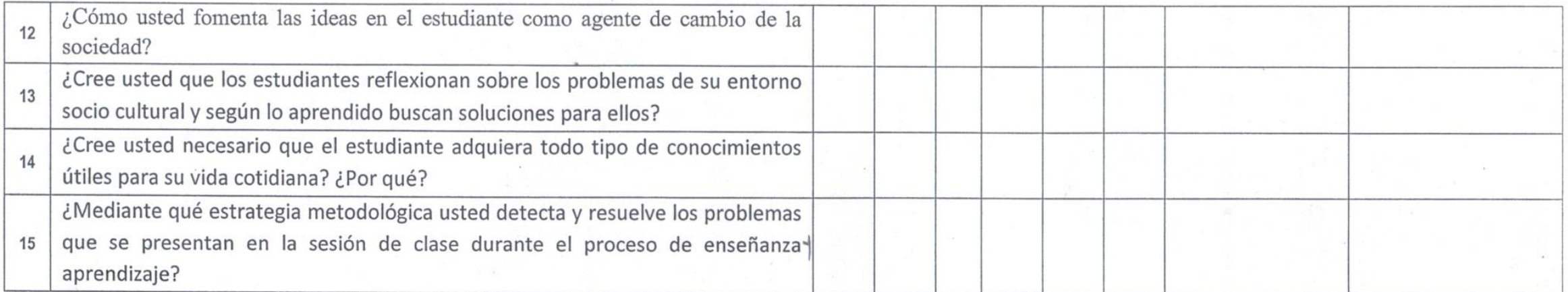

\section{OPINIÓN DE APLICABILIDAD DE LA ENTREVISTA:}

Observaciones (precisar si hay suficiencia):

Opinión de aplicabilidad: $\quad$ Aplicable $[/ \quad$ Aplicable después de corregir 5 No aplicable [ ]

\begin{tabular}{|c|c|c|c|}
\hline Nombres y Apellidos & Maria Teresa Herrera Montoya & $\mathrm{DNIN}^{\circ}$ & 25600207 \\
\hline Dirección domiciliaria & Av. Ricardo Palmo 636 San foaquen & Teléfono / Celular & 966948837 \\
\hline $\begin{array}{l}\text { Título profesional / } \\
\text { Especialidad }\end{array}$ & Lic Educación & Firma & \\
\hline Grado Académico & Ma Psico pedagogía. & & \\
\hline Metodólogo/ temático & 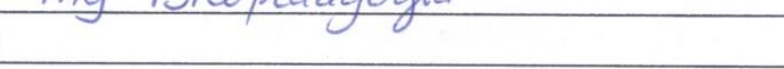 & Lugar y fecha & La Molino 76 feb 2019 \\
\hline
\end{tabular}

1Pertinencia: El item corresponde al concepto teórico formulado.

2Relevancia: El item es apropiado para representar al componente o dimensión específica del constructo

${ }^{3}$ Claridad: Se entiende sin dificultad alguna el enunciado del item, es conciso, exacto y directo

Nota: Suficiencia, se dice suficiencia cuando los ítems planteados son suficientes para medir la dimensión 
${ }_{26}$ ¿El profesor promueve la creación de propuestas artísticas creativas y novedosas

basadas en conceptos tomados de su entorno real?

\section{OPINIÓN DE APLICABILIDAD DEL CUESTIONARIO:}

Observaciones (precisar si hay suficiencia):

\section{Opinión de aplicabilidad: $\quad$ Aplicable $[-$ ] Aplicable después de corregir [}

\begin{tabular}{|c|c|c|c|}
\hline Nombres y Apellidos & ManaTeresa Iterrera Montoyg & DNI N ${ }^{\circ}$ & 25600207 \\
\hline Dirección domiciliaria & Av. Ricardo Palma 636 San foaquin & Teléfono / Celular & 966948837 \\
\hline $\begin{array}{l}\text { Título profesional / } \\
\text { Especialidad }\end{array}$ & Lie Educacion & Firma & \\
\hline Grado Académico & Mg Psicopedagogia & & \\
\hline Metodólogo/ temático & 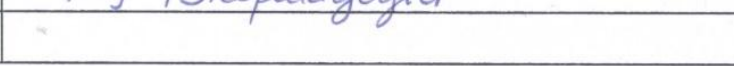 & Lugar y fecha & La Medina \\
\hline
\end{tabular}

1Pertinencia: El item corresponde al concepto teórico formulado.

${ }^{2}$ Relevancia: El item es apropiado para representar al componente o dimensión especifica del constructo

${ }^{3}$ Claridad: Se entiende sin dificultad alguna el enunciado del item, es conciso, exacto y directo

Nota: Suiiciencia, se dice suficiencia cuando los ítems planteados son suficientes para medir la dimensión 


\section{OPINIÓN DE APLICABILIDAD DE LA OBSERVACIÓN:}

Observaciones (precisar si hay suficiencia):

\section{Opinión de aplicabilidad: Aplicable [ $\quad$ Aplicable después de corregir [ ] No aplicable [ ]}

\begin{tabular}{|c|c|c|c|}
\hline Nombres y Apellidos & Maria Tenesa Herrera Montoyo & $\mathrm{DNIN}^{\circ}$ & 25600207 \\
\hline Dirección domiciliaria & Ar. Rucardo Palmo 636 San poaquen & Teléfono / Celular & 966948837 \\
\hline $\begin{array}{l}\text { Título profesional / } \\
\text { Especialidad }\end{array}$ & Lic iducación & Firma & \\
\hline Grado Académico & Mag Psicopedagogio. & & \\
\hline Metodólogo/ temático & ing of & Lugar y fecha & La Molina 16 Febro's \\
\hline
\end{tabular}

1Pertinencia: El item corresponde al concepto teórico formulado.

Relevancia: El ítem es apropiado para representar al componente o dimensión especifica del constructo

${ }^{3}$ Claridad: Se entiende sin dificultad alguna el enunciado del ítem, es conciso, exacto y directo

Nota: Suficiencia, se dice suficiencia cuando los ítems planteados son suficientes para medir la dimensión 


\section{Especialista 2}

\section{Validación de instrumentos}

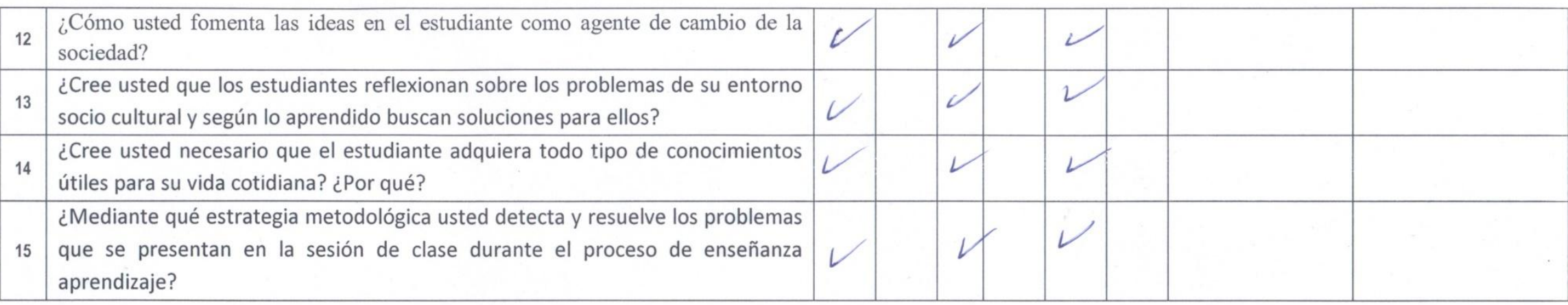

\section{OPINIÓN DE APLICABILIDAD DE LA ENTREVISTA:}

Observaciones (precisar si hay suficiencia): ..................................................

Opinión de aplicabilidad: Aplicable [X] Aplicable después de corregir [ ] No aplicable [ ]

\begin{tabular}{|c|c|c|c|}
\hline Nombres y Apellidos & Tosedlaniol dentó falazar & $\mathrm{DNIN}^{\circ}$ & $04536) 83$ \\
\hline Dirección domiciliaria & & Teléfono / Celular & \\
\hline $\begin{array}{l}\text { Título profesional / } \\
\text { Especialidad }\end{array}$ & & Firma & \\
\hline Grado Académico & 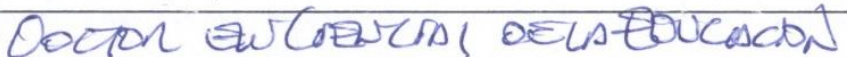 & & \\
\hline Metodólogo/ temático & & Lugar y fecha & \\
\hline
\end{tabular}

'Pertinencia: El item corresponde al concepto teórico formulado.

${ }^{2}$ Relevancia: El item es apropiado para representar al componente o dimensión específica del constructo

${ }^{3}$ Claridad: Se entiende sin dificultad alguna el enunciado del ítem, es conciso, exacto y directo

Nota: Suficiencia, se dice suficiencia cuando los items planteados son suficientes para medir la dimensión 


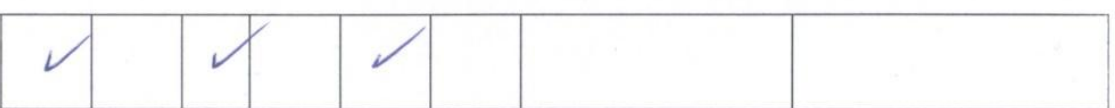

\section{OPINIÓN DE APLICABILIDAD DEL CUESTIONARIO:}

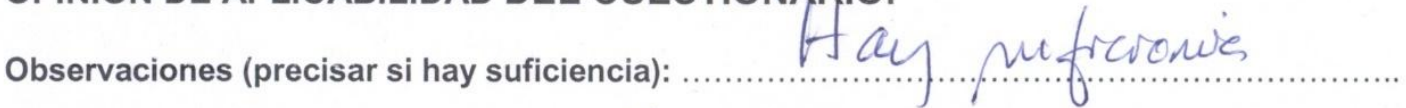

Opinión de aplicabilidad: Aplicable [ $\quad$ Aplicable después de corregir [ ] No aplicable [ ]

\begin{tabular}{|c|c|c|c|}
\hline Nombres y Apellidos & 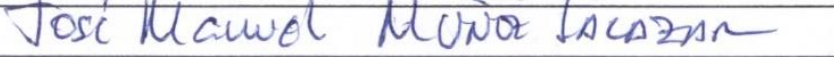 & DNI N ${ }^{\circ}$ & 04536753 \\
\hline Dirección domiciliaria & & Teléfono / Celular & \\
\hline Título profesional / & & & \\
\hline Especialidad & & Firma & \\
\hline Grado Académico & Doctorea liencialoe la elúcadon & & \\
\hline Metodólogo/ temático & & Lugar y fecha & \\
\hline
\end{tabular}

1Pertinencia: El item corresponde al concepto teórico formulado.

2Relevancia: El ítem es apropiado para representar al componente o dimensión especifica del constructo

${ }^{3}$ Claridad: Se entiende sin dificultad alguna el enunciado del item, es conciso, exacto y directo

Nota: Suficiencia, se aice suficiencia cuando los items planteados son suficientes para medir la dimensión 


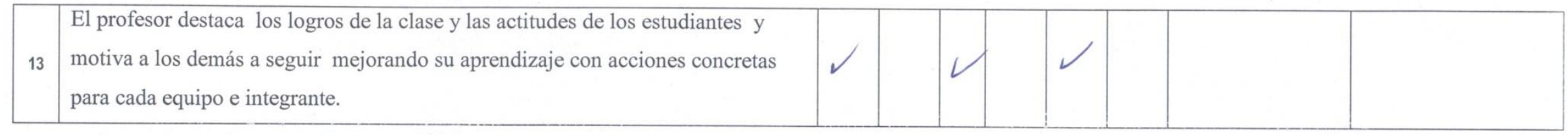

\section{OPINIÓN DE APLICABILIDAD DE LA OBSERVACIÓN:}

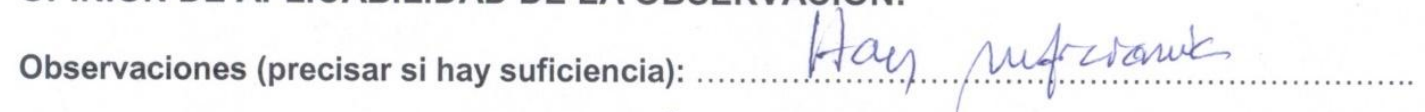

Opinión de aplicabilidad: Aplicable [ 1 Aplicable después de corregir [ ] No aplicable [ ]

\begin{tabular}{|c|c|c|c|}
\hline Nombres y Apellidos & Jose MunNol Mundoz falatar & $\mathrm{DNIN}^{\circ}$ & 04536753 \\
\hline Dirección domiciliaria & & Teléfono / Celular & \\
\hline $\begin{array}{l}\text { Título profesional / } \\
\text { Especialidad }\end{array}$ & & Firma & \\
\hline Grado Académico & coctonen ContedAs de ca Garcactow & & \\
\hline Metodólogo/ temático & & Lugar y fecha & \\
\hline
\end{tabular}

'Pertinencia: El item corresponde al concepto teórico formulado.

2Relevancia: El item es apropiado para representar al componente o dimensión especifica del constructo

${ }^{3}$ Claridad: Se entiende sin dificultad alguna el enunciado del item, es conciso, exacto y directo

Nota: Suficiencia, se dice suficiencia cuando los ítems planteados son suficientes para medir la dimensión 


\section{Especialista 3}

\section{Validación de instrumentos}

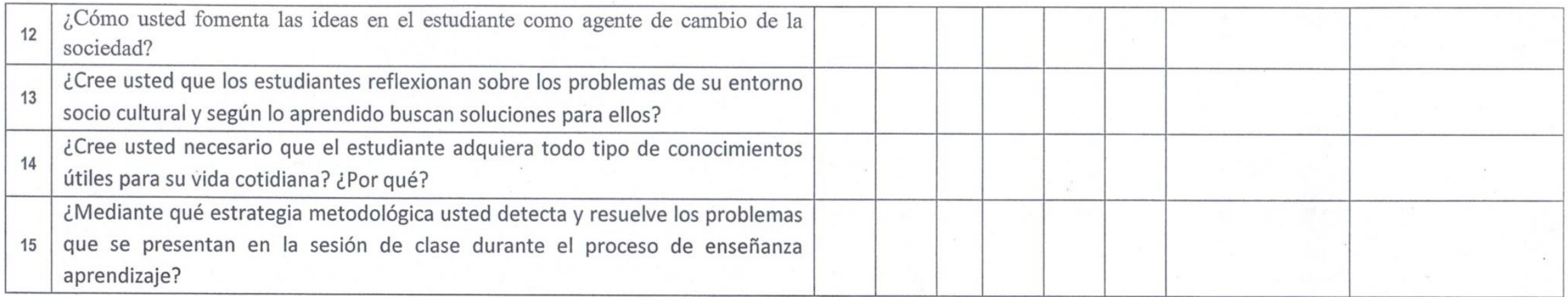

\section{OPINIÓN DE APLICABILIDAD DE LA ENTREVISTA:}

Observaciones (precisar si hay suficiencia):

Opinión de aplicabilidad: Aplicable [ ] Aplicable después de corregir [ ] No aplicable [ ]

\begin{tabular}{|c|c|c|c|}
\hline Nombres y Apellidos & Mirian \&. Nel'zagn Tucda & $\mathrm{DNIN}^{\circ}$ & aro 85 80 24 \\
\hline Dirección domiciliaria & $x<14 \pi$ & Teléfono / Celular & 991766522 \\
\hline $\begin{array}{l}\text { Título profesional / } \\
\text { Especialidad }\end{array}$ & & Firma & \\
\hline Grado Académico & 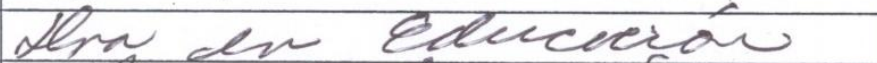 & & \\
\hline Metodólogo/ temático & Diserapedergogéa & Lugar y fecha & Linew $12-2-2019$ \\
\hline
\end{tabular}

1Pertinencia: El item corresponde al concepto teórico formulado.

${ }^{2}$ Relevancia: El ítem es apropiado para representar al componente o dimensión específica del constructo

${ }^{3}$ Claridad: Se entiende sin dificultad alguna el enunciado del ítem, es conciso, exacto y directo

Nota: Suficiencia, se dice suficiencia cuando los ítems planteados son suficientes para medir la dimensión 


\section{OPINIÓN DE APLICABILIDAD DEL CUESTIONARIO:}

Observaciones (precisar si hay suficiencia):

Opinión de aplicabilidad: $\quad$ Aplicable [๔] Aplicable después de corregir [ ] No aplicable [ ]

\begin{tabular}{|c|c|c|c|}
\hline Nombres y Apellidos & 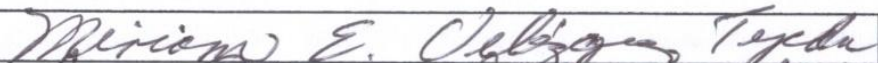 & $\mathrm{DNIN}^{\circ}$ & 908858024 \\
\hline Dirección domiciliaria & 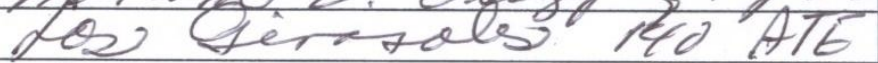 & Teléfono / Celular & 991766522 \\
\hline $\begin{array}{l}\text { Título profesional / } \\
\text { Especialidad }\end{array}$ & ( & Firma & \\
\hline Grado Académico & Hoctin un Edcucreañ & & \\
\hline Metodólogo/ temático & Tsecapedergogin & Lugar y fecha & $12-02-2019$ \\
\hline
\end{tabular}

1Pertinencia: El item corresponde al concepto teórico formulado.

2Relevancia: El ítem es apropiado para representar al componente o dimensión especifica del constructo

${ }^{3}$ Claridad: Se entiende sin dificultad alguna el enunciado del ítem, es conciso, exacto y directo

Nota: Suficiencia, se dice suficiencia cuando los ítems planteados son suficientes para medir la dimensión 


\begin{tabular}{|l|l|l|l|l|l|l|l|}
\hline 13 & $\begin{array}{l}\text { El profesor destaca los logros de la clase y las actitudes de los estudiantes y } \\
\text { motiva a los demás a seguir mejorando su aprendizaje con acciones concretas } \\
\text { para cada equipo e integrante. }\end{array}$ & & & & & & \\
\hline
\end{tabular}

\section{OPINIÓN DE APLICABILIDAD DE LA OBSERVACIÓN:}

Observaciones (precisar si hay suficiencia):

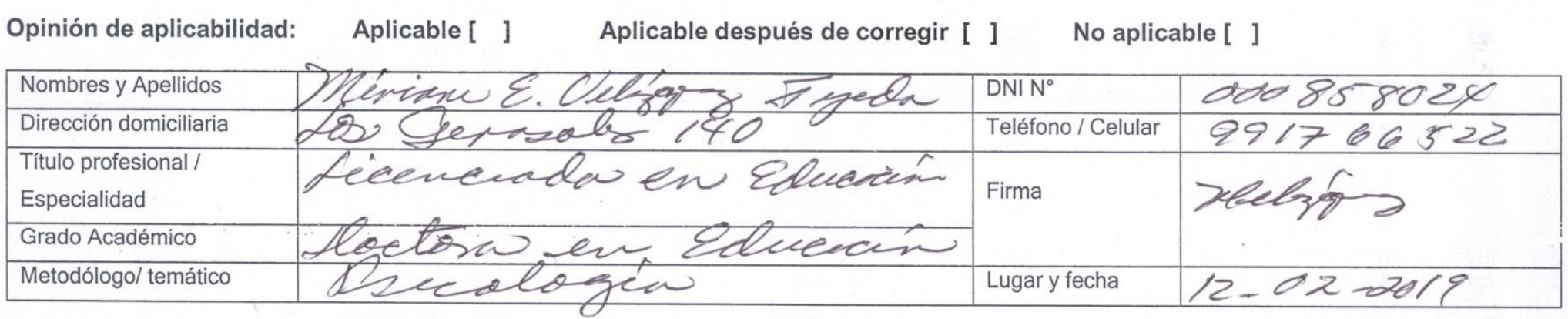

1Pertinencia: El item corresponde al concepto teórico formulado.

2Relevancia: El ítem es apropiado para representar al componente o dimensión especifica del constructo

${ }^{3}$ Claridad: Se entiende sin dificultad alguna el enunciado del ítem, es conciso, exacto y directo

Nota: Suficiencia, se dice suficiencia cuando los ítems planteados son suficientes para medir la dimensión 
SESIÓN DE APRENDIZAJE Nro. 1

\section{Datos Generales:}

Institución de Educación Superior :

Especialidad

Nivel

Asignatura

Duración

Tema

Docente

\author{
Pintura \\ Tercer ciclo \\ Pintura I \\ : 4 horas $(8.30-12.30 \mathrm{AM})$ \\ : Los soportes e imprimaciones en la técnica del óleo \\ : Gino Sessarego Díaz
}

\section{Organización de Aprendizajes para la sesión 1 del curso de Pintura I}

\begin{tabular}{|c|c|c|c|}
\hline Conceptos & Procedimientos & Actitudes & Indicador \\
\hline $\begin{array}{l}\text { - Pigmentos. } \\
\text {-Diluyentes y solventes. } \\
\text { - Imprimaciones. } \\
\text { - Tipos de soporte. } \\
\text { - Materiales auxiliares. }\end{array}$ & $\begin{array}{l}\text { Reconoce y conceptualiza los } \\
\text { pigmentos, diluyentes, } \\
\text { solventes y materiales } \\
\text { auxiliares en el uso de la } \\
\text { pintura artística. } \\
\text { Conoce la importancia de las } \\
\text { imprimaciones y sus } \\
\text { diferentes efectos en el } \\
\text { acabado de la pintura. } \\
\text { Conoce y determina los } \\
\text { diferentes tipos de soporte } \\
\text { para la pintura al óleo. }\end{array}$ & $\begin{array}{l}\text { Es protagonista de su } \\
\text { propio aprendizaje y } \\
\text { trabaja } \\
\text { colaborativamente. } \\
\text { Valorar los aprendizajes } \\
\text { desarrollados } \\
\text { interpersonal y grupal. } \\
\text { Participa del debate de las } \\
\text { interpretaciones de las } \\
\text { lecturas propuestas. } \\
\text { Tiene un juicio crítico. }\end{array}$ & $\begin{array}{lr}\text { Demuestra } & \text { el } \\
\text { interés } & \text { por } \\
\text { conocer } & \text { los } \\
\text { diversos } & \\
\text { soportes } & \text { e } \\
\text { imprimaciones } \\
\text { en la técnica del } \\
\text { óleo. }\end{array}$ \\
\hline
\end{tabular}

\section{Aprendizajes esperados}

La Pintura y las características del material.

Percepción y Sensación de la Pintura.

La Pintura Tradicional. La Pintura Occidental. La Pintura Moderna.

Luz y sombra.

Técnicas: Variables.

Valores y Actitudes

\begin{tabular}{|l|l|}
\hline \multicolumn{1}{|c|}{ Ejes transversales } & \multicolumn{1}{|c|}{ Valores } \\
\hline $\begin{array}{l}\text { Educación para la identidad nacional e } \\
\text { Interculturalidad }\end{array}$ & $\begin{array}{l}\text { Responsabilidad, laboriosidad, ética } \\
\text { honestidad, solidaridad, respeto }\end{array}$ \\
\hline
\end{tabular}


SECUENCIA DIDÁCTICA DE LA SESIÓN DE CLASE Nro. 1

\begin{tabular}{|c|c|c|}
\hline Momentos & Actividades / Estrategias & $\begin{array}{l}\text { Medios y } \\
\text { Materiales }\end{array}$ \\
\hline $\begin{array}{l}\text { Inicio } \\
20 \mathrm{~min} .\end{array}$ & $\begin{array}{l}\text { Motivación } \\
\text { El docente da la bienvenida a los estudiantes en el aula de Pintura I. } \\
\text { En el inicio, se motiva a los estudiantes, relacionando la asignatura con su contexto } \\
\text { y la relevancia de esta en su formación académica. } \\
\text { Estrategias para activar los conocimientos previos } \\
\text { Se rescata saberes previos y los estudiantes exponen las que expectativas que } \\
\text { tienen del curso. } \\
\text { Se define el pensamiento crítico y se presenta el modelo de pensamiento crítico de } \\
\text { Viterbo University, también se presenta las fases del método de resolución de } \\
\text { problemas y las normas, compromisos, responsabilidades de los estudiantes para el } \\
\text { trabajo en equipo. } \\
\text { Se presenta el modelo de evaluación de la propuesta artística y del informe que este } \\
\text { conlleva. } \\
\text { Conflicto cognitivo } \\
\text { Se realiza preguntas sobre los conceptos del arte y las tendencias modernas } \\
\text { Conflicto cognitivo. } \\
\text { El docente realiza la siguiente pregunta. ¿Qué es el arte? ¿Cuáles son las corrientes } \\
\text { artísticas contemporáneas? } \\
\text { Se pide respuestas voluntarias a alumnos. } \\
\text { Los estudiantes dan sus respuestas y pueden comentar la respuesta de un } \\
\text { compañero } \\
\text { Por último el docente escribe el tema a abordar en la pizarra y expone las } \\
\text { capacidades que se esperan lograr con el aprendizaje y da instrucciones para iniciar } \\
\text { el desarrollo del tema. }\end{array}$ & $\begin{array}{l}\text { Imágenes } \\
\text { Diálogo }\end{array}$ \\
\hline $\begin{array}{l}\text { Desarrollo } \\
150 \mathrm{~min} .\end{array}$ & $\begin{array}{l}\text { Construcción del conocimiento } \\
\text { Estrategias y técnicas para el procesamiento de la información. } \\
\text { Se exponen los conocimientos correspondientes a la sesión, según el sílabo. } \\
\text { Los estudiantes están atentos a la explicación acerca de los pigmentos, diluyentes, } \\
\text { solventes, imprimaciones y tipos de soporte. } \\
\text { Se emplea situaciones problémicas } \\
\text { El docente muestra imágenes referentes al tema y se invita a los estudiantes a dar } \\
\text { una opinión sobre lo observado y expuesto. } \\
\text { Aplicación del aprendizaje } \\
\text { Estrategias para la transferencia de lo aprendido: } \\
\text { Se forman grupos de trabajo de cuatro a cinco estudiantes, a cada grupo se le } \\
\text { proporciona una lectura para realizar una interpretación literaria y psicológica. } \\
\text { El estudiante busca información relevante respecto a la lectura y la interpretación } \\
\text { desde distintos enfoques, luego seleccionará la información relevante para la } \\
\text { solución del problema. } \\
\text { Una vez que los estudiantes hayan realizado su interpretación, el grupo dialoga con } \\
\text { el docente para establecer los aciertos de dicha interpretación. } \\
\text { A partir de estas interpretaciones, los estudiantes realizan bocetos para la } \\
\text { elaboración de una propuesta artística. } \\
\text { El docente entrega una rúbrica para la evaluación: orden y limpieza en la } \\
\text { presentación del trabajo, su interpretación es clara y asertiva, muestra creatividad en } \\
\text { sus bocetos, las interpretaciones expuestas en los bocetos son coherentes. } \\
\text { Los estudiantes escuchan la asesoría que efectúa el docente sobre las }\end{array}$ & $\begin{array}{l}\text { Diapositivas } \\
\text { Bitácora }\end{array}$ \\
\hline
\end{tabular}




\begin{tabular}{|l|l|l|} 
& $\begin{array}{l}\text { interpretaciones sobre el tema y los bocetos elaborados. } \\
\text { El docente continúa desarrollando el tema y mostrando imágenes de pinturas que } \\
\text { contienen concepto y propuesta propia. } \\
\text { El docente invita a los estudiantes a escuchar todas las propuestas y promueve el } \\
\text { diálogo, las sugerencias y opiniones. }\end{array}$ & \\
\hline $\begin{array}{l}\text { Cierre } \\
\mathbf{3 0} \text { min. }\end{array}$ & $\begin{array}{l}\text { La sesión de clase se cierra con una exposición por equipo, de las interpretaciones y y } \\
\text { los bocetos realizados a partir de las lecturas propuestas. } \\
\text { Los estudiantes y el docente realizan preguntas sobre lo expuesto por cada grupo. } \\
\text { Se plantean las conclusiones del tema. } \\
\text { Se realiza una metacognición donde explican los pasos seguidos: } \\
\text { ¿Qué pasos realicé para asimilar el tema abordado? } \\
\text { iPara qué me sirve lo aprendido? } \\
\text { ¿Cómo lo aplicaré en la profesión y en la vida diaria? } \\
\text { Presenta los resultados de la rúbrica con su autoevaluación. } \\
\text { Se deja como tarea: } \\
\text { Investigar sobre las marcas, costos y calidades de pigmentos, diluyentes, solventes } \\
\text { y otros materiales auxiliares. }\end{array}$ & Bitácora \\
& cotejo \\
\hline
\end{tabular}




\section{SECUENCIA DIDÁCTICA DE LA SESIÓN DE CLASE Nro. 2}

\begin{tabular}{|c|c|c|}
\hline Momentos & Actividades / Estrategias & $\begin{array}{l}\text { Medios y } \\
\text { Materiales }\end{array}$ \\
\hline $\begin{array}{l}\text { Inicio } \\
20 \mathrm{~min} .\end{array}$ & $\begin{array}{l}\text { Motivación } \\
\text { Se motiva resaltando los logros alcanzados en la clase anterior, así como mostrando } \\
\text { imágenes de pinturas célebres, al mismo tiempo el docente propone encontrar } \\
\text { soluciones a los problemas propuestos en la sesión de clase. } \\
\text { Estrategias para activar los conocimientos previos } \\
\text { En esta etapa se muestra imágenes de pinturas con contenido que permita } \\
\text { vislumbrar el pensamiento crítico, a partir de su identificación se rescata los saberes } \\
\text { previos. } \\
\text { Conflicto cognitivo } \\
\text { El docente realiza las siguientes preguntas } \\
\text { El profesor realiza la siguiente pregunta. ¿Qué entiende por lenguaje pictórico? ¿Qué } \\
\text { concepto tiene sobre las formas? } \\
\text { Se pide respuestas voluntarias a alumnos. } \\
\text { Los alumnos dan sus respuestas y pueden comentar la respuesta de un compañero. } \\
\text { Por último el docente escribe el tema a abordar en la pizarra y expone las } \\
\text { capacidades que se esperan lograr con el aprendizaje y da instrucciones para iniciar } \\
\text { el desarrollo del tema. }\end{array}$ & $\begin{array}{l}\text { Imágenes } \\
\text { Diálogo }\end{array}$ \\
\hline $\begin{array}{l}\text { Desarrollo } \\
150 \mathrm{~min} .\end{array}$ & $\begin{array}{l}\text { Construcción del conocimiento } \\
\text { Estrategias y técnicas para el procesamiento de la información } \\
\text { Se exponen mediante un PPT los conocimientos correspondientes a la sesión, según } \\
\text { el sílabo. } \\
\text { Los estudiantes están atentos a la explicación acerca de la línea, la imagen, el } \\
\text { volumen y el lenguaje pictórico. } \\
\text { Se emplea situaciones problémicas } \\
\text { El docente propone hallar líneas, formas, volúmenes y lenguaje visual comprendido } \\
\text { en las pinturas célebres que expone. } \\
\text { Aplicación del aprendizaje } \\
\text { Estrategias para la transferencia de lo aprendido: } \\
\text { Los estudiantes elaboran las conclusiones del problema propuesto en la primera } \\
\text { sesión, estas serán expuestas y dialogadas con el docente. } \\
\text { Los estudiantes proceden a realizar sus bocetos finales, los cuales son sustentados } \\
\text { por ellos y con la mediación del docente seleccionan uno, que servirá para la } \\
\text { elaboración de su propuesta artística. } \\
\text { El docente entrega una rúbrica para la evaluación: orden y limpieza en la } \\
\text { presentación del trabajo, su interpretación es clara y asertiva, muestra creatividad en } \\
\text { sus bocetos, las interpretaciones expuestas en los bocetos son coherentes. } \\
\text { Los estudiantes escuchan la asesoría que efectúa el docente sobre los resultados } \\
\text { alcanzados. } \\
\text { El docente continúa desarrollando el tema y mostrando imágenes de pinturas que } \\
\text { contienen concepto y propuesta propia. } \\
\text { El docente invita a los estudiantes a escuchar todas las propuestas y promueve el } \\
\text { diálogo, las sugerencias y opiniones. }\end{array}$ & $\begin{array}{l}\text { Diapositivas } \\
\text { Bitácora }\end{array}$ \\
\hline
\end{tabular}




\begin{tabular}{|c|c|c|}
\hline $\begin{array}{l}\text { Cierre } \\
30 \mathrm{~min} .\end{array}$ & $\begin{array}{l}\text { La sesión de clase se cierra con una exposición por equipo del análisis de todos los } \\
\text { elementos conceptuales recabados para establecer soluciones. } \\
\text { Los estudiantes y el docente realizan preguntas sobre lo expuesto por cada grupo. } \\
\text { Se plantean las conclusiones del tema. } \\
\text { Se realiza una metacognición donde explican los pasos seguidos: } \\
\text { ¿Qué pasos realicé para asimilar el tema abordado? } \\
\text { ¿Para qué me sirve lo aprendido? } \\
\text { ¿Cómo lo aplicaré en la profesión y en la vida diaria? } \\
\text { Presenta los resultados de la rúbrica con su autoevaluación. } \\
\text { Se deja como tarea: Investigar las leyes de la Gestalt y aplicarlas en pinturas famosas. }\end{array}$ & \begin{tabular}{|ll} 
Lista de \\
cotejo
\end{tabular} \\
\hline
\end{tabular}


SECUENCIA DIDÁCTICA DE LA SESIÓN DE CLASE Nro. 3

\begin{tabular}{|c|c|c|}
\hline Momentos & Actividades / Estrategias & $\begin{array}{l}\text { Medios y } \\
\text { Materiales }\end{array}$ \\
\hline $\begin{array}{l}\text { Inicio } \\
20 \mathrm{~min} .\end{array}$ & $\begin{array}{l}\text { Motivación } \\
\text { Se motiva resaltando los logros alcanzados en la presentación de bocetos, en la } \\
\text { creación artística como un proceso donde interviene el pensamiento crítico. } \\
\text { Asimismo, el docente motiva a la elaboración de la propuesta. } \\
\text { Estrategias para activar los conocimientos previos } \\
\text { En esta etapa se muestra un video del proceso creativo del artista José Tola, a partir } \\
\text { de este, el docente realizará preguntas a los estudiantes para obtener los saberes } \\
\text { previos de los estudiantes. } \\
\text { Conflicto cognitivo } \\
\text { El docente realiza las siguientes preguntas } \\
\text { El profesor realiza la siguiente pregunta. ¿Qué entiende la imagen? ¿Qué relación } \\
\text { existe entre imagen y plano? ¿Qué entiende por composición en arte? } \\
\text { Se pide respuestas voluntarias a alumnos. } \\
\text { Los alumnos dan sus respuestas y pueden comentar la respuesta de un compañero. } \\
\text { Por último el docente escribe el tema a abordar en la pizarra y expone las } \\
\text { capacidades que se esperan lograr con el aprendizaje y da instrucciones para iniciar } \\
\text { el desarrollo del tema. }\end{array}$ & $\begin{array}{l}\text { Imágenes } \\
\text { Diálogo }\end{array}$ \\
\hline $\begin{array}{l}\text { Desarrollo } \\
150 \mathrm{~min} .\end{array}$ & $\begin{array}{l}\text { Construcción del conocimiento } \\
\text { Estrategias y técnicas para el procesamiento de la información } \\
\text { Se exponen mediante un PPT los conocimientos correspondientes a la sesión, según } \\
\text { el sílabo. } \\
\text { Los estudiantes están atentos a la explicación acerca de la imagen, el plano y la } \\
\text { composición en la pintura. } \\
\text { Se emplea situaciones problémicas } \\
\text { El docente propone elaborar imágenes a partir de planos, usando las leyes de la } \\
\text { composición pictórica. } \\
\text { Aplicación del aprendizaje } \\
\text { Estrategias para la transferencia de lo aprendido: } \\
\text { Con los bocetos seleccionados en la sesión anterior, los estudiantes proceden a } \\
\text { realizar sus pinturas. } \\
\text { El docente asesora de forma individual sobre la técnica, procedimientos y otros } \\
\text { aspectos necesarios para la elaboración del trabajo, así como inculca valores y } \\
\text { relaciona su trabajo como un promotor de cambios en su contexto. } \\
\text { El docente entrega una rúbrica para la evaluación: orden y limpieza en la } \\
\text { presentación del trabajo, su interpretación es clara y asertiva, muestra creatividad en } \\
\text { sus bocetos, las interpretaciones expuestas en los bocetos son coherentes. } \\
\text { Los estudiantes escuchan la asesoría que efectúa el docente sobre los resultados } \\
\text { alcanzados. } \\
\text { El docente continúa desarrollando el tema y mostrando imágenes de pinturas que } \\
\text { contienen concepto y propuesta propia. } \\
\text { El docente invita a los estudiantes a escuchar todas las propuestas y promueve el } \\
\text { diálogo, las sugerencias y opiniones. }\end{array}$ & Diapositivas \\
\hline
\end{tabular}




\begin{tabular}{|l|l|l|}
\hline Cierre & La sesión de clase se cierra con la preparación de un informe sobre el proceso, el & Lista \\
co min. & cual será expuesto en la sesión de clase. & de \\
& El docente evalúa los avances de la propuesta artística. & \\
& Los estudiantes y el docente realizan preguntas sobre lo expuesto por cada grupo. & Bitácora \\
Se plantean las conclusiones del tema. & Se realiza una metacognición donde explican los pasos seguidos: \\
& ¿Qué pasos realicé para asimilar el tema abordado? & \\
& ¿Para qué me sirve lo aprendido? & \\
¿Cómo lo aplicaré en la profesión y en la vida diaria? & Presenta los resultados de la rúbrica con su autoevaluación. \\
& $\begin{array}{l}\text { Se deja como tarea: Investigar cómo se aplican las leyes de composición en pinturas } \\
\text { célebres. }\end{array}$ & \\
\hline
\end{tabular}




\section{Guía de evaluación}

\section{Guía de evaluación de interpretación de lectura}

Capacidad: Pensamiento crítico

Indicador: Interpreta la lectura propuesta, busca información y realiza resúmenes en grupo.

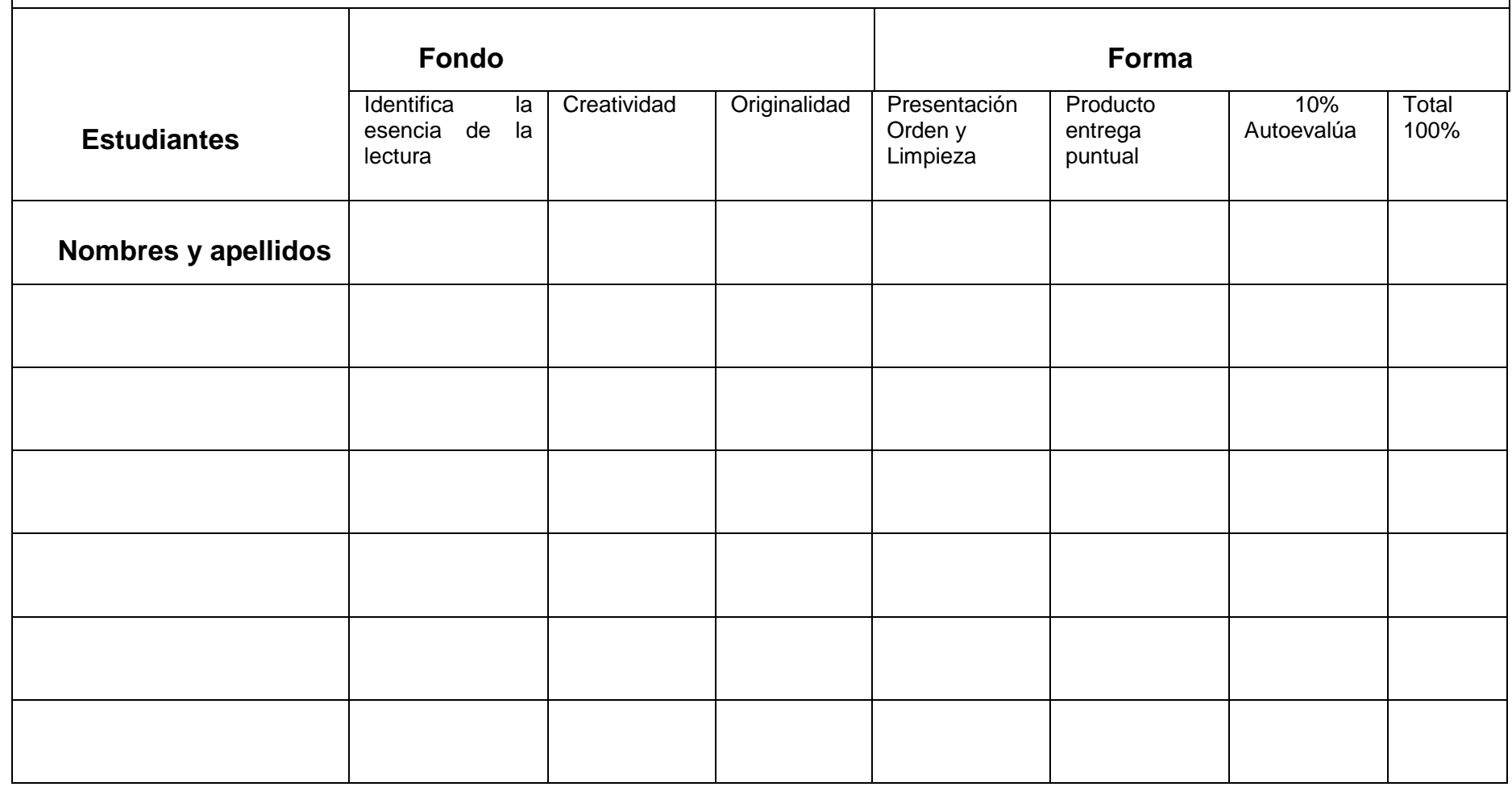




\section{EVALUACIÓN Y APROBACIÓN DE LA MODELACIÓN DE LA PROPUESTA \\ POR ESPECIALISTA}

\section{Estimado profesor:}

Le solicitamos su amable disposición para colaborar en el proceso de validación metodológica de modelación de la propuesta en la investigación aplicada educacional cuyo título es: Estrategia metodológica para desarrollar el pensamiento crítico en los estudiantes de pintura de una institución educativa de arte de Lima, presentada en la Maestría en Educación con Mención en Docencia en Educación Superior de la EPG de la Universidad San Ignacio de Loyola.

Por esta razón, se adjuntan las fichas de valoración interna y externa con los ítems para que usted nos pueda manifestar sus apreciaciones en cada una de ellas. Ajuntamos la propuesta y la matriz de categorización.

Agradecemos sus importantes aportes para este proceso culminación de investigación científica.

Saludos cordiales,

Nombres y apellidos: Gino Sessarego Díaz, autor de la investigación.

FIRMA:

Fecha: 24/ 09 / 2019 


\section{FICHA DE VALIDACIÓN DE LA PROPUESTA METODOLÓGICA}

\section{Datos generales.}

1.1. Apellidos y nombres del especialista:

1.2. Grado de estudios alcanzado

1.3. Resultado científico en valoración: Estrategia metodológica para desarrollar el pensamiento crítico en los estudiantes de pintura de una institución educativa de arte de Lima.

1.4. Autor del resultado científico : Bachiller Gino Sessarego Díaz

II. Aspectos a observar

\section{VALIDACIÓN INTERNA}

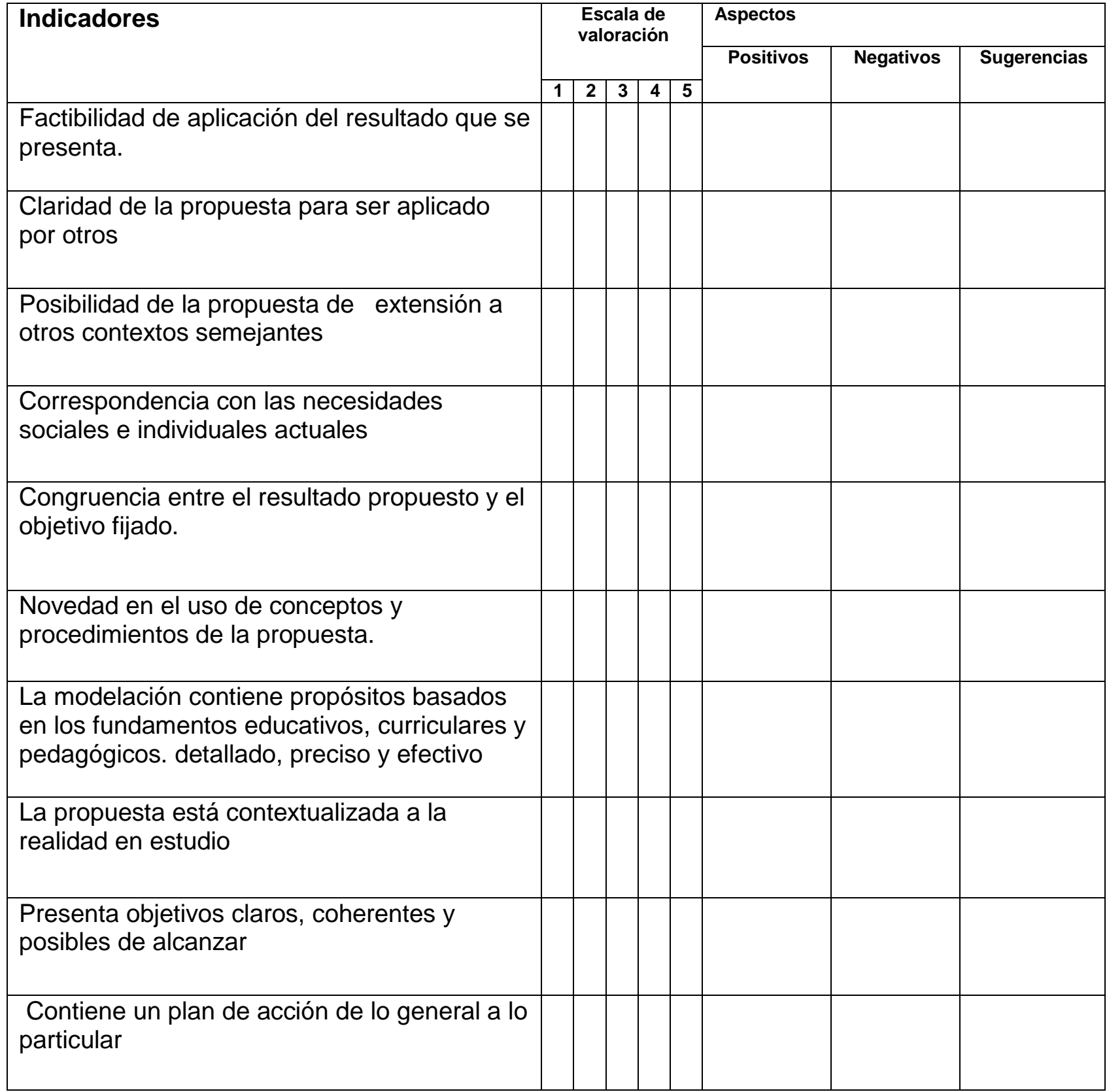


FICHA DE VALIDACIÓN EXTERNA (FORMA)

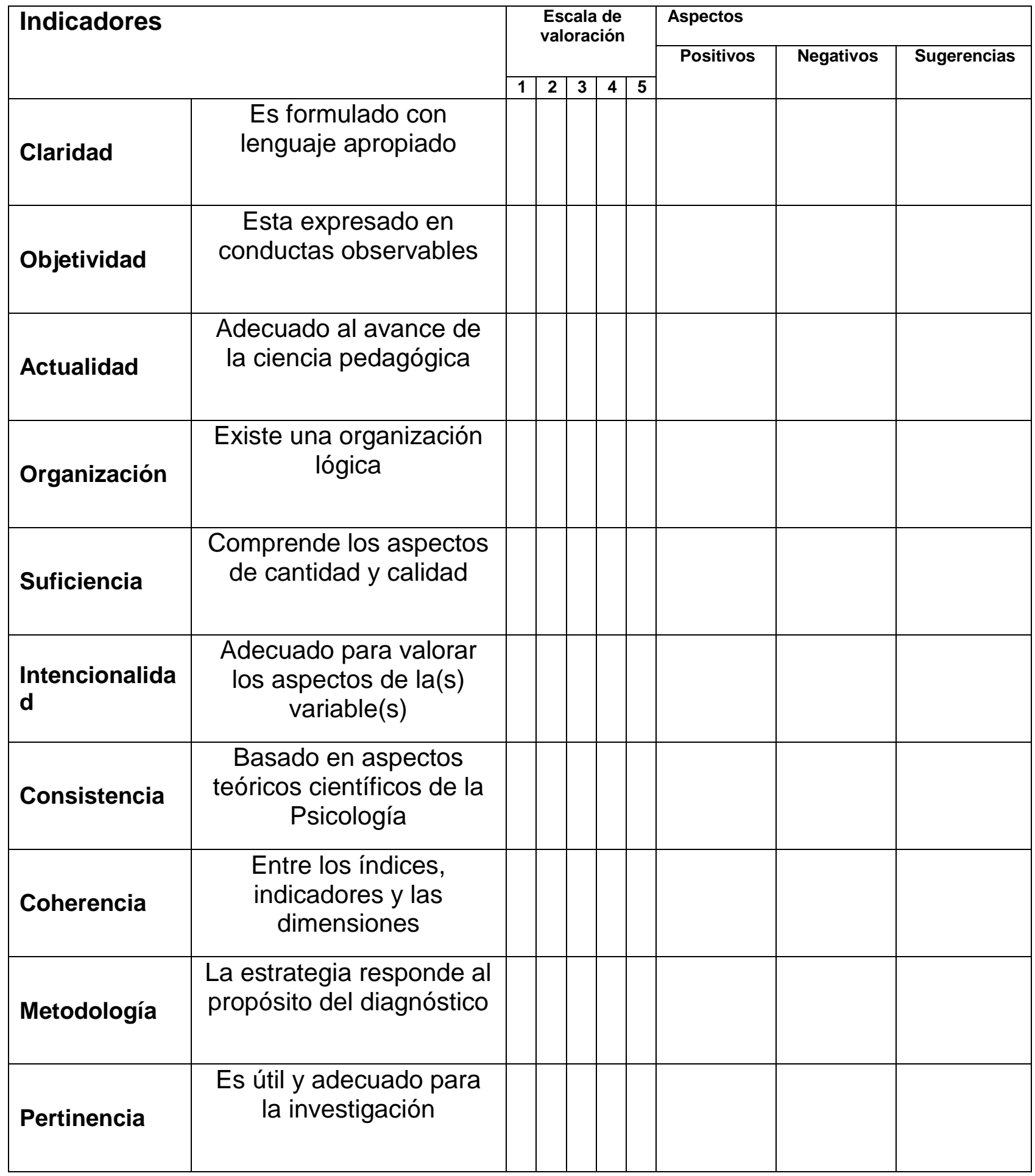




\section{Aportes o sugerencias para el perfeccionamiento del resultado científico:}

\section{Opinión de aplicabilidad.}

\section{RESULTADOS}

PROMEDIO DE VALORACIÓN INTERNA: $(50 \%)$ (50\%) + PUNTAJE DE VALORACIÓN EXTERNA:

\section{RESULTADO DE VALORACIÓN:}

\section{Tabla de Valoración}

\begin{tabular}{|l|l|}
\hline Deficiente & $0-25$ \\
\hline Baja & $25-50$ \\
\hline Regular & $51-70$ \\
\hline Buena & $\mathbf{7 1 - 8 5}$ \\
\hline Muy Buena & $\mathbf{8 6 - 1 0 0}$ \\
\hline
\end{tabular}

1. Deficiente ( )

2. Baja ()

3. Regular ( )

4. Buena ( )

5. Muy buena ( )

OPINIÓN DE APLICABILIDAD:
a) Deficiente ( )
b) Baja ( )
c) Regular ( )
d) Buena ( )
e) Muy Buena ( )

\begin{tabular}{|l|l|l|l|}
\hline Nombres y Apellidos & DNI Na & \\
\hline Dirección domiciliaria & & Teléfono / Celular & \\
\hline $\begin{array}{l}\text { Título profesional / } \\
\text { Especialidad }\end{array}$ & & \\
\hline Grado Académico & & \\
\hline Mención & & \\
\hline
\end{tabular}




\section{Especialista 1}

\section{FICHA DE VALIDACIÓN DE LA PROPUESTA METODOLÓGICA}

I. Datos generales.

1.1. Apellidos y nombres del especialista:

1.2. Grado de estudios alcanzado

1.3. Resultado científico en valoración: Estrategia metodológica para desarrollar el pensamiento crítico en los estudiantes de pintura de una institución educativa de arte de Lima.

1.4. Autor del resultado científico : Bachiller Gino Sessarego Díaz

II. Aspectos a observar

VALIDACIÓN INTERNA

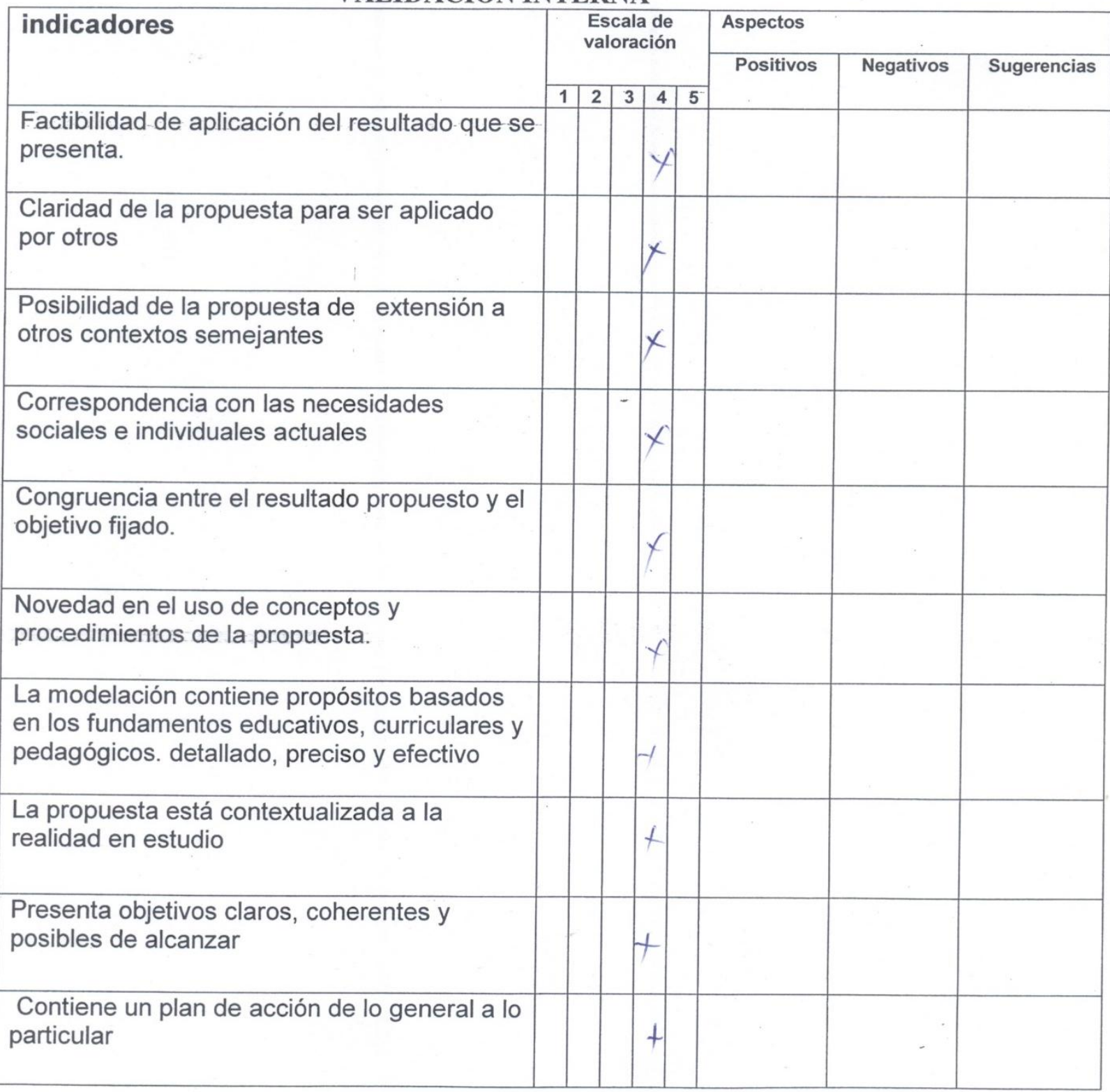


FICHA DE VALIDACIÓN EXTERNA (FORMA)

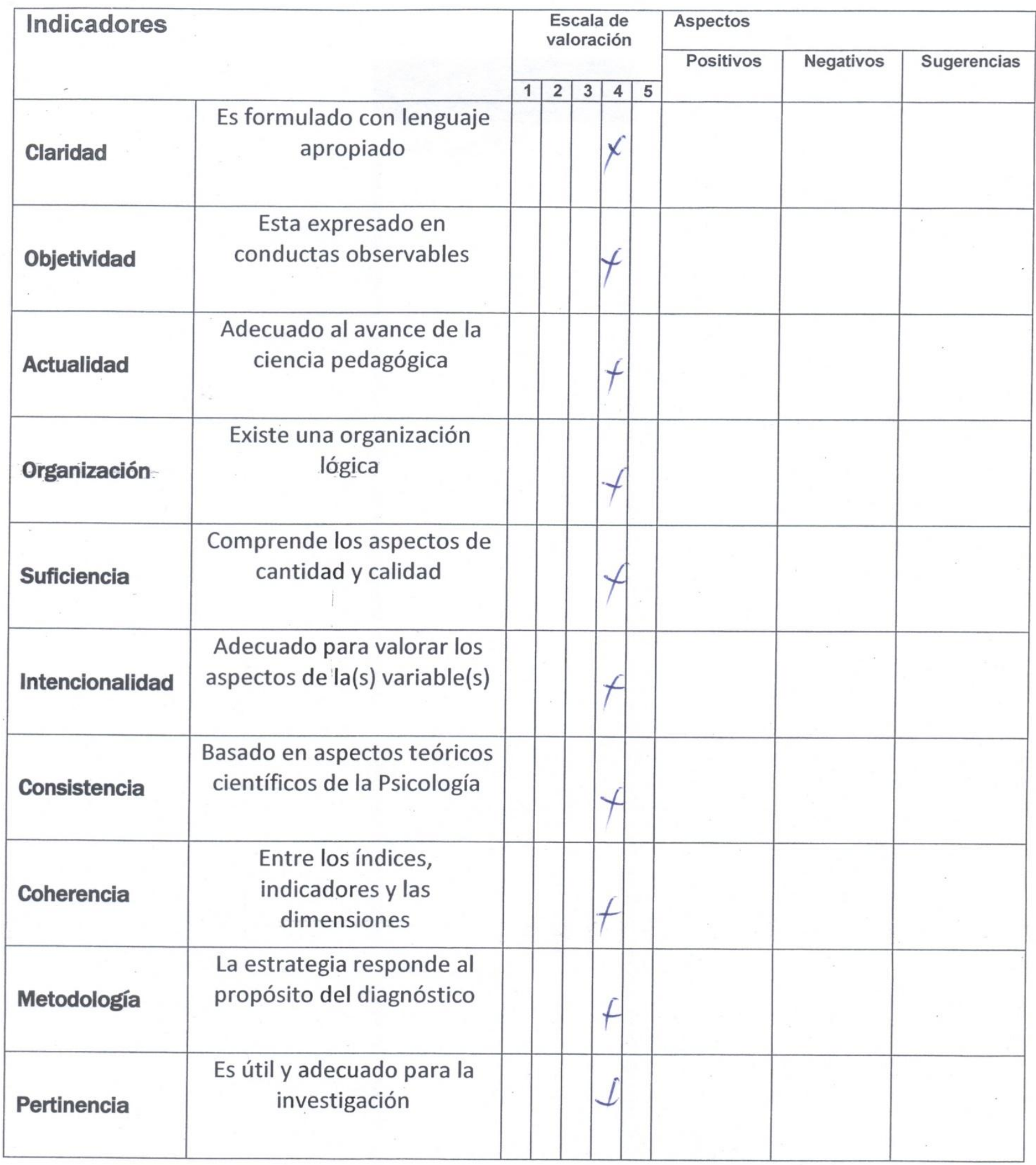




\section{Aportes o sugerencias para el perfeccionamiento del resultado científico:}

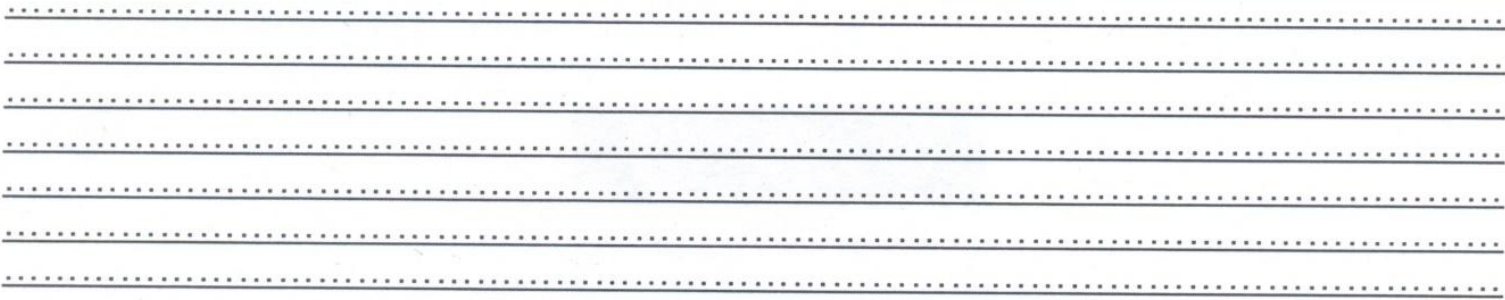

\section{Opinión de aplicabilidad.}

\section{RESULTADOS}

PROMEDIO DE VALORACIÓN INTERNA: (50\%) + PUNTAUE DE VALORACIÓN EXTERNA:

$(50 \%)$ RESULTADO DE VALORACIÓN:

\section{Tabla de Valoración}

\begin{tabular}{|l|l|}
\hline Deficiente & $0-25$ \\
\hline Baja & $25-50$ \\
\hline Regular & $51-70$ \\
\hline Buena & $\mathbf{7 1 - 8 5}$ \\
\hline Muy Buena & $\mathbf{8 6 - 1 0 0}$ \\
\hline
\end{tabular}

1. Deficiente ( )

2. Baja

3. Regular

4. Buena

5. Muy buena

\section{OPINIÓN DE APLICABILIDAD:}
a) Deficiente ( )
b) Baja ( )
c) Regular ( )
d) Buena (
e) Muy Buena ( )

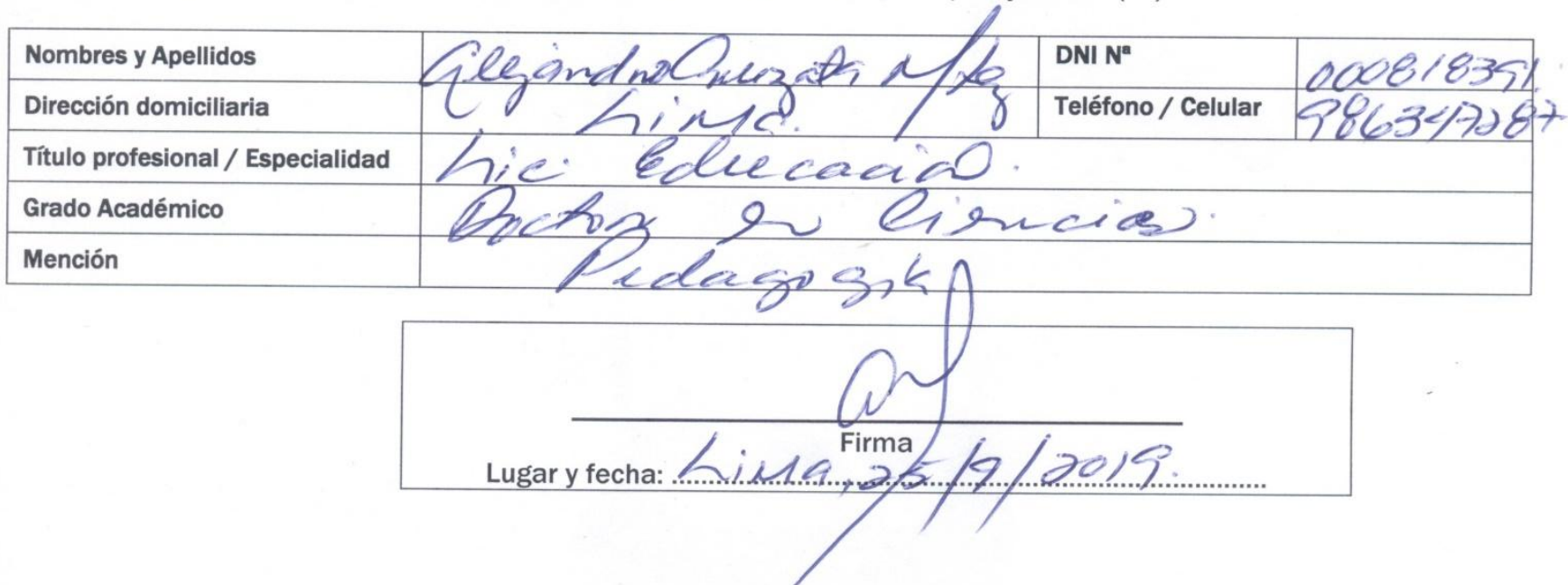




\section{Especialista 2}

\section{FICHA DE VALIDACIÓN DE LA PROPUESTA METODOLÓGICA}

I. Datos generales.

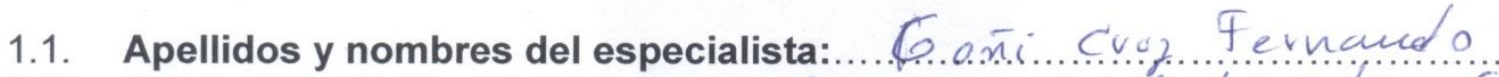

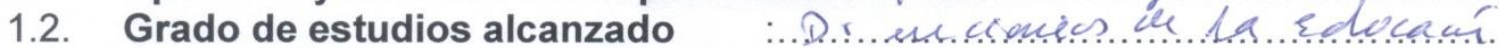

1.3. Resultado científico en valoración: Estrategia metodológica para desarrollar el pensamiento crítico en los estudiantes de pintura de una institución educativa de arte de Lima.

1.4. Autor del resultado científico : Bachiller Gino Sessarego Díaz

II. Aspectos a observar

\section{VALIDACIÓN INTERNA}

\begin{tabular}{|c|c|c|c|c|c|c|}
\hline \multirow[t]{3}{*}{ indicadores } & \multirow{2}{*}{\multicolumn{3}{|c|}{$\begin{array}{l}\text { Escala de } \\
\text { valoración }\end{array}$}} & \multicolumn{3}{|l|}{ Aspectos } \\
\hline & & & & Positivos & Negativos & Sugerencias \\
\hline & \begin{tabular}{l|l}
1 & 2 \\
\end{tabular} & 3 & \begin{tabular}{|l|l|}
4 & 5 \\
\end{tabular} & & & \\
\hline $\begin{array}{l}\text { Factibilidad de aplicación del resultado que se } \\
\text { presenta. }\end{array}$ & & & $x$ & & & \\
\hline $\begin{array}{l}\text { Claridad de la propuesta para ser aplicado } \\
\text { por otros }\end{array}$ & & & $x$ & & & \\
\hline $\begin{array}{l}\text { Posibilidad de la propuesta de extensión a } \\
\text { otros contextos semejantes }\end{array}$ & & & $x$ & & & \\
\hline $\begin{array}{l}\text { Correspondencia con las necesidades } \\
\text { sociales e individuales actuales }\end{array}$ & & - & $x$ & & & \\
\hline $\begin{array}{l}\text { Congruencia entre el resultado propuesto y el } \\
\text { objetivo fijado. }\end{array}$ & & & $x$ & & & \\
\hline $\begin{array}{l}\text { Novedad en el uso de conceptos y } \\
\text { procedimientos de la propuesta. }\end{array}$ & & & $x$ & & & \\
\hline $\begin{array}{l}\text { La modelación contiene propósitos basados } \\
\text { en los fundamentos educativos, curriculares y } \\
\text { pedagógicos. detallado, preciso y efectivo }\end{array}$ & & & $x$ & & & \\
\hline $\begin{array}{l}\text { La propuesta está contextualizada a la } \\
\text { realidad en estudio }\end{array}$ & & & $x$ & & & \\
\hline $\begin{array}{l}\text { Presenta objetivos claros, coherentes y } \\
\text { posibles de alcanzar }\end{array}$ & & & $x$ & & & \\
\hline $\begin{array}{l}\text { Contiene un plan de acción de lo general a lo } \\
\text { particular }\end{array}$ & & N & & & - & \\
\hline
\end{tabular}


FICHA DE VALIDACIÓN EXTERNA (FORMA)

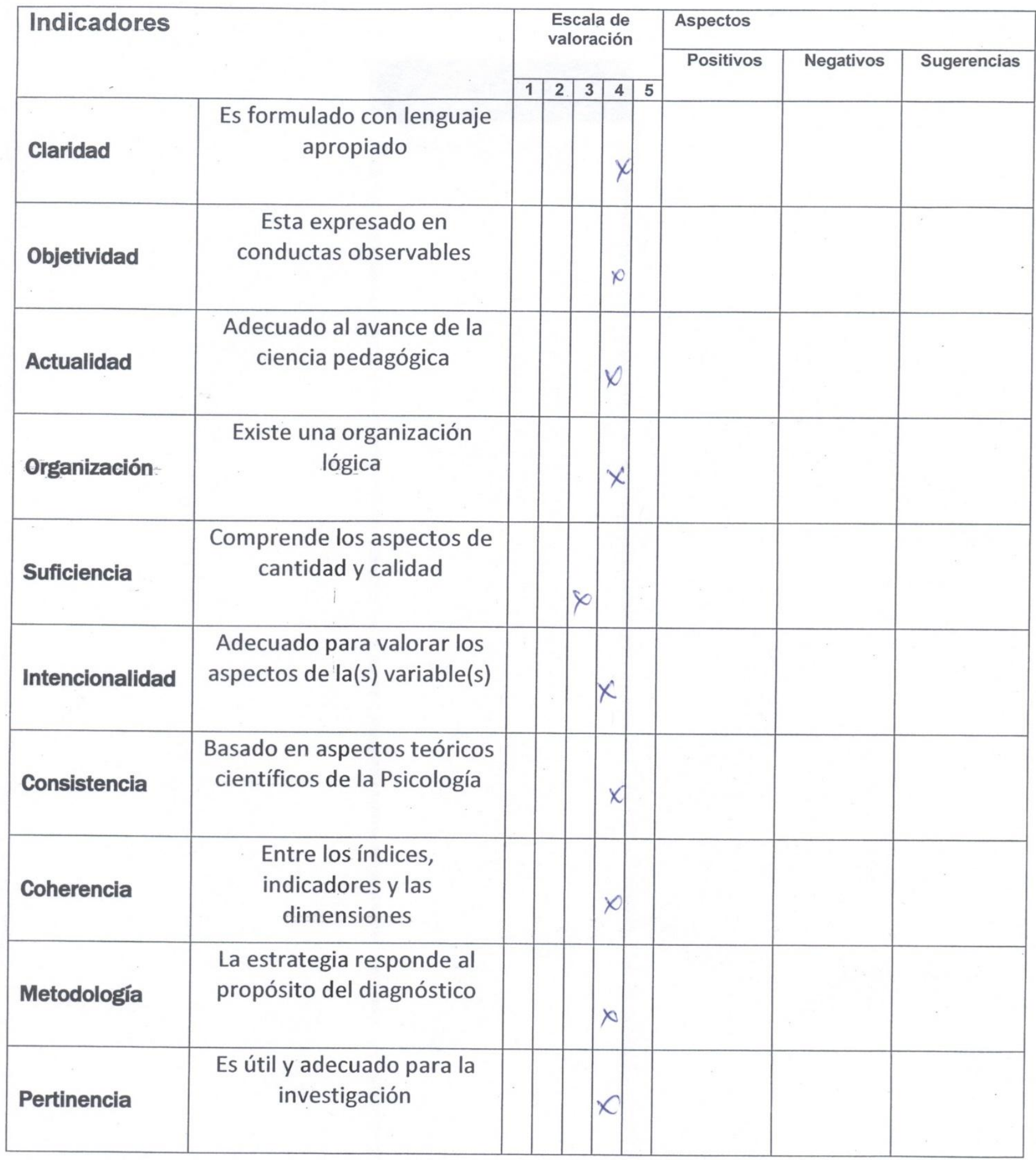




\section{Aportes o sugerencias para el perfeccionamiento del resultado científico:}

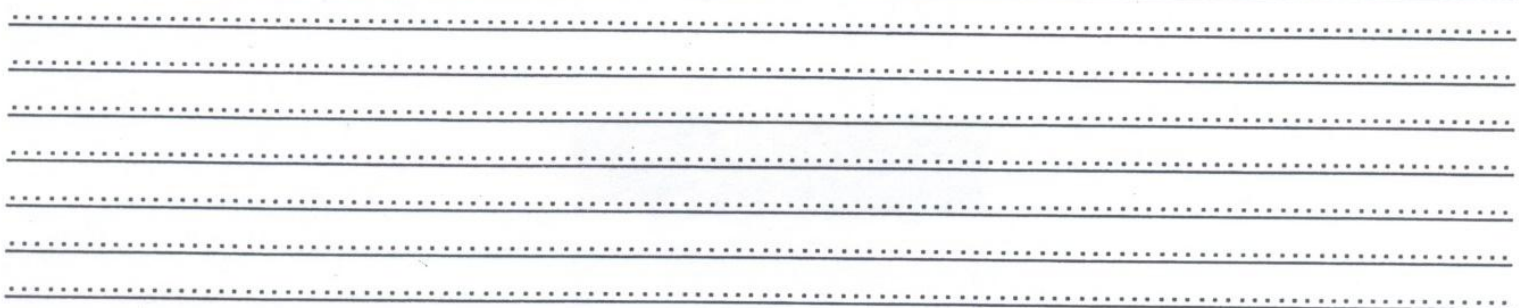

II. Opinión de aplicabilidad.

III. RESULTADOS

PROMEDIO DE VALORACIÓN INTERNA: (50\%) + PUNTAJE DE VALORACIÓN EXTERNA: (50\%) RESULTADO DE VALORACIÓN:

Tabla de Valoración

\begin{tabular}{|l|l|}
\hline Deficiente & $0-25$ \\
\hline Baja & $25-50$ \\
\hline Regular & $51-70$ \\
\hline Buena & $71-85$ \\
\hline Muy Buena & $86-100$ \\
\hline
\end{tabular}

1. Deficiente ( )

2. Baja

3. Regular

4. Buena

5. Muy buena ( )

OPINIÓN DE APLICABILIDAD:
a) Deficiente ( )
b) Baja ( )
c) Regular ( )
d) Buena ( )
e) Muy Buena ( )

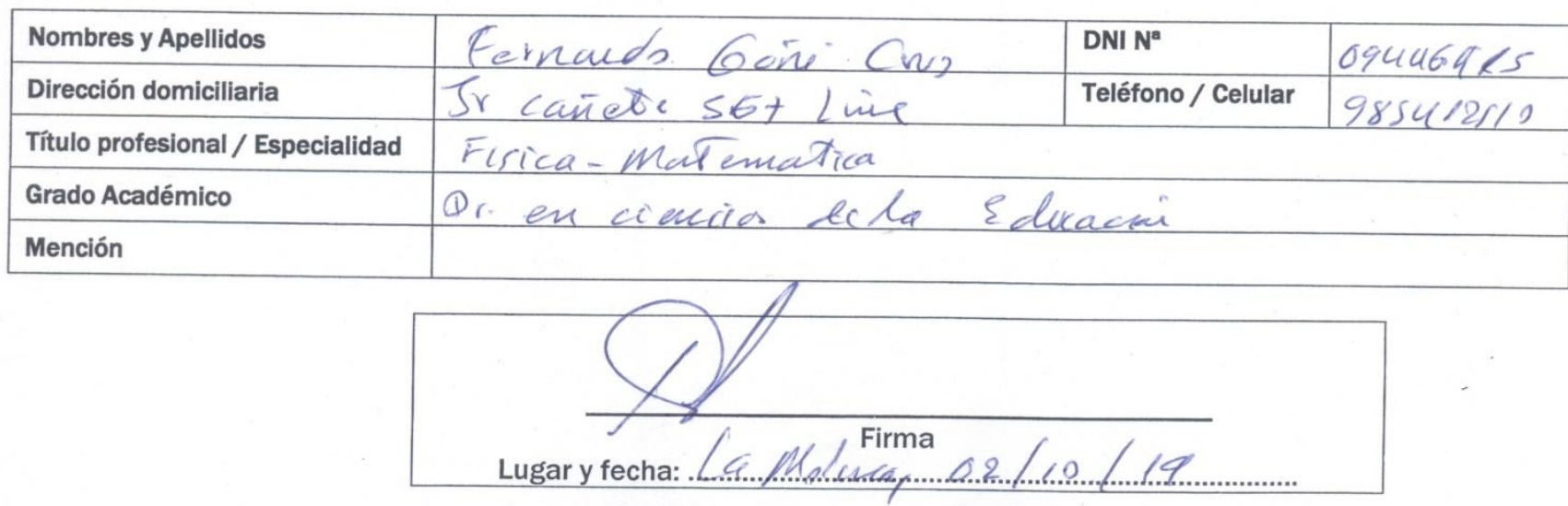


Validación de propuesta por especialistas

\section{Especialista 3}

FICHA DE VALIDACIÓN DE LA PROPUESTA METODOLÓGICA

I. Datos generales.

1.1. Apellidos y nombres del especialista:

1.2. Grado de estudios alcanzado

1.3. Resultado científico en valoración: Estrategia metodológica para desarrollar el pensamiento crítico en los estudiantes de pintura de una institución educativa de arte de Lima.

1.4. Autor del resultado científico : Bachiller Gino Sessarego Díaz

II. Aspectos a observar

\section{VALIDACIÓN INTERNA}

\begin{tabular}{|l|l|l|l|l|l|l|l|}
\hline indicadores & \multicolumn{2}{|c|}{ Escala de } & \multicolumn{2}{|l|}{ Aspectos } \\
\cline { 2 - 7 } & valoración & & & \\
\hline $\begin{array}{l}\text { Factibilidad de aplicación del resultado que se } \\
\text { presenta. }\end{array}$ & & & & & & & \\
\hline
\end{tabular}


FICHA DE VALIDACIÓN EXTERNA (FORMA)

\begin{tabular}{|c|c|c|c|c|c|c|c|}
\hline \multirow{2}{*}{\multicolumn{2}{|c|}{ Indicadores }} & \multirow{2}{*}{\multicolumn{3}{|c|}{$\begin{array}{l}\text { Escala de } \\
\text { valoración }\end{array}$}} & \multirow{2}{*}{\multicolumn{3}{|c|}{ Aspectos }} \\
\hline & & & & & & & \\
\hline & & \begin{tabular}{|l|l|}
2 & \\
\end{tabular} & \begin{tabular}{l|l|}
3 & \\
\end{tabular} & \begin{tabular}{l|l}
4 & 5 \\
\end{tabular} & Positivos & Negativos & Sugerencias \\
\hline Claridad & $\begin{array}{c}\text { Es formulado con lenguaje } \\
\text { apropiado }\end{array}$ & & & $x$ & & & \\
\hline Objetividad & $\begin{array}{c}\text { Esta expresado en } \\
\text { conductas observables }\end{array}$ & & & $x$ & & & \\
\hline Actualidad & $\begin{array}{l}\text { Adecuado al avance de la } \\
\text { ciencia pedagógica }\end{array}$ & & & $x$ & & & \\
\hline Organización & $\begin{array}{l}\text { Existe una organización } \\
\text { lógica }\end{array}$ & & & $x^{\prime}$ & & & \\
\hline Suficiencia & $\begin{array}{l}\text { Comprende los aspectos de } \\
\text { cantidad y calidad }\end{array}$ & & $x$ & & & & \\
\hline Intencionalidad & $\begin{array}{l}\text { Adecuado para valorar los } \\
\text { aspectos de la(s) variable(s) } \\
\qquad \begin{array}{c}\text { calegorios } \\
\text { valo }\end{array}\end{array}$ & & & $x$ & & & \\
\hline Consistencia & $\begin{array}{l}\text { Basado en aspectos teóricos } \\
\text { científicos de la Psicología }\end{array}$ & & & & & & \\
\hline Coherencia & $\begin{array}{l}\text { Entre los índices, } \\
\text { indicadores y las } \\
\text { dimensiones }\end{array}$ & & & $x$ & & & \\
\hline Metodologia & $\begin{array}{l}\text { La estrategia responde al } \\
\text { propósito del diagnóstico }\end{array}$ & & & & & & \\
\hline Pertinencia & $\begin{array}{l}\text { Es útil y adecuado para la } \\
\text { investigación }\end{array}$ & & & & & & \\
\hline
\end{tabular}


I. Aportes o sugerencias para el perfeccionamiento del resultado científico:

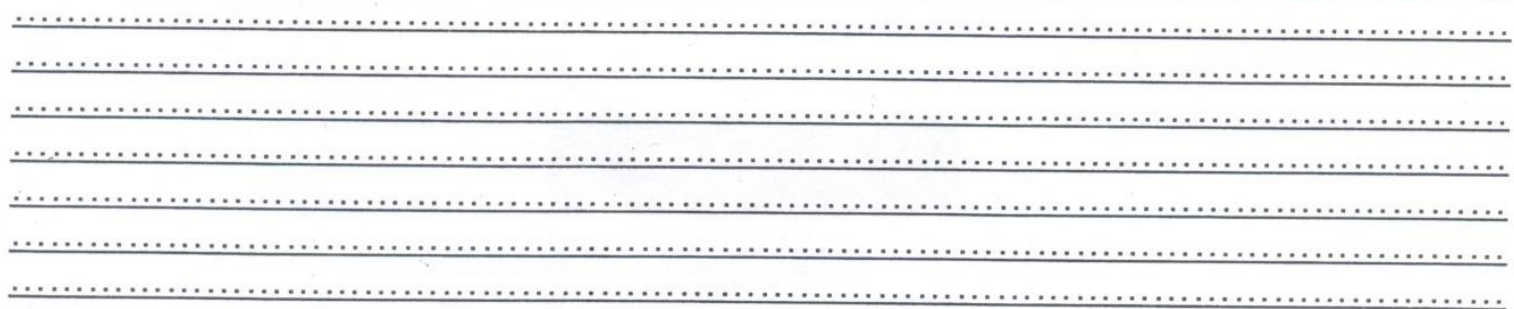

II. Opinión de aplicabilidad.

III. RESULTADOS

PROMEDIO DE VALORACIÓN INTERNA:

(50\%) + PUNTAUE DE VALORACIÓN EXTERNA:

(50\%)

RESULTADO DE VALORACIÓN:

Tabla de Valoración

\begin{tabular}{|l|l|}
\hline Deficiente & $0-25$ \\
\hline Baja & $25-50$ \\
\hline Regular & $51-70$ \\
\hline Buena & $71-85$ \\
\hline Muy Buena & $\mathbf{8 6 - 1 0 0}$ \\
\hline
\end{tabular}

1. Deficiente ( )

2. Baja ( )

3. Regular ( )

4. Buena ( )

5. Muy buena ( $)$

OPINIÓN DE APLICABILIDAD:
a) Deficiente ( )
b) Baja ( )
c) Regular ( )
d) Buena ( )
e) Muy Buena ( )

\begin{tabular}{|c|c|c|c|}
\hline Nombres y Apellidos & Minian \&. Vulge & DNI Na & 000858024 \\
\hline Dirección domiciliaria & als 140 & Teléfono / Celular & 94176652 \\
\hline \multicolumn{4}{|c|}{ Título profesional / Especialidad } \\
\hline \multicolumn{4}{|c|}{ Grado Académico } \\
\hline Mención & rdech & & \\
\hline
\end{tabular}

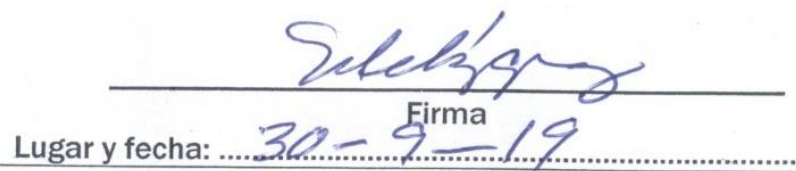

